\title{
Calcium Bridging Drives Polysaccharide Co-Adsorption to a Proxy Sea Surface Microlayer
}

Kimberly Carter-Fenk, Abigail Dommer, Michelle E Fiamingo, Jeongin Kim, Rommie Amaro, Heather Allen Submitted date: 31/03/2021 - Posted date: 01/04/2021

Licence: CC BY-NC-ND 4.0

Citation information: Carter-Fenk, Kimberly; Dommer, Abigail; Fiamingo, Michelle E; Kim, Jeongin; Amaro, Rommie; Allen, Heather (2021): Calcium Bridging Drives Polysaccharide Co-Adsorption to a Proxy Sea Surface Microlayer. ChemRxiv. Preprint. https://doi.org/10.26434/chemrxiv.14347265.v1

Saccharides comprise a significant mass fraction of organic carbon in sea spray aerosol (SSA), but the mechanisms through which saccharides are transferred from seawater to the ocean surface and eventually into SSA are unclear. It is hypothesized that saccharides cooperatively adsorb to other insoluble organic matter at the air/sea interface, known as the sea surface microlayer (SSML). Using a combination of surface-sensitive infrared reflection-absorption spectroscopy and all-atom molecular dynamics simulations, we demonstrate that the marine-relevant, anionic polysaccharide alginate co-adsorbs to an insoluble palmitic acid monolayer via divalent cationic bridging interactions. $\mathrm{Ca}^{2+}$ induces the greatest extent of alginate co-adsorption to the monolayer, evidenced by the $\sim 30 \%$ increase in surface coverage, whereas $\mathrm{Mg}^{2+}$ only facilitates one-third the extent of co-adsorption at seawater-relevant cation concentrations due to its strong hydration propensity. $\mathrm{Na}^{+}$cations alone do not facilitate alginate co-adsorption, and palmitic acid protonation hinders the formation of divalent cationic bridges between the palmitate and alginate carboxylate moieties. Alginate co-adsorption is largely confined to the interfacial region beneath the monolayer headgroups, so surface pressure, and thus monolayer surface coverage, only changes the amount of alginate co-adsorption by less than $5 \%$. Our results provide physical and molecular characterization of a potentially significant polysaccharide enrichment mechanism within the SSML.

File list (2)

AlginateCationicBridgingCo-Ads_Main.pdf (1.36 MiB) view on ChemRxiv • download file 


\section{Calcium bridging drives polysaccharide co- adsorption to a proxy sea surface microlayer}

Kimberly A. Carter-Fenk, ${ }^{a}$ Abigail C. Dommer, ${ }^{b}$ Michelle E. Fiamingo, ${ }^{a}$ Jeongin Kim, ${ }^{a}$ Rommie E. Amaro, ${ }^{b}$ and Heather C. Allen ${ }^{a *}$

a. Department of Chemistry and Biochemistry, The Ohio State University, Columbus, $\mathrm{OH}$ 43210, USA

b. Department of Chemistry and Biochemistry, University of California, San Diego, La Jolla, CA 92093, USA

\section{Corresponding Author}

* Heather C. Allen (allen@chemistry.ohio-state.edu) 


\section{Abstract}

Saccharides comprise a significant mass fraction of organic carbon in sea spray aerosol (SSA), but the mechanisms through which saccharides are transferred from seawater to the ocean surface and eventually into SSA are unclear. It is hypothesized that saccharides cooperatively adsorb to other insoluble organic matter at the air/sea interface, known as the sea surface microlayer (SSML). Using a combination of surface-sensitive infrared reflection-absorption spectroscopy and all-atom molecular dynamics simulations, we demonstrate that the marine-relevant, anionic polysaccharide alginate co-adsorbs to an insoluble palmitic acid monolayer via divalent cationic bridging interactions. $\mathrm{Ca}^{2+}$ induces the greatest extent of alginate co-adsorption to the monolayer, evidenced by the $\sim 30 \%$ increase in surface coverage, whereas $\mathrm{Mg}^{2+}$ only facilitates one-third the extent of co-adsorption at seawater-relevant cation concentrations due to its strong hydration propensity. $\mathrm{Na}^{+}$cations alone do not facilitate alginate co-adsorption, and palmitic acid protonation hinders the formation of divalent cationic bridges between the palmitate and alginate carboxylate moieties. Alginate co-adsorption is largely confined to the interfacial region beneath the monolayer headgroups, so surface pressure, and thus monolayer surface coverage, only changes the amount of alginate co-adsorption by less than 5\%. Our results provide physical and molecular characterization of a potentially significant polysaccharide enrichment mechanism within the SSML. 


\section{Introduction}

Saccharides constitute one of the most abundant classes of organic carbon in sea spray aerosol (SSA); ${ }^{1-3}$ but the mechanisms through which these compounds are selectively transferred from bulk seawater to the ocean surface, known as the sea surface microlayer (SSML), and finally to SSA, are not fully understood. ${ }^{4}$ Compared with seawater concentrations, saccharides are enriched 1.2-12.1-fold in the SSML, ${ }^{5-7} 38-3700$-fold in super-micron SSA, ${ }^{8}$ and $100-930,000-$ fold in sub-micron SSA. ${ }^{8,9}$ It is thought that soluble saccharides co-adsorb to insoluble organic films at the SSML and transfer into SSA via bubble bursting at the ocean surface. ${ }^{10-14}$ Chemical composition is a significant driver of SSA particle radiative properties, so climate models require predictive representations of marine aerosol composition to accurately model climate processes in the marine boundary layer. ${ }^{10,15-18}$ SSA containing polysaccharides, especially polysaccharides within marine microgels, comprise a significant fraction of cloud condensation nuclei $(\mathrm{CCN})^{19-22}$ and ice nucleating particles (INPs), ${ }^{23-30}$ thereby affecting cloud formation and albedo. Thus, characterization of polysaccharide enrichment mechanisms in SSA is imperative for improving aerosol representation in global climate models.

Recent work by Hasenecz et al. has shown that the polysaccharide alginate is enriched in laboratory-generated marine aerosol, and alginate enrichment can be enhanced upon adding protein and additional $\mathrm{CaCl}_{2}$ salt to the model seawater solution. ${ }^{31}$ Alginate is a type of exopolymeric substance derived from marine brown algae and bacteria; ${ }^{32,33}$ it is composed of $(1 \rightarrow 4)$-linked $\alpha$-L-guluronic $(\mathrm{G})$ and $\beta$-D-mannuronic $(\mathrm{M})$ monomers that form a block copolymer with random sequences of M-, G-, and MG-blocks. ${ }^{34-39}$ Alginate polymers undergo ionic crosslinking to form hydrophilic gels via metal ion coordination primarily to the $\mathrm{G}$ residue carboxylic acid moieties. ${ }^{36,39,40}$ The rigidity and stability of the hydrogels are largely driven by the $\mathrm{M} / \mathrm{G}$ 
residue ratio and the molecular weight of the polymers, ${ }^{39,41,42}$ but the ionic cross-linker identities and concentrations also play a crucial role. ${ }^{43-48}$ Multivalent cations readily induce gelation, and the cation hydration free energies dictate the local interaction configurations with $\mathrm{G}$ residues. ${ }^{48} \mathrm{Of}$ the abundant seawater cations, $\mathrm{Ca}^{2+}$ is the most efficient gelling agent. ${ }^{43,44,48} \mathrm{Mg}^{2+}$ only induces gelation at high alginate concentrations $\left(>3 \mathrm{wt} \%\right.$ alginate and $\left.\left[\mathrm{Mg}^{2+}\right]>50 \mathrm{mM}\right)$ because of its high affinity for water such that the $\mathrm{G}$ residue carboxylate moieties cannot readily dehydrate $\mathrm{Mg}^{2+}$ for coordination. ${ }^{45-48}$ Extensive experimental and computational studies ${ }^{49-54}$ have investigated polysaccharide aggregation into surface-active marine gels via ionic coordination, but less is known about polysaccharide complexation to other surface-active organic molecules derived from marine biota. Enhanced saccharide enrichment in laboratory-generated SSA in the presence of divalent cations and other surface-active organic material strongly suggests a co-adsorption mechanism mediated by divalent cationic bridging. ${ }^{12,31}$

A divalent cation mediated co-adsorption mechanism was also postulated by Schill et al. to explain enrichment of the monosaccharide glucuronic acid in laboratory-generated SSA. ${ }^{12}$ Glucuronic acid likely co-adsorbs to an insoluble palmitic acid (hexadecanoic acid, $\left.\mathrm{CH}_{3}\left(\mathrm{CH}_{2}\right)_{14} \mathrm{COOH}\right)$ monolayer via seawater divalent cationic bridging interactions. Palmitic acid is one of the most abundant lipids in the $\mathrm{SSML}^{55,56}$ and in nascent $\mathrm{SSA},{ }^{55,57,58}$ making it a good model for insoluble organic matter in an SSML proxy film. ${ }^{59-62}$ Cooperative adsorption (coadsorption) to insoluble lipid monolayers has been indirectly observed for other saccharides and polysaccharides as well. ${ }^{10,11,13,63}$ Electrostatic interactions between charged saccharides and either charged or zwitterionic lipid headgroups have been the predominant mechanism of co-adsorption proposed. For example, the cationic polysaccharide chitosan primarily interacts with negatively charged and zwitterionic phospholipids through electrostatic interactions between the chitosan 
ammonium and phospholipid phosphate moieties. ${ }^{64-69}$ Chitosan co-adsorption expands the monolayer, ${ }^{70}$ and chitosan likely intercalates into the monolayer at low mean molecular area through dispersive interactions. ${ }^{68,69}$ Divalent cationic bridging between the anionic polysaccharide dextran sulfate and the zwitterionic phospholipids 1,2-dipalmitoyl-phosphatidylethanolamine (DPPE) and 1,2-dimyristoyl-sn-glycero-3-phosphocholine (DMPC) has also been measured..$^{71-73}$ $\mathrm{Ca}^{2+}$ bridges the sulfate and phosphate moieties, whereas $\mathrm{Na}^{+}$does not. ${ }^{72}$ Strength of dextran sulfate co-adsorption increases with the number of calcium bridges formed, and unlike chitosan, dextran sulfate does not intercalate into the monolayer; instead, the authors argued that strong bridging interactions tether the polysaccharide to the underside of the phosphate headgroups. ${ }^{73}$ Thus, divalent cationic bridging interactions could promote polysaccharide co-adsorption to the SSML and enrichment in SSA.

In this study, we examine the cationic bridging mechanism responsible for alginate coadsorption to a deprotonated palmitic acid monolayer using surface-sensitive infrared reflectionabsorption spectroscopy (IRRAS) and molecular dynamics simulations. In this work, we directly observe polyelectrolyte adsorption to an insoluble monolayer of the same charge state bridged by an ion of opposite charge. $\mathrm{Ca}^{2+}$ induces the greatest degree of alginate co-adsorption to the monolayer, but the divalent cationic bridges break apart upon palmitic acid protonation. $\mathrm{Mg}^{2+}$ also promotes co-adsorption to the deprotonated monolayer, but the interaction is much weaker due to the strong hydration of $\mathrm{Mg}^{2+} \cdot \mathrm{Na}^{+}$alone does not facilitate alginate co-adsorption. Our detailed experimental and computational analyses of the alginate co-adsorption mechanism to an SSML proxy film suggest that the $\mathrm{Ca}^{2+}$ bridge to surface-active marine organic matter is an important driver of polysaccharide enrichment in the SSML, and thus, in SSA. 


\section{Experimental and computational methods}

\section{Materials}

Calcium chloride dihydrate (Certified ACS, Fisher Chemical), magnesium chloride hexahydrate (Crystalline/Certified ACS, Fisher Chemical), d31-palmitic acid (98\%, Cambridge Isotope Laboratories, Inc.), and $\mathrm{d}_{33}$-cetyl alcohol ( $\mathrm{d}_{33}$-hexadecanol, 98\%, Cambridge Isotope Laboratories, Inc.) were used as received. Sodium chloride (99.5\%, for biochemistry, ACROS Organics ${ }^{\mathrm{TM}}$ ) was baked for at least 10 hours in a furnace at $650^{\circ} \mathrm{C}$ to remove residual organic impurities. ${ }^{74}$ Alginic acid (sodium salt, ACROS Organics ${ }^{\mathrm{TM}}$, Lot: A0406891) was also used as received from the same batch to maximize homogeneity in molecular weight and composition. All aqueous solutions were prepared with ultrapure water $(18.2 \mathrm{M} \Omega \cdot \mathrm{cm}$, Milli-Q Advantage A10, EMD Millipore) in glassware cleaned in a piranha acid bath. Acidification by atmospheric $\mathrm{CO}_{2}$ causes the ultrapure water $\mathrm{pH}$ to be $5.8 \pm 0.1$; hence, the $\mathrm{pH} 5.8$ aqueous solutions were not $\mathrm{pH}$ adjusted. Atmospheric $\mathrm{CO}_{2}$ acidifies the solutions at seawater $\mathrm{pH}$ too, so the solutions were initially $\mathrm{pH}$ adjusted with sodium hydroxide pellets $\left(98 \%\right.$, extra pure, ACROS Organics $\left.{ }^{\mathrm{TM}}\right)$ to $8.6 \pm 0.1$ to ensure that the $\mathrm{pH}$ would be $8.2 \pm 0.1$ throughout spectral acquisition. Lipids were dissolved in chloroform (Reagent ACS, 99.8+\%, ACROS Organics ${ }^{\mathrm{TM}}$ ) to prepare $\sim 1.25 \mathrm{mM}$ solutions for spreading onto the aqueous surface.

\section{Surface pressure-area isotherms}

Surface pressure - area isotherms were performed using the Wilhelmy plate method in a Teflon Langmuir trough with Delrin barriers (Biolin Scientific). The platinum Wilhelmy plate, trough, and barriers were cleaned thoroughly with ultrapure water and ethanol, and the Wilhelmy plate was fired with a Bunsen burner until red hot. Surface cleanliness of the aqueous solution was assessed by sweeping the barriers at maximum compression speed $(270 \mathrm{~mm} / \mathrm{min} / \mathrm{barrier})$ to ensure 
that the surface pressure did not rise above $0.20 \mathrm{mN} / \mathrm{m}$. $\mathrm{d}_{31}$-Palmitic acid dissolved in chloroform was spread dropwise onto the aqueous surface using a glass syringe (Hamilton), and the chloroform solvent was allowed to evaporate over 10 minutes. The barriers were symmetrically compressed at a rate of $5 \mathrm{~mm} / \mathrm{min} / \mathrm{barrier}$, and constant surface pressure was maintained during spectroscopic measurements via slow barrier position fluctuations ( $1 \mathrm{~mm} / \mathrm{min} / \mathrm{barrier})$.

\section{Infrared reflection-absorption spectroscopy}

Infrared-reflection absorption spectroscopy was conducted using an in-lab-built optical setup. Two planar gold mirrors positioned at $48^{\circ}$ relative to surface normal were placed inside a Fourier transform infrared spectrometer (Spectrum 100, PerkinElmer) to direct the incident beam towards the aqueous surface and to direct the reflected light towards the liquid nitrogen-cooled $\mathrm{HgCdTe}(\mathrm{MCT})$ detector. Spectra were collected with unpolarized light as an average of 400 scans in the single-beam mode, and the spectral resolution was set to $4 \mathrm{~cm}^{-1}$. Energy values were recorded between 450 and $4000 \mathrm{~cm}^{-1}$ in $0.5 \mathrm{~cm}^{-1}$ increments. Experiments were repeated in at least triplicate, and each spectrum was reported as the average of all trials. Spectral background subtraction and peak integration were performed using OriginPro 9.0. The $\mathrm{OH}$ stretching region was analyzed by fitting a line between endpoints 2985 and $3000 \mathrm{~cm}^{-1}$ for baseline subtraction, and the area under the curve was integrated between these endpoints. The IRRAS spectra and integrated peak areas were numerically corrected to account for differences in monolayer mean molecular area (MMA) between experiments. The average MMA value of the solution containing alginate was divided by the corresponding average MMA value of the salt water solution. This ratio was then multiplied into the reflectance-absorbance values of the spectra containing alginate. Similar spectral analyses were performed in the $\mathrm{COOH}$ stretching $\left(1150-1850 \mathrm{~cm}^{-1}\right)$ and $\mathrm{CD}_{2}$ scissoring mode $\left(1070-1110 \mathrm{~cm}^{-1}\right)$ regions, and descriptions of the peak fitting procedures can be 
found in the Electronic Supplementary Information (ESI). All spectra and data points represent averages of at least three measurements, and error bars represent one standard deviation from the mean.

\section{Computational methods}

Explicit solvent all-atom molecular dynamics simulations were performed using NAMD ${ }^{75}$ at a temperature of $298.15 \mathrm{~K}$. The initial configurations of each system were constructed using Packmol. ${ }^{76}$ To approximate a TC palmitic acid monolayer at $\mathrm{pH}$ 5.6, palmitic acid molecules were packed into two planar $25 \AA$ x $25 \AA$ monolayer slabs, each containing 96 molecules. A pH of 8.2 was approximated by packing 46 molecules each of palmitate and palmitic acid into monolayer slabs of the same dimensions. The monolayer slabs were then separated on one side by vacuum and the other side with a $60 \AA$-deep water box with 15 proxy alginate molecules (ESI Fig. S1). The initial structure for the alginate was constructed using the CHARMM-GUI glycan modeler ${ }^{77-}$ ${ }^{80}$ and consists of $6(1 \rightarrow 4)-\beta$-linked $\mathrm{M}$ monomers. For each representative $\mathrm{pH}$, the aqueous phase either contained $0.47 \mathrm{M} \mathrm{NaCl}+10 \mathrm{mM} \mathrm{CaCl}_{2}$ or $0.47 \mathrm{M} \mathrm{NaCl}$ only. For the systems containing $\mathrm{Ca}^{2+}$, all negative charges were balanced using random placement of calcium ions and otherwise balanced with sodium. Identical systems without alginate were also constructed as controls. TIP3P water ${ }^{81}$ was used in conjunction with the CHARMM36 forcefield. ${ }^{82}$ The system was simulated using constant number, volume and temperature (NVT) with temperature controlled via Langevin dynamics $^{83}$ with a coupling constant of 1 ps. The equations of motion were integrated with a timestep of 2 fs, with long-range electrostatics calculated every other timestep using the Particle Mesh Ewald method with a cutoff of $12 \AA .^{84}$ A correction was applied to prevent center of mass drift due to PME by enabling the zeroMomentum parameter. The systems were energy-minimized and equilibrated for 800 ps. Production simulations consisting of 200-ns trajectories each were 
then performed in triplicate for a total of $600 \mathrm{~ns}$ per system. The production run simulation length of $200 \mathrm{~ns}$ was chosen to allow for any long timescale diffusion and settling of ions and alginate. All simulations were performed on an AgilityValue Tower AMD ROME Workstation (Applied Data Systems Inc., Poway, CA) equipped with an NVIDIA GeForce RTX 3090 Graphics Card (Santa Clara, CA).

Analyses of the MD trajectories were performed in a Jupyter Notebook iPython environment. The density and radial distribution function (RDF) calculations were performed with pytraj ${ }^{85,86}$ Lipid order parameters were calculated using the GROMACS gmx order tool from GROMACS version 2018.3. ${ }^{87}$

\section{Results and discussion}

The mechanism of alginate co-adsorption to a $\mathrm{d}_{31}$-palmitic acid $\left(\mathrm{CD}_{3}\left(\mathrm{CD}_{2}\right)_{14} \mathrm{COOH}\right)$ monolayer was investigated experimentally as a function of solution ionic composition, $\mathrm{d}_{31^{-}}$ palmitic acid protonation state, and surface pressure. We will use the terms "monolayer" to refer to the monomolecular layer of $\mathrm{d}_{31}$-palmitic acid alone and "film" to describe alginate complexed to the $\mathrm{d}_{31}$-palmitic acid monolayer. Deuterated palmitic acid was used to spectrally isolate the $\mathrm{CD}_{2}$ scissoring mode from the carboxylate stretching region. The ionic composition was selected to model concentrations of the most abundant cations in seawater: $0.47 \mathrm{M} \mathrm{NaCl}, 10 \mathrm{mM} \mathrm{CaCl}_{2}$, and $53 \mathrm{mM} \mathrm{MgCl}{ }_{2}{ }^{88,89}$ As a direct comparison to the $10 \mathrm{mM} \mathrm{CaCl}_{2}$ solution, alginate co-adsorption in $10 \mathrm{mM} \mathrm{MgCl} 2$ aqueous solution was also measured. All aqueous solutions have a background of $0.47 \mathrm{M} \mathrm{NaCl}$ to maintain high ionic strength as in seawater.

The carboxylic acid protonation state was varied through the solution $\mathrm{pH}$ values of 8.2 and 5.8. Palmitic acid has a reported surface $\mathrm{pK}_{\mathrm{a}}$ between 8.34 and $8.7,{ }^{60,90-92}$ and the $\mathrm{pK}_{\mathrm{a}}$ values of 
alginate $\mathrm{G}$ and $\mathrm{M}$ residues are 3.7 and 3.4, respectively. ${ }^{93}$ Thus at $\mathrm{pH} 8.2$, the $\mathrm{pH}$ of seawater, ${ }^{94}$ palmitic acid is partially deprotonated and alginate is fully deprotonated. At $\mathrm{pH} 5.8$, palmitic acid is mostly protonated, and alginate carboxylate groups remain deprotonated. Salts can deprotonate carboxylic acids at $\mathrm{pH}$ values significantly below the $\mathrm{pK}_{\mathrm{a}},{ }^{61,95,96}$ however, so a $\mathrm{d}_{33}$-cetyl alcohol (d $\mathrm{d}_{33}$-hexadecanol, $\left.\mathrm{CH}_{3}\left(\mathrm{CH}_{2}\right)_{15} \mathrm{OH}\right)$ monolayer was used as a control to study alginate coadsorption to a fully protonated monolayer. Alginic acid is insoluble in water, so a lower $\mathrm{pH}$ value was not tested instead to avoid significant changes in solubility. Alginate hydrolysis kinetics are also enhanced in acidic solution, thereby changing the alginate molecular weight distribution in solution over time. ${ }^{97,98}$ Deprotonated palmitate molecules are slightly more soluble in water, ${ }^{60,61}$ so IRRAS spectra were maintained and collected at constant surface pressure to minimize any interpretation impacts from dissolution. The surface pressure values of $5 \mathrm{mN} / \mathrm{m}$ and $25 \mathrm{mN} / \mathrm{m}$ were chosen to represent the tilted condensed (TC) and untilted condensed (UC) two-dimensional monolayer phases, respectively. ${ }^{99}$ Both phases exhibit long-range lateral order in the alkyl tails, but the $\mathrm{d}_{31}$-palmitic acid molecules in the UC phase are closer together on average (more tightly packed) and less tilted relative to surface normal. ${ }^{100}$

To experimentally measure co-adsorption of alginate to the $\mathrm{d}_{31}$-palmitic acid monolayer, IRRAS spectra were analyzed in the $\mathrm{OH}$-stretching region $\left(2985-3800 \mathrm{~cm}^{-1}\right)$, the $\mathrm{COOH}$ stretching region (1150-1850 $\left.\mathrm{cm}^{-1}\right)$, and the $\mathrm{CD}_{2}$ scissoring mode region $\left(1070-1110 \mathrm{~cm}^{-1}\right)$. IRRAS spectra are plotted as reflectance-absorbance (RA),

$$
\mathrm{RA}=-\log \frac{R_{\mathrm{f}}}{R_{0}},
$$

where $R_{\mathrm{f}}$ corresponds to the film reflectance and $R_{0}$ corresponds to the reflectance of the bare aqueous solution. Hence, the signal from the interfacial film is captured, whereas the signal from the bulk aqueous phase is subtracted. When the film reflectance is greater than the solution 
reflectance $\left(R_{\mathrm{f}} / R_{0}>1\right)$, the reflectance-absorbance values are negative. Conversely, if the reflected signal from the solution is greater than that of the film $\left(R_{\mathrm{f}} / R_{0}<1\right)$, then the reflectanceabsorbance values are positive. To isolate the signal from alginate co-adsorption due to the presence of the $\mathrm{d}_{31}$-palmitic acid monolayer, alginate was also included in the aqueous solution spectrum $\left(R_{0}\right)$. Yet, the contribution of alginate adsorbed to the air-water interface due to surface activity alone is small and below our spectroscopic limit of detection.
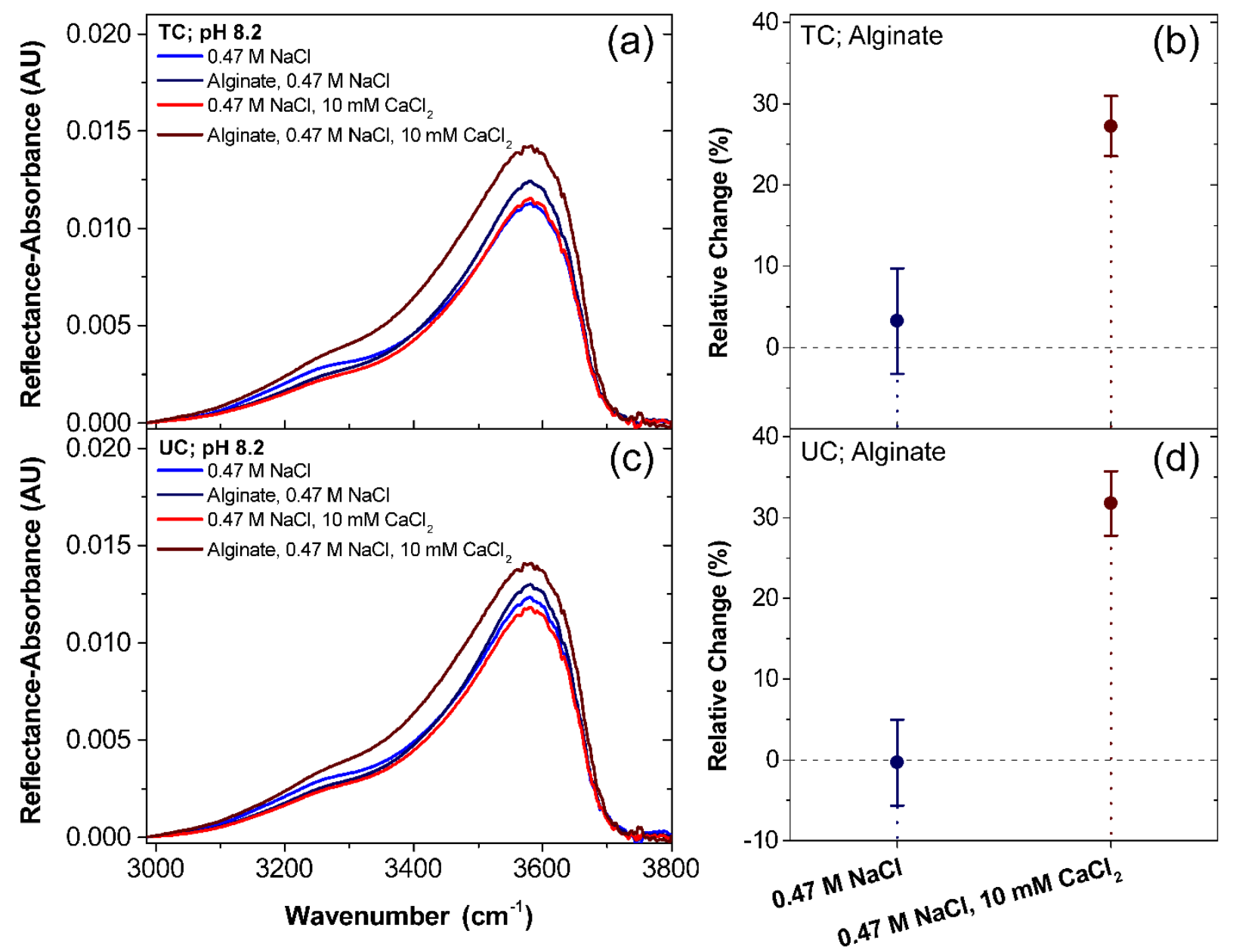

Fig. 1. IRRAS spectra of the $\mathrm{OH}$ stretching region and the corresponding relative changes in integrated peak area of the film indicate that $\mathrm{CaCl}_{2}$ induces significant alginate co-adsorption to the $\mathrm{d}_{31}$-palmitic acid monolayer. Data points and error bars are color-coded to indicate differences in solution composition. Surface pressure was held constant in the (a) tilted condensed $(5 \mathrm{mN} / \mathrm{m})$ and (c) untilted condensed $(25 \mathrm{mN} / \mathrm{m})$ phases throughout spectral acquisition. The relative changes 
in integrated peak area between the solutions with and without alginate are quantified in the (b) tilted condensed and (d) untilted condensed phases. Positive relative change indicates alginate coadsorption to the monolayer, and $0 \%$ relative change indicates no co-adsorption.

\section{Experimental evidence of cation-specific alginate co-adsorption mechanisms}

The $\mathrm{OH}$ stretching region provides sensitive detection of the aqueous solution reflectance, making the spectra useful for quantifying changes in interfacial coverage as a function of alginate co-adsorption. As shown in Figs. 1a and 1c, the IRRAS OH-stretching modes are positive in sign, indicating that the $\mathrm{OH}$ region reflectance decreases upon spreading $\mathrm{d}_{31}$-palmitic acid onto the aqueous solution. The magnitude of the reflectance-absorbance signal intensity also increases with compression of the monolayer to higher surface pressure. Thus, increasing organic surface coverage decreases reflectance from the underlying aqueous solution. Consequently, alginate coadsorption to $\mathrm{d}_{31}$-palmitic acid molecules increases surface coverage, and the $\mathrm{OH}$ stretching region reflectance-absorbance values increase with alginate co-adsorption to the film. If there is no alginate co-adsorption, then the film spectrum with alginate in the solution directly overlaps the monolayer spectrum without alginate.

Figs. 1a and 1c illustrate changes in the $\mathrm{OH}$ stretching region spectra caused by increasing organic surface coverage due to alginate co-adsorption. The spectrum of $\mathrm{d}_{31}$-palmitic acid spread onto an aqueous solution containing $50 \mathrm{ppm}$ alginate, $0.47 \mathrm{M} \mathrm{NaCl}$, and $10 \mathrm{mM} \mathrm{CaCl}$ is significantly enhanced relative to $\mathrm{d}_{31}$-palmitic acid spread onto the salt water solution. IRRAS signal corresponding to the $\mathrm{NaCl}$ and alginate solution is slightly greater relative to the $\mathrm{NaCl}$ solution alone, but the differences are much smaller in the absence of $\mathrm{CaCl}_{2}$. The IRRAS film spectrum corresponding to alginate co-adsorption closely follows the shape of the monolayer spectrum on salt water solution, and the greatest $\mathrm{OH}$ stretching region signal enhancement occurs around $\sim 3580 \mathrm{~cm}^{-1}$ which has been assigned to surface water molecules hydrogen bonded to a 
carboxylic acid group. ${ }^{90,101,102}$ Therefore, alginate co-adsorption enhances the signal around $3580 \mathrm{~cm}^{-1}$ due to the alginate carboxylate hydration.

To better quantify organic surface coverage as a function of alginate co-adsorption, the MMA-corrected $\mathrm{OH}$ region was integrated between 2985 and $3800 \mathrm{~cm}^{-1}$. The relative change in the integrated peak areas between the spectra with and without alginate was calculated using the following formula:

$$
\text { Relative Change }=\frac{\left(A_{\text {Alginate }}-A_{\text {SW }}\right)}{A_{S W}} \times 100 \% .
$$

In this equation, $A_{\text {Alginate }}$ represents the integrated peak area of the spectrum with alginate in the solution, and $A_{\mathrm{SW}}$ represents the integrated peak area of the spectrum containing only salt water (no alginate) in the solution. Alginate co-adsorption corresponds to a positive relative change in surface coverage, and no adsorption results in a $0 \%$ relative change. While the $0.47 \mathrm{M} \mathrm{NaCl}$ solution might induce some alginate co-adsorption to the TC monolayer, as shown by the small but positive relative change value in Fig. 1b, the value is not statistically significant given that the error (represented as one standard deviation from the mean) is larger than the average relative change value. Addition of $10 \mathrm{mM} \mathrm{CaCl}_{2}$ to the solution containing alginate induces a significant increase in the integrated peak area and consequently a $27 \%$ relative change in surface coverage. This increase suggests an alginate co-adsorption mechanism of divalent cationic bridging between alginate and $\mathrm{d}_{31}$-palmitic acid carboxylate moieties.

The differences between the TC and UC spectra and associated relative changes in surface coverage provide insights into the co-adsorption mechanism. The UC film spectrum corresponding to the $50 \mathrm{ppm}$ alginate and $0.47 \mathrm{M} \mathrm{NaCl}$ solution nearly overlaps with the $\mathrm{UC}$ monolayer spectrum corresponding to the $0.47 \mathrm{M} \mathrm{NaCl}$ solution (Figure 1c), suggesting little to no alginate coadsorption. The average relative difference in integrated peak area of the UC monolayer and film 
spectra is approximately $0 \%$ (Figure 1d), indicating a lack of alginate co-adsorption. Additionally, the slightly larger relative change in the TC spectrum surface coverage suggests that alginate expands the monolayer. It is possible that repulsive electrostatic interactions between the $d_{31}$ palmitic acid and alginate carboxylate moieties expand the monolayer, consequently increasing surface coverage in the TC phase. However, in the UC phase, increased dispersion interactions between the alkyl tails counteract the repulsive forces. This hypothesis is further supported by greater MMA expansion with alginate in the solution for the TC film relative to the UC film (see Table S1). Higher surface pressure increases alginate co-adsorption for the solution containing $10 \mathrm{mM} \mathrm{CaCl}_{2}$ to a $32 \%$ relative change in surface coverage, and film expansion in the presence of alginate is not significantly different between the TC and UC phases. Thus, alginate likely does not intercalate between the $\mathrm{d}_{31}$-palmitic acid molecules with $\mathrm{CaCl}_{2}$ in the solution, and the $\mathrm{UC}$ film possibly provides more ideally spaced sites for the $\mathrm{Ca}^{2+}$ bridges.

\section{Monolayer protonation impacts on alginate co-adsorption}

Palmitic acid protonation state significantly impacts the extent of alginate co-adsorption. For the $\mathrm{d}_{31}$-palmitic acid monolayer at $\mathrm{pH} 5.8$, there is a reduced degree of alginate co-adsorption to the film in comparison to the chemical system at $\mathrm{pH}$ 8.2. The $\mathrm{d}_{31}$-palmitic acid TC and UC spectra corresponding to the solution containing alginate have higher reflectance-absorbance values across the entire $\mathrm{OH}$ stretching region (Figs. $2 \mathrm{a}$ and $2 \mathrm{c}$ ), indicative of alginate coadsorption. The relative changes in surface coverage presented in Figs. $2 b$ and $2 d$ quantify this observation, in which alginate co-adsorption at $\mathrm{pH} 5.8$ results in a $14 \%$ and $9 \%$ increase in the integrated peak area for the TC and UC phase spectra, respectively. At $\mathrm{pH} 8.2$, alginate coadsorption results in a $27 \%$ and $32 \%$ integrated peak area increase for the TC and UC phase 
spectra, respectively. Therefore, increased $d_{31}$-palmitic acid protonation decreases the extent of alginate co-adsorption. Unlike the interfacial film at $\mathrm{pH} 8.2$, monolayer compression decreases the magnitude of alginate co-adsorption for the solution at $\mathrm{pH} 5.8$. Alginate might be expanding the TC film similarly to the mechanism proposed for the solution containing only $0.47 \mathrm{M} \mathrm{NaCl}$.
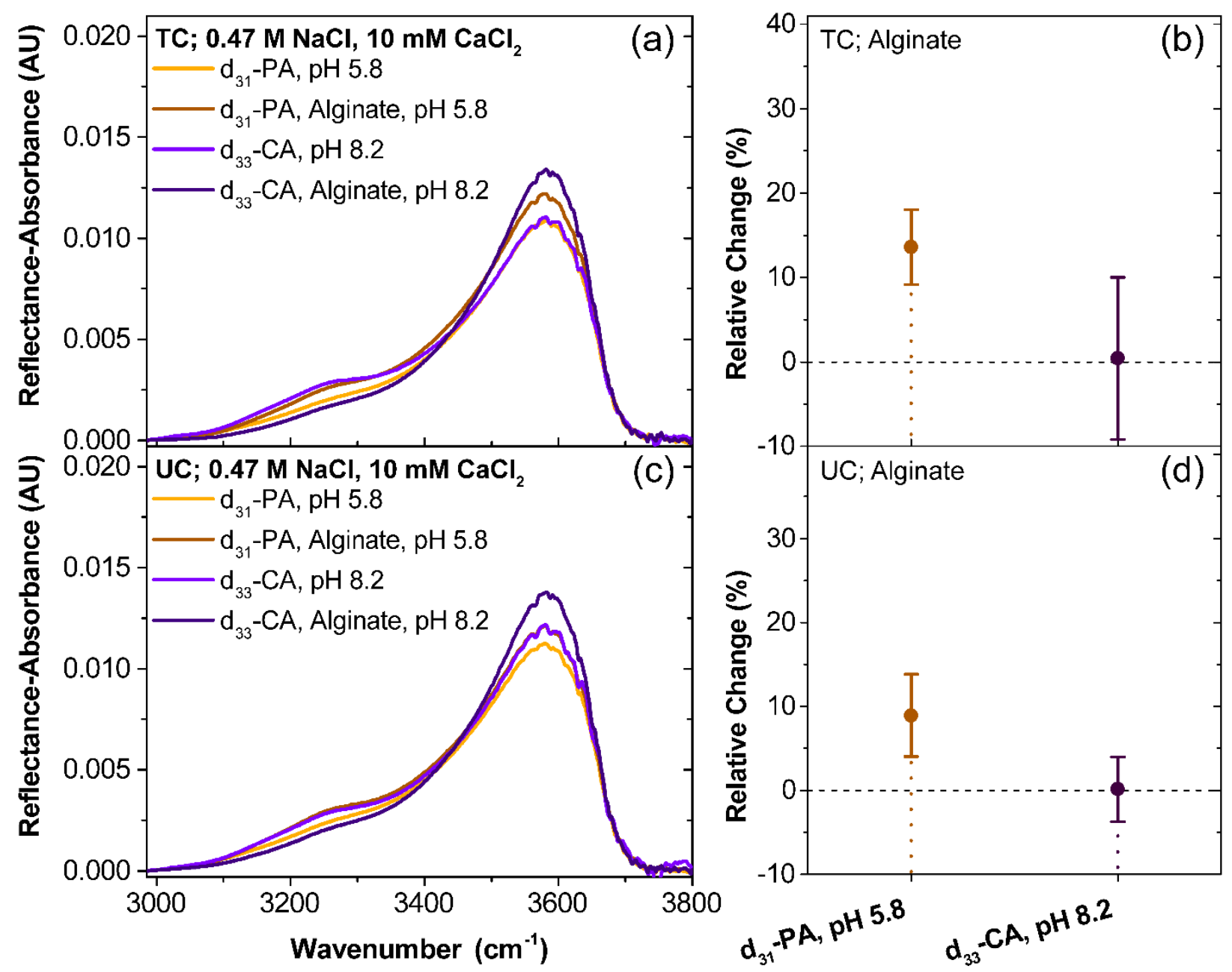

Fig. 2. IRRAS spectra of the $\mathrm{OH}$ stretching region and the corresponding relative changes in integrated peak area of $\mathrm{d}_{31}$-palmitic acid $\left(\mathrm{d}_{31}-\mathrm{PA}\right)$ and $\mathrm{d}_{33}$-cetyl alcohol $\left(\mathrm{d}_{33}-\mathrm{CA}\right)$ monolayers show that headgroup protonation prevents alginate co-adsorption. Data points and error bars are colorcoded to indicate differences in monolayer and solution composition. Surface pressure was held constant in the (a) tilted condensed $(5 \mathrm{mN} / \mathrm{m})$ and (c) untilted condensed $(25 \mathrm{mN} / \mathrm{m})$ phases throughout spectral acquisition. (Note that the light purple and dark brown data curves overlap in (c).) The relative changes in integrated peak area between the solutions with and without alginate are quantified in the (b) tilted condensed and (d) untilted condensed phases. Positive relative 
change indicates alginate co-adsorption to the monolayer, and $0 \%$ relative change indicates no coadsorption.

A fully protonated $\mathrm{d}_{33}$-cetyl alcohol monolayer was examined as a control because it does not become partially deprotonated in the presence of salts at any of the $\mathrm{pH}$ values tested. Trends in the IRRAS spectra of $\mathrm{d}_{33}$-cetyl alcohol alone are less clear (Figs. 2a and 2c). In both monolayer phases, the alginate solution enhances IRRAS signal at $\sim 3580 \mathrm{~cm}^{-1}$ and decreases the signal between $\sim 3050$ and $3440 \mathrm{~cm}^{-1}$ relative to the salt water solution. The region around $3050 \mathrm{~cm}^{-1}$ has been attributed to cyclic carboxylic acid dimers observed in polyacrylic acid solutions, ${ }^{102,103}$ and the region from $\sim 3200 \mathrm{~cm}^{-1}$ to $\sim 3400 \mathrm{~cm}^{-1}$ corresponds to a more ordered hydrogen bonding structure to a less-ordered water structure. ${ }^{101,104,105}$ Further analysis reveals no significant differences between the $\mathrm{OH}$ region integrated peak areas for the solutions with and without alginate in both the TC and UC phases, resulting in a $0 \%$ relative change in surface coverage (Figs. $2 \mathrm{~b}$ and 2d). It is likely that alginate perturbs the interfacial hydration structure but does not co-adsorb to the cetyl alcohol monolayer. Thus, a protonated monolayer blocks alginate co-adsorption, indicating the importance of electrostatic interactions in polysaccharide co-adsorption to an SSML proxy film.

The carboxylic acid spectral region $\left(1150-1850 \mathrm{~cm}^{-1}\right)$ provides further insight into the $\mathrm{d}_{31}$ palmitic acid protonation state and the extent of alginate co-adsorption. Harmonic vibrational frequency calculations were performed to predict the relative frequency shifts between the $d_{31^{-}}$ palmitic acid carboxylate and carboxylic acid modes and the alginate carboxylate modes (see ESI Section S3). Additionally, peaks were fitted to Gaussian functions to resolve the center wavelengths and full width at half maximum (FWHM) values; the fitting procedure and summary of the Gaussian fits for each spectrum are summarized in ESI Section S4. Spectra of a d31-palmitic 
acid TC (Fig. 3a) and UC (Fig. 3c) monolayer exhibit four negative peaks corresponding to the lipid carboxylic acid moieties and one positive band at $\sim 1660 \mathrm{~cm}^{-1}$ corresponding to the water bending mode $(\delta \mathrm{H}-\mathrm{O}-\mathrm{H})$. The protonated carboxylic acid moiety is characterized by the $\mathrm{C}-\mathrm{OH}$ stretching mode $\left(v \mathrm{C}-\mathrm{OH}, \sim 1270 \mathrm{~cm}^{-1}\right)$ and the $\mathrm{C}=\mathrm{O}$ stretching mode $\left(v \mathrm{C}=\mathrm{O}, \sim 1720 \mathrm{~cm}^{-1}\right)$. Deprotonation of the carboxylic acid leads to the appearance of the $\mathrm{COO}^{-}$symmetric $\left(v_{\mathrm{S}} \mathrm{COO}^{-}\right.$, $\left.\sim 1410 \mathrm{~cm}^{-1}\right)$ and asymmetric $\left(v_{\mathrm{AS}} \mathrm{COO}^{-}, \sim 1540 \mathrm{~cm}^{-1}\right)$ stretching modes (negative bands).

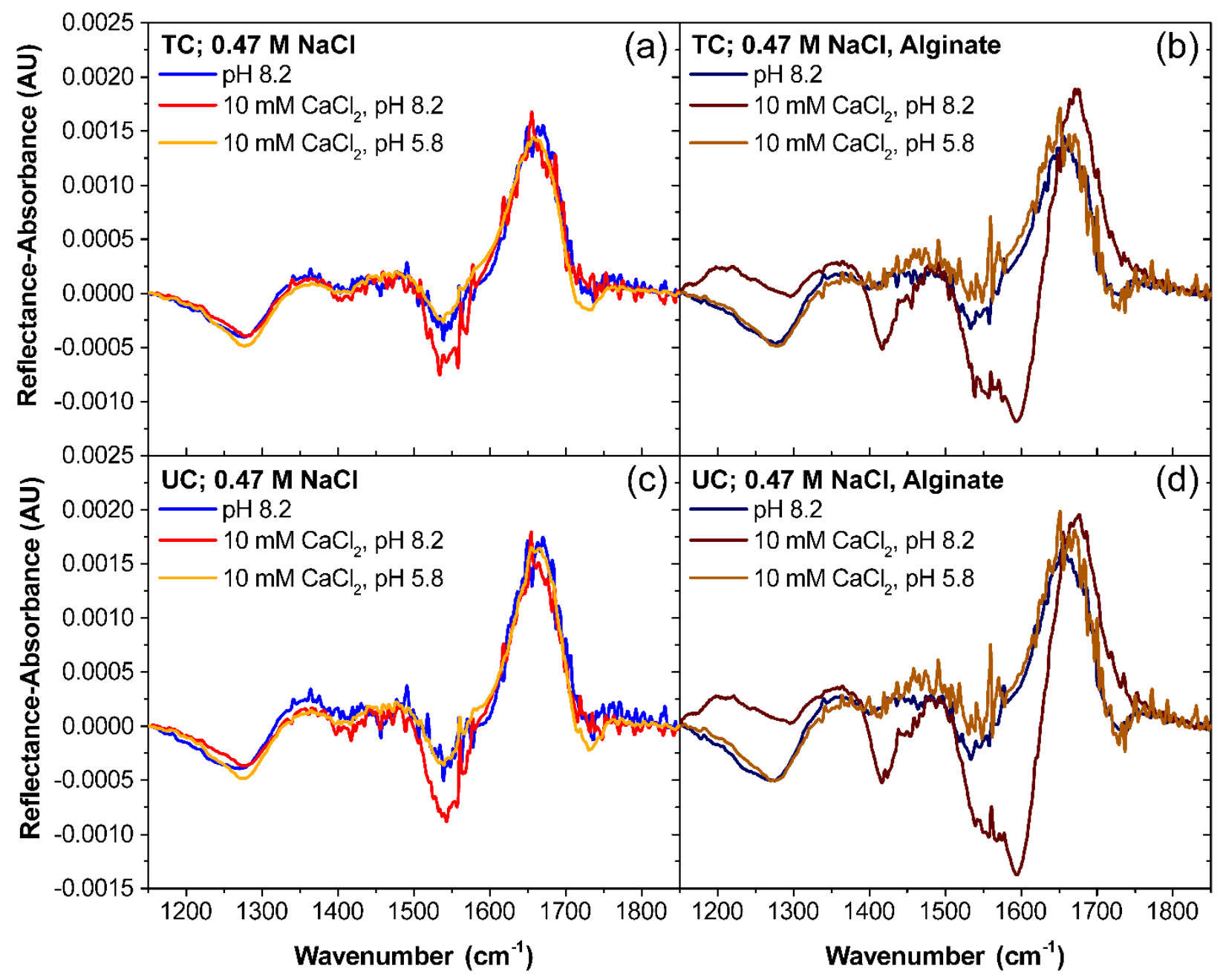

Fig. 3. IRRAS spectra of the $\mathrm{COOH}$ stretching region provide direct evidence of alginate coadsorption via $\mathrm{Ca}^{2+}$ bridging interactions to the $\mathrm{d}_{31}$-palmitic acid monolayer at $\mathrm{pH} 8.2$. Spectral lines are color-coded to indicate differences in solution composition. Surface pressure was held constant in the (a), (b) tilted condensed $(5 \mathrm{mN} / \mathrm{m})$ and (c), (d) untilted condensed $(25 \mathrm{mN} / \mathrm{m})$ 
phases throughout spectral acquisition. Spectra corresponding to the salt water solutions are shown in (a) and (c), and spectra corresponding to the salt water solutions containing $50 \mathrm{ppm}$ alginate are shown in (b) and (d).

As anticipated, $\mathrm{d}_{31}$-palmitic acid spread onto a $0.47 \mathrm{M} \mathrm{NaCl}$ solution at $\mathrm{pH} 8.2$ is partially deprotonated, demonstrated by the presence of all four carboxylic acid and carboxylate stretching modes (Figs. 3a and 3c). Addition of $10 \mathrm{mM} \mathrm{CaCl}_{2}$ further deprotonates the headgroups, as shown by the increase in $\mathrm{COO}^{-}$stretching intensities and by the disappearance of the $\mathrm{C}=\mathrm{O}$ stretching mode in both TC and UC phases (Tables S6 and S8). Decreasing the pH to 5.8 increases the extent of $\mathrm{d}_{31}$-palmitic acid protonation; the $\mathrm{C}-\mathrm{OH}$ and $\mathrm{C}=\mathrm{O}$ stretching modes are most intense at this $\mathrm{pH}$ (Table S10). However, the presence of the $\mathrm{COO}^{-}$stretching modes in the $\mathrm{TC}$ and UC phase spectra indicates that $\mathrm{Ca}^{2+}$ induces some deprotonation which has been shown previously. ${ }^{61,106-108}$

Direct measurement of alginate co-adsorption to the $\mathrm{d}_{31}$-palmitic acid monolayer is observed in Figs. $3 \mathrm{~b}$ and $3 \mathrm{~d}$. There is a large increase in the negative $\mathrm{COO}^{-}$stretching peak intensities and breadth for $\mathrm{d}_{31}$-palmitic acid spread onto the $0.47 \mathrm{M} \mathrm{NaCl}, 10 \mathrm{mM} \mathrm{CaCl}_{2}$, and $50 \mathrm{ppm}$ alginate solution at $\mathrm{pH} 8.2$. The asymmetric and symmetric stretches appear to split into higher and lower frequency bands, so an additional Gaussian function was used to fit both peaks (Fig. S6). Vibrational frequency calculations predict a $47 \mathrm{~cm}^{-1}$ blue shift and a $20 \mathrm{~cm}^{-1}$ blue shift for the alginate asymmetric and symmetric $\mathrm{COO}^{-}$stretching modes, respectively, relative to the corresponding $\mathrm{d}_{31}$-palmitic acid modes (Tables $\mathrm{S} 3$ and $\mathrm{S} 5$ ). The theoretical predictions quite closely match the experimental $\sim 55 \mathrm{~cm}^{-1}$ blue shift for the second $v_{\mathrm{AS}} \mathrm{COO}^{-}$peak and the $\sim 37 \mathrm{~cm}^{-}$ ${ }^{1}$ blue shift for the second $v_{\mathrm{S}} \mathrm{COO}^{-}$peak (Table S9). Hence, the higher frequency $\mathrm{COO}^{-}$stretching bands indicate alginate co-adsorption to the largely deprotonated monolayer in the presence of $\mathrm{CaCl}_{2}$. 
The carboxylate region also provides evidence for $\mathrm{Ca}^{2+}$ ionic bridges driving alginate coadsorption to the $\mathrm{d}_{31}$-palmitic acid monolayer. Alginate co-adsorption induces $\mathrm{d}_{31}$-palmitic acid deprotonation, as shown by increased $\mathrm{COO}^{-}$stretching intensities and decreased $\mathrm{C}-\mathrm{OH}$ stretching intensity for the $\mathrm{pH} 8.2$ solution containing $10 \mathrm{mM} \mathrm{CaCl}_{2}$ (Fig. 3). Similar peak broadening and intensity enhancement was observed for the phosphate headgroup vibrational modes of 1,2dipalmitoyl-sn-glycero-3-phosphatidic acid (DPPA) upon arginine and guanidinium binding. ${ }^{109}$ Palmitic acid deprotonation likely facilitates the formation of energetically favorable ionic complexes between alginate, $\mathrm{Ca}^{2+}$, and palmitate. Furthermore, the $v_{\mathrm{AS}} \mathrm{COO}^{-}, v_{\mathrm{S}} \mathrm{COO}^{-}$, and $v \mathrm{C}-$ $\mathrm{OH}$ modes blue shift upon addition of alginate to the solution (Table S9). The $v_{\mathrm{AS}} \mathrm{COO}^{-}$mode blue shifts $\sim 2.5 \mathrm{~cm}^{-1}$ in the TC phase but does not shift in the UC phase, the $v_{\mathrm{S}} \mathrm{COO}^{-}$mode blue shifts $7 \mathrm{~cm}^{-1}$ in the TC phase and $\sim 6 \mathrm{~cm}^{-1}$ in the UC phase, and the $v \mathrm{C}$-OH mode blue shifts $\sim 13 \mathrm{~cm}^{-}$in the TC phase and $\sim 15 \mathrm{~cm}^{-1}$ in the UC phase. It is possible that the alginate carboxylate interacting with the $\mathrm{Ca}^{2+}$ ion complexed to the $\mathrm{d}_{31}$-palmitate headgroup weakens ionic interactions between the monolayer carboxylate and the $\mathrm{Ca}^{2+}$ ion alone, thereby leading to an increased palmitic acid $\mathrm{COO}^{-}$force constant and blue shifts in the palmitate carboxylate vibrational modes. However, it is more likely that the alginate carboxylate moieties further dehydrate the $\mathrm{d}_{31}$-palmitate .. $\mathrm{Ca}^{2+}$ complex upon alginate co-adsorption.

Spectra of $\mathrm{d}_{31}$-palmitic acid spread onto the $0.47 \mathrm{M} \mathrm{NaCl}$ solution at $\mathrm{pH} 8.2$ and the $0.47 \mathrm{M}$ $\mathrm{NaCl}$ and $10 \mathrm{mM} \mathrm{CaCl}_{2}$ solution at $\mathrm{pH} 5.8$ do not exhibit any higher frequency $\mathrm{COO}^{-}$stretching peaks upon alginate addition to the solution, suggesting minimal to no alginate co-adsorption (Fig. 3). Secondly, the $v_{\mathrm{AS}} \mathrm{COO}^{-}, v_{\mathrm{S}} \mathrm{COO}^{-}$, and $v \mathrm{C}-\mathrm{OH}$ mode peak areas are insignificantly different between the solutions with and without alginate, meaning that alginate co-adsorption to the monolayer is unlikely (Tables S6 and S7; Tables S10 and S11). Smaller blue shifts in the 
$v_{\mathrm{AS}} \mathrm{COO}^{-}, v_{\mathrm{S}} \mathrm{COO}^{-}$, and $v \mathrm{C}-\mathrm{OH}$ modes are observed for the solutions containing $10 \mathrm{mM} \mathrm{CaCl}_{2}$ and alginate at $\mathrm{pH} 5.8$ as compared to the identical solution at $\mathrm{pH} 8.2$ (Table S11). While these spectral shifts are not direct evidence of alginate co-adsorption to the monolayer, it is likely that alginate perturbs the $\mathrm{d}_{31}$-palmitic acid headgroup hydration structure via electrostatic interactions with the headgroups. The less numerous $\mathrm{d}_{31}$-palmitate headgroups may facilitate $\mathrm{Ca}^{2+}$ bridging interactions with alginate carboxylate moieties at various points across the monolayer, as also indicated by the small relative change in surface coverage (Figs. $2 \mathrm{~b}$ and $2 \mathrm{~d}$ ). However, having fewer $\mathrm{Ca}^{2+}$ bridging sites hinders concerted alginate co-adsorption. For the $\mathrm{d}_{33}$-cetyl alcohol monolayer (Figure S13), there are no detectable peaks corresponding to alginate carboxylate modes, further supporting the lack of alginate co-adsorption to the fully protonated monolayer.

To determine if alginate co-adsorption perturbs $\mathrm{d}_{31}$-palmitic acid interfacial organization, the $\mathrm{CD}_{2}$ scissoring mode was analyzed as a function of solution composition, $\mathrm{pH}$, and surface pressure (Fig. 4). All conditions yield a $\mathrm{CD}_{2}$ scissoring mode center wavelength of $1089 \mathrm{~cm}^{-1}$ (see Table S16), indicative of hexagonal lattice packing structure. ${ }^{110}$ Furthermore, the absence of perturbations in the lattice packing structure, regardless of alginate presence in solution, indicates that alginate does not intercalate into the film. $\mathrm{CD}_{2}$ scissoring mode spectra corresponding to the salt water and alginate solutions directly overlap for the $0.47 \mathrm{M} \mathrm{NaCl}$ solution at $\mathrm{pH} 8.2$ (Figs. 4a and $4 \mathrm{~d}$ ) and for the $0.47 \mathrm{M} \mathrm{NaCl}$ and $10 \mathrm{mM} \mathrm{CaCl}_{2}$ solution at $\mathrm{pH} 5.8$ (Figs. $4 \mathrm{c}$ and $4 \mathrm{f}$ ), further indicating no alginate co-adsorption. However, the $\mathrm{CD}_{2}$ scissoring mode reflectance-absorbance signal magnitude in the TC and UC phase is significantly enhanced for $\mathrm{d}_{31}$-palmitic acid spread onto the $0.47 \mathrm{M} \mathrm{NaCl}, 10 \mathrm{mM} \mathrm{CaCl}_{2}$, and $50 \mathrm{ppm}$ alginate solutions at $\mathrm{pH} 8.2$ (Figs. $4 \mathrm{~b}$ and $4 \mathrm{e}$ ). Signal enhancement is most apparent in the high frequency regime, and a smaller extent of signal enhancement occurs in the lower frequency region of the spectra. From the harmonic frequency 
analysis results (Tables S3 and S5), the signal enhancement can be attributed to alginate $\mathrm{C}-\mathrm{OH}$ stretching and bending and $\mathrm{CH}$ stretching. The $\mathrm{CD}_{2}$ shoulder features overlap in frequency with the $\mathrm{CD}_{2}$ scissoring modes, and particularly intense alginate vibrational transitions occur $\sim 10 \mathrm{~cm}^{-1}$ lower than and $\sim 20 \mathrm{~cm}^{-1}$ higher than the center frequency of the $\mathrm{d}_{31}$-palmitate $\mathrm{CD}_{2}$ scissoring mode. As a result, the signal enhancement surrounding the $\mathrm{CD}_{2}$ scissoring peak can be confidently attributed to alginate co-adsorption to the monolayer via $\mathrm{Ca}^{2+}$ bridging interactions.

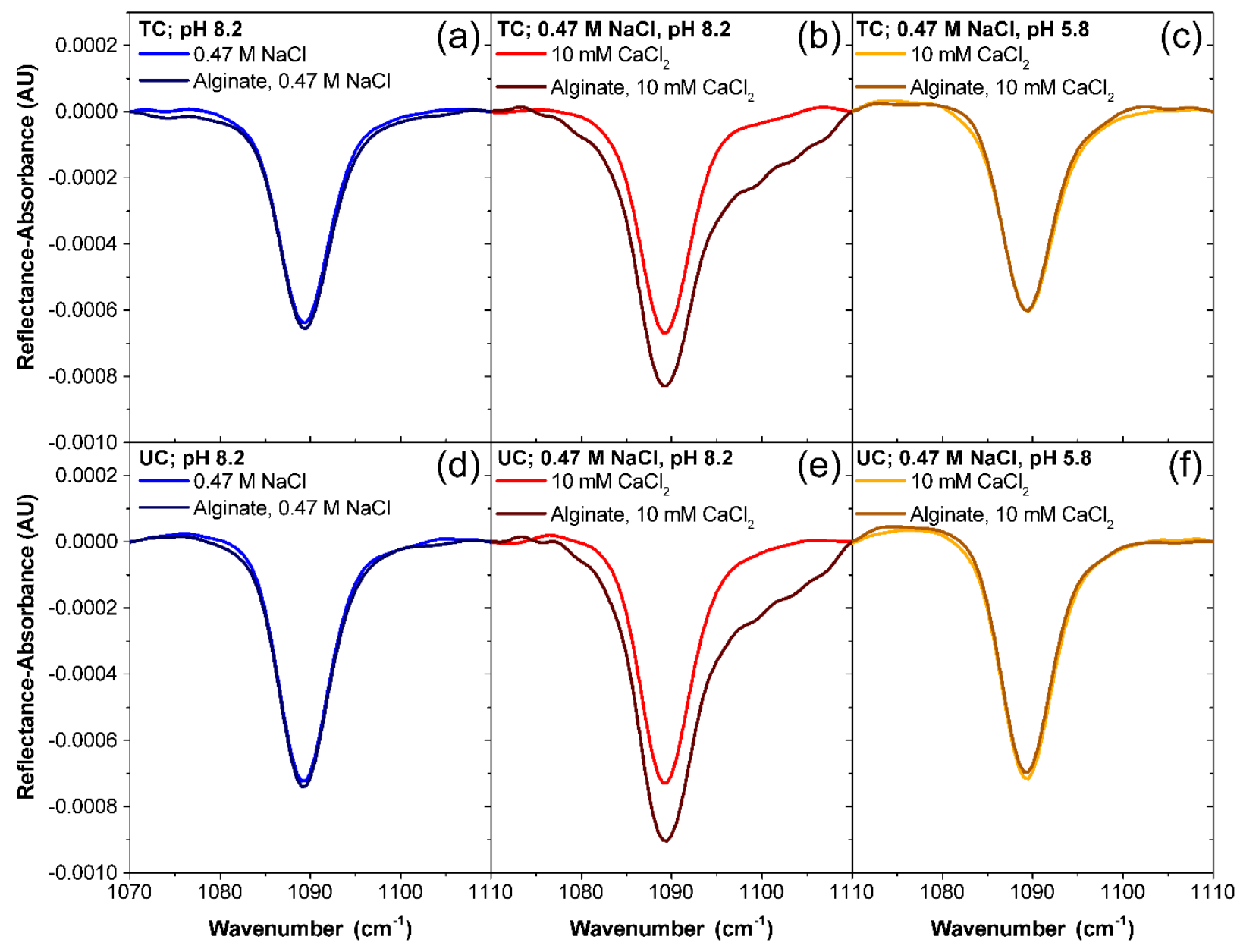

Fig. 4. IRRAS spectra of the $\mathrm{CD}_{2}$ scissoring mode region demonstrate alginate co-adsorption to the $\mathrm{d}_{31}$-palmitic acid monolayer in the presence of $10 \mathrm{mM} \mathrm{CaCl}_{2}$ at $\mathrm{pH} 8.2$, and the spectra indicate no changes in $\mathrm{d}_{31}$-palmitic acid lattice packing upon adsorption. Spectral lines are color-coded to indicate differences in solution composition. Surface pressure was held constant in the (a), (b), (c) tilted condensed $(5 \mathrm{mN} / \mathrm{m})$ and (d), (e), (f) untilted condensed $(25 \mathrm{mN} / \mathrm{m})$ phases throughout spectral acquisition. 


\section{Density and radial distribution profiles from MD simulations}

Additional atomistic insights into the proposed divalent cationic bridging mechanism were obtained through explicit solvent all-atom molecular dynamics simulations of a TC palmitic acid monolayer at varying $\mathrm{pH}$ in the presence and absence of $\mathrm{Ca}^{2+}$ in the aqueous phase. Fig. 5 gives the number density and radial distribution profiles of selected species in each of the simulation conditions containing alginate at $\mathrm{pH}$ 8.2. The relative locations of the palmitic acid headgroups in the number density profiles (Figs. 5a and 5b) are in agreement with previous studies, ${ }^{60,111}$ where the carboxylate headgroup of the palmitate sinks lower into the aqueous phase relative to the carboxylic acid. The peaks associated with the $\mathrm{Ca}^{2+}$ ion trace in Fig. 5a are indicative of selective calcium binding to the charged carboxylate headgroups. Similar coordination peaks associated with $\mathrm{Na}^{+}$are found in the sodium-only system shown in Fig. 5 b.
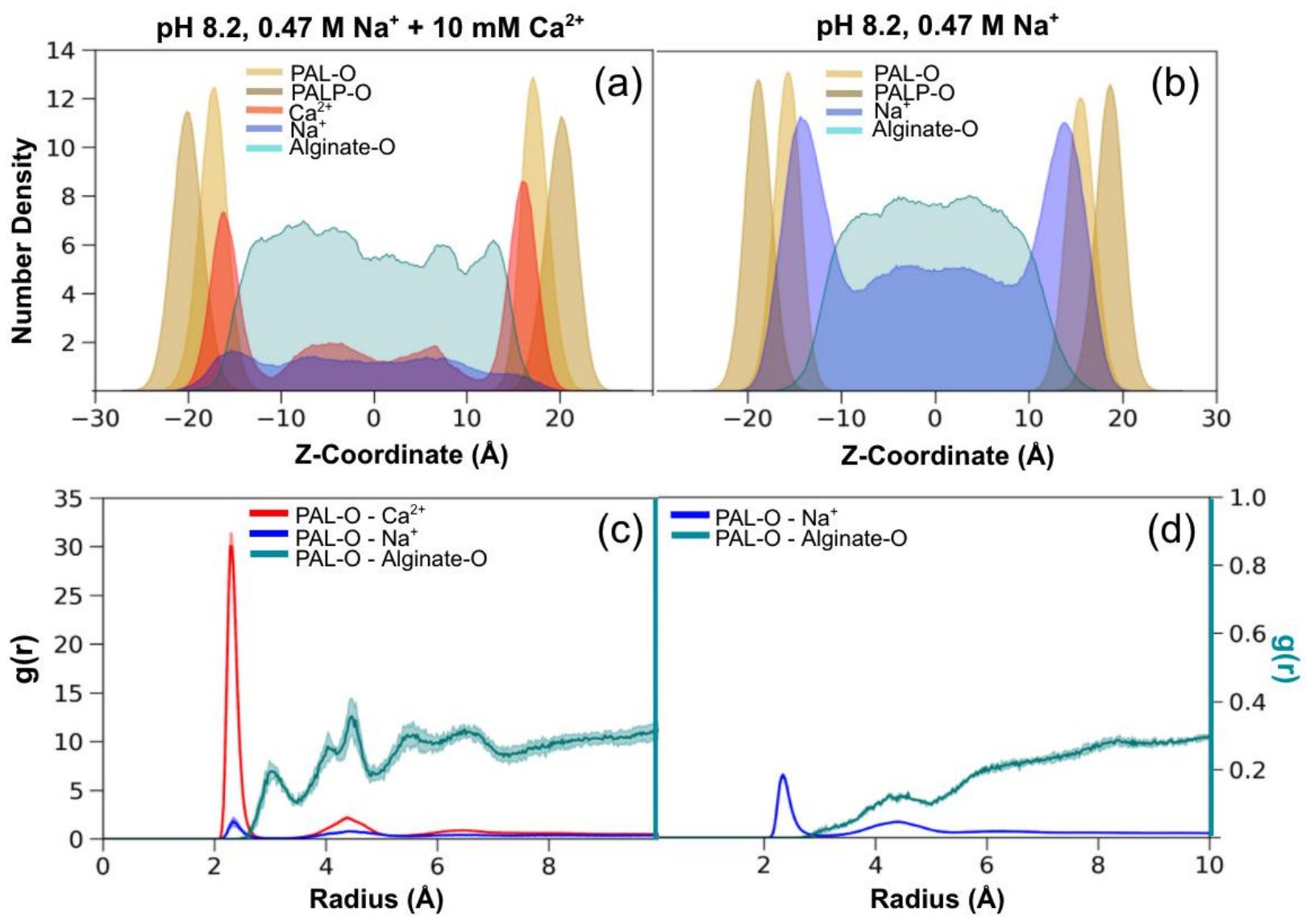
Fig. 5. Number density profiles (a, b) and radial distribution functions (c-d) of selected species from molecular dynamics simulations at $\mathrm{pH} 8.2$ with a $0.47 \mathrm{M} \mathrm{NaCl}$ subphase either in the presence (a) or absence (b) of $\mathrm{Ca}^{2+}$. In the number density profiles, the oxygen atom of the palmitate headgroup carboxylate (PAL-O) is used to represent the location of palmitate (light tan). The $\mathrm{OH}-$ oxygen atom of the palmitic acid headgroup (PALP-O) is used to represent the location of palmitic acid (dark tan). Similarly, a carboxylate oxygen atom on each M monomer in alginate (Alginate$\mathrm{O}$ ) is used to quantify the distribution of alginate (teal). The radial distribution functions of $\mathrm{Ca}^{2+}$, $\mathrm{Na}^{+}$and the alginate carboxylate with respect to the palmitate carboxylate are given for the systems in the presence (c) and absence (d) of $\mathrm{Ca}^{2+}$ at $\mathrm{pH} 8.2$ over a $0.47 \mathrm{M} \mathrm{NaCl}$ subphase.

To determine whether alginate molecules co-adsorb to the monolayer by a cationic bridging mechanism as indicated by experiments, we can evaluate the alginate carboxylate traces. At $\mathrm{pH} 8.2$, the alginate trace exhibits a broader, flatter profile in the presence of $\mathrm{Ca}^{2+}$ and a sharper rise in alginate coordination that occurs closer to the palmitate headgroups. We can also investigate this behavior using the radial distribution function (RDF) in which the probability density of the cation $\left(\mathrm{Ca}^{2+}\right.$ or $\left.\mathrm{Na}^{+}\right)$or functional group (alginate $\left.\mathrm{COO}^{-}\right)$as a function of distance (r) from the palmitate headgroup is plotted (Figs $5 \mathrm{c}-\mathrm{d}$ ). There is a sharp cation peak as expected at just over $2 \AA$ in both systems. However, the alginate $\mathrm{COO}^{-}$group exhibits distinctly different behavior between the two systems. The sharp peak at $3 \AA$ in the presence of $\mathrm{Ca}^{2+}$ suggests that calcium likely serves as a bridge between the two $\mathrm{COO}^{-}$moieties; conversely, in the absence of $\mathrm{Ca}^{2+}$, the alginate peak occurs over much larger distances from the palmitate, has significantly lower probability, and is much broader. Furthermore, the RDFs of the water atoms $\left(\mathrm{H}_{\mathrm{w}}\right.$ and $\left.\mathrm{O}_{\mathrm{w}}\right)$ with respect to the palmitate $\mathrm{COO}^{-}$are given in Fig. $\mathrm{S} 14$. The sharp $\mathrm{H}_{\mathrm{w}}$ and $\mathrm{O}_{\mathrm{w}}$ peaks at approximately 2 and $3 \AA$, respectively, are associated with the water hydration shell around the palmitate $\mathrm{COO}^{-}$ headgroup. ${ }^{111}$ With $\mathrm{Ca}^{2+}$ coordination, the $\mathrm{COO}^{-}$headgroups are significantly less hydrated in comparison to $\mathrm{Na}^{+}$-coordinated headgroups, where the solvation shell trace is much stronger. This observation agrees with the $\mathrm{d}_{31}$-palmitic acid $v_{\mathrm{AS}} \mathrm{COO}^{-}, v_{\mathrm{S}} \mathrm{COO}^{-}$, and $v \mathrm{C}-\mathrm{OH}$ vibrational mode blue shifts upon alginate co-adsorption, indicative of monolayer headgroup dehydration. Taken 
together, these results strongly suggest that $\mathrm{Ca}^{2+}$ enables the adsorption of alginate to the palmitic acid monolayer at $\mathrm{pH} 8.2$ through a divalent cation bridge.

In comparison, we also provide the number density profiles and RDFs for the monolayer systems at pH 5.8 in which the monolayer is fully protonated (Figs. 6a-d). The number density plots exhibit distinctly different profiles from their higher $\mathrm{pH}$ counterparts; with $\mathrm{Ca}^{2+}$ present, rather than adsorbing to the surface, there is clear aggregation of the alginate in solution that is consistent with the gelation of alginate. ${ }^{112-115} \mathrm{Without} \mathrm{Ca}^{2+}$, the alginate shows a broader, flatter profile, indicating even distribution of alginate throughout solution and very little adsorption to the interface. The RDFs, in contrast with the higher $\mathrm{pH}$ system, show that alginates peak at just over $2 \AA$, which indicate that alginate weakly interacts with the monolayer via hydrogen bonding or dispersive forces between the alginate $\mathrm{COO}^{-}$and palmitic acid -OH. The small cation hump at the same radius can be attributed to contact-ion pairing at the double-bonded oxygen of the carboxylic acid. ${ }^{60}$ The subsequent increase in cation density after $4 \AA$ may be attributed to either solvent-shared ion pairing between the cations and the first hydration shell of the headgroups, or, more likely, to contact-ion pairing between the cations and the alginate $\mathrm{COO}^{-}$. These results are consistent with the experimental findings presented above, which suggest that palmitic acid protonation hinders alginate co-adsorption. 


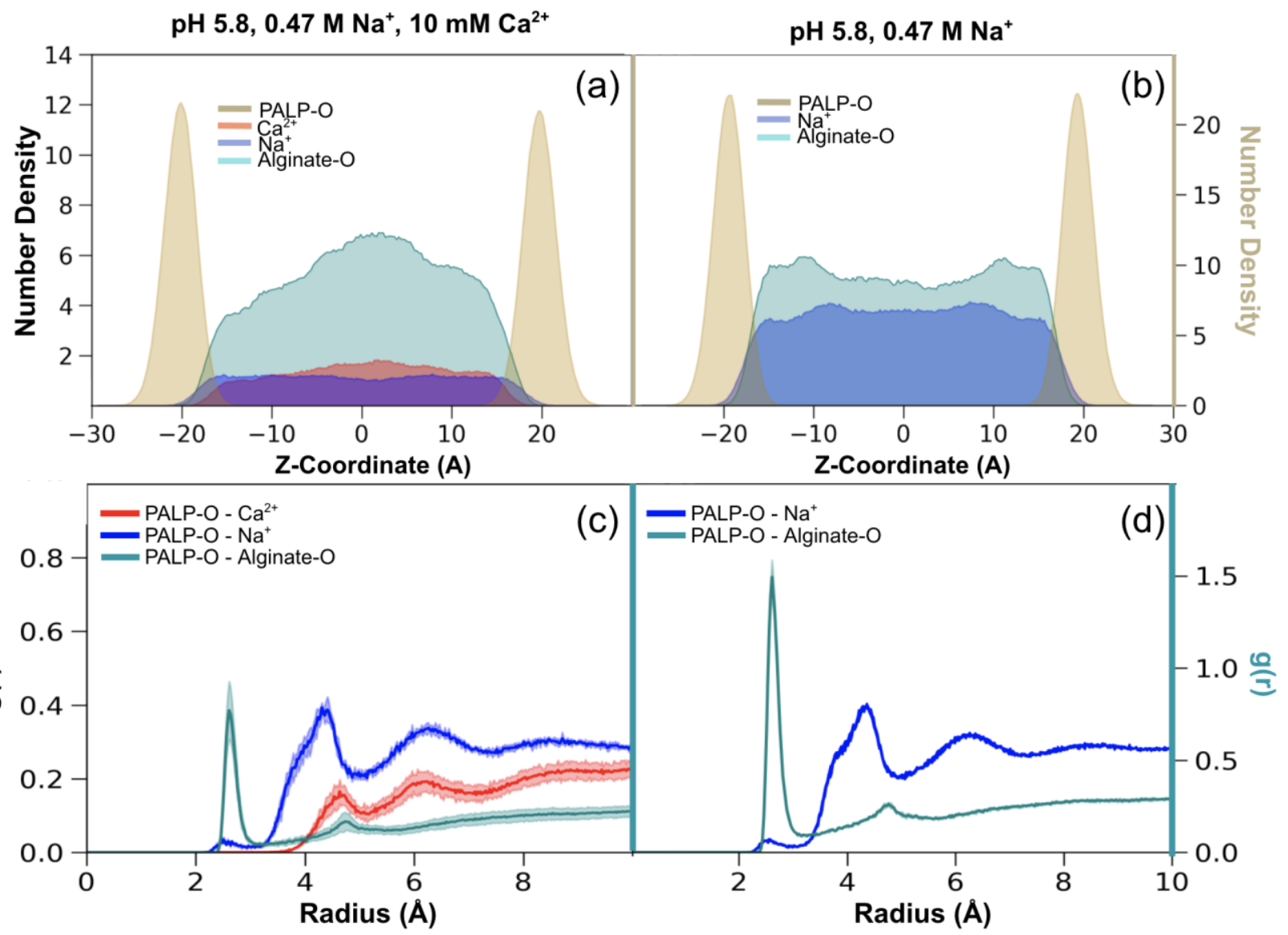

Fig. 6. Number density (a-b) and radial distribution functions (c-d) from molecular dynamics simulations at pH 5.8 in which the palmitic acid monolayer is fully protonated.

\section{Impacts of alginate adsorption on palmitic acid interfacial structure}

The number density plots also show that, for all systems, the alginate trace goes to zero as the monolayer headgroup densities increase. Thus, there is little to no alginate intercalation into the monolayer. Alginate remains largely in the subsurface region, which is in good agreement with the experimental observation that hexagonal packing structure of the palmitic acid chains is preserved upon alginate co-adsorption.

To further investigate the impacts of alginate adsorption on the dynamics and organization of the palmitic acid monolayer, local order parameters were extracted from molecular dynamics simulations (Fig. 7 and Fig. S15). These order parameters are calculated by 


$$
S_{C D}=\frac{3 \times\left\langle\cos ^{2} \theta\right\rangle-1}{2}
$$

where $\theta$ is the angle between the vector normal to the surface and adjacent carbon atoms, $\mathrm{C}_{\mathrm{n}-1}$ and $\mathrm{C}_{\mathrm{n}+1}$. A high order parameter indicates high ordering among the alkyl chains with low motional anisotropy. Fig. S15 gives the order parameters for the palmitic acid and palmitate chains of the monolayers with and without alginate in the aqueous phase. With the exception of carbons 2 and 15, which tend to have low order parameters due to their geometric positions at the top and bottom of the monolayer, the order parameters remain relatively constant at low $\mathrm{pH}$, indicating similar levels of ordering across the alkyl chains and thus no significant perturbations due to alginate interaction. However, at high $\mathrm{pH}$, the order parameters vary across the chain. Additionally, the presence of alginate slightly decreases the order parameters, with the largest decrease seen in the absence of $\mathrm{Ca}^{2+}$. Finally, compared to the low $\mathrm{pH}$ systems in which the order parameters steadily decrease from $\mathrm{C} 4$ to $\mathrm{C} 2$, the relative orders between $\mathrm{C} 2$ and $\mathrm{C} 3$ are reversed at high $\mathrm{pH}$ with $\mathrm{C} 2$ having a higher order parameter than $\mathrm{C} 3$. This reversal indicates that the headgroup carbons experience increased rotational rigidity at high $\mathrm{pH}$. 


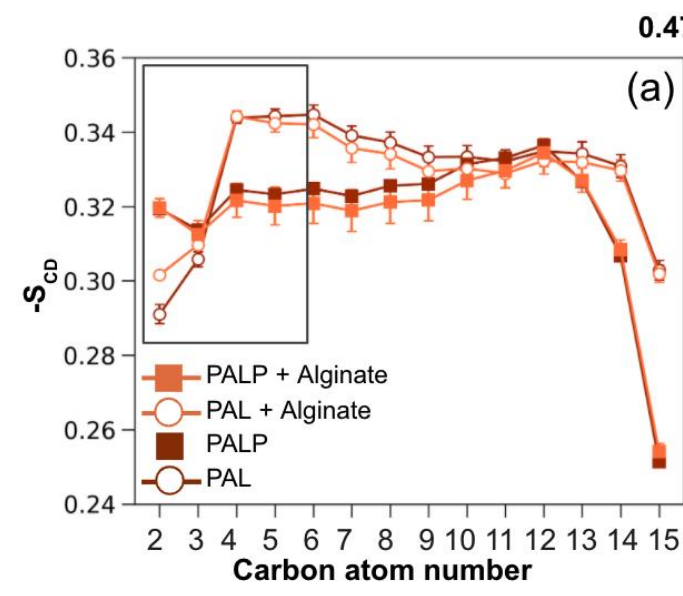

$0.47 \mathrm{M} \mathrm{NaCl}+10 \mathrm{mM} \mathrm{CaCl}{ }_{2}, \mathrm{pH} 8.2$
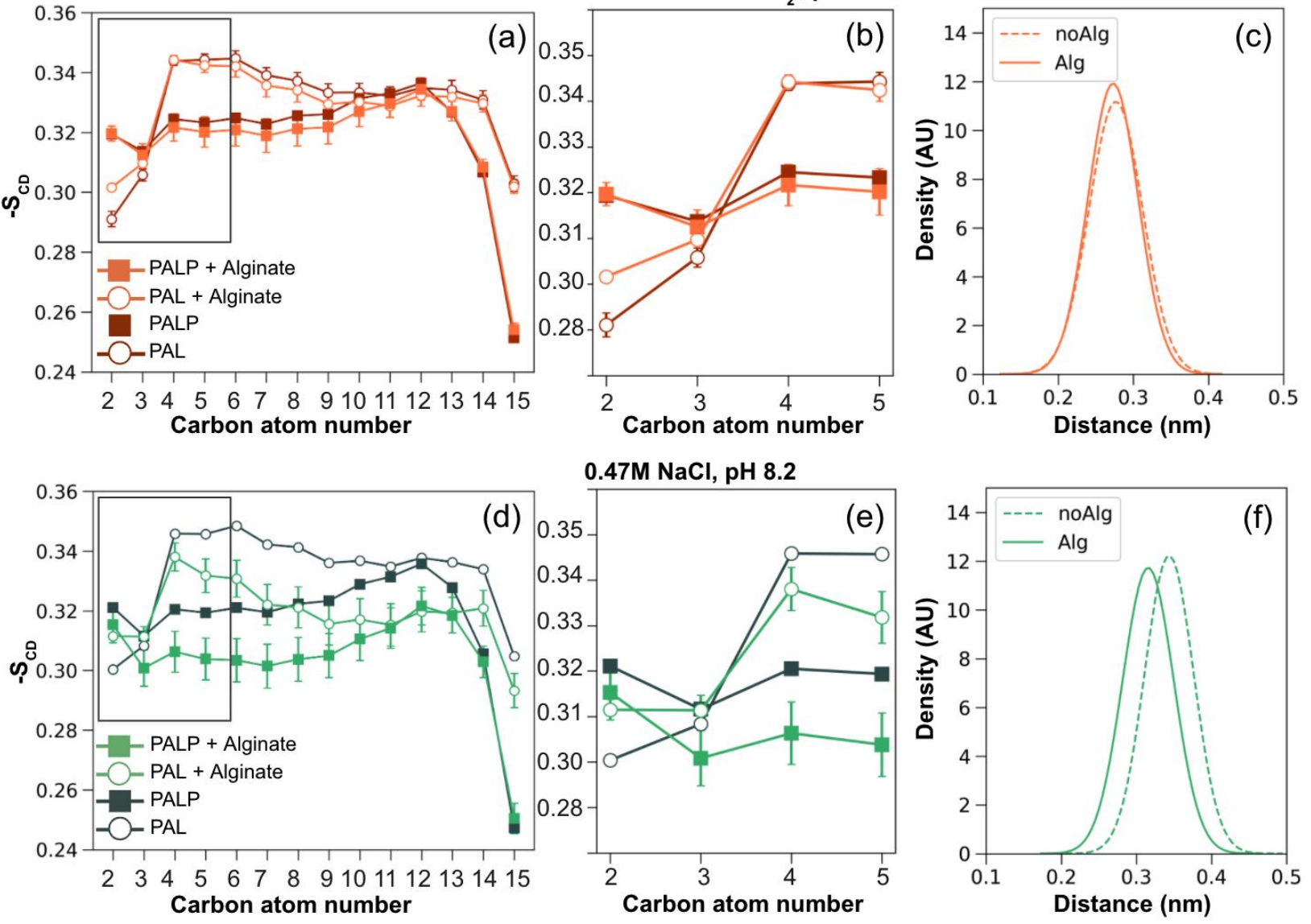

Fig 7. Local order parameters (a-b, d-e) and headgroup separation (c, f) for palmitic acid monolayers at $\mathrm{pH} 8.2$ in the presence (a-c) and absence (d-f) of calcium. Order parameters are calculated based on protonation state for all systems with and without alginate. Figures $b$ and e are specific to the $\mathrm{C} 2-\mathrm{C} 4$ carbon range in the presence and absence of calcium, respectively.

To understand the physical basis of these structural differences, we recalculated order parameters based on residue protonation state (Fig. 7). In all systems at $\mathrm{pH} 8.2$, the deprotonated palmitic acid shows higher ordering than the protonated form, and the addition of alginate generally decreases ordering with the exception of $\mathrm{C} 2$ in both cases (Figs $7 \mathrm{a}$ and $7 \mathrm{~d}$ ). In the presence of $\mathrm{Ca}^{2+}$, alginate adsorption appears to increase ordering of the carboxylate groups but has no effect on the ordering of the protonated form (Fig 7b). In the absence of $\mathrm{Ca}^{2+}$, the addition of alginate similarly increases ordering of the palmitate carboxylate headgroups but decreases ordering of the acid (Fig 7e). 
To understand the differences in ordering based on headgroup protonation, we plotted the variations in headgroup position within the monolayer. Recalling that the palmitate headgroup tends to sink further into the aqueous phase in comparison to the palmitic acid, in Figs. $7 \mathrm{c}$ and $7 \mathrm{f}$ we provide distributions of the height differences between carboxylate and carboxylic acid headgroups. The carboxylates are drawn into the aqueous phase, where they experience stabilizing ion-pairing with the cations, but the magnitude of the separation varies based on cation type. In the presence of $\mathrm{Ca}^{2+}$, the headgroup separation decreases by nearly $1 \AA$ to $2.8 \AA$, down from $3.8 \AA$ without $\mathrm{Ca}^{2+}$. The smaller difference in headgroup positions can be attributed to calcium-induced monolayer compression; $\mathrm{Ca}^{2+}$ binds neighboring carboxylate headgroups, thereby effectively shielding repulsive negative charges and bringing the headgroups closer together. Monovalent sodium does not participate in the ionic bridging and does less to screen the charges. Furthermore, whether alginate impacts the headgroup separation depends on the dominant adsorption or interaction mechanism. Because alginate adsorbs to the monolayer via calcium ion bridging, adsorption does not impact headgroup separation. However, without $\mathrm{Ca}^{2+}$ present, it is possible that the alginate $\mathrm{COO}^{-}$slightly destabilizes the palmitate headgroups through repulsive interactions that are less mediated by $\mathrm{Na}^{+}$, expanding the monolayer and allowing more space for the headgroups to align. Indeed, monolayer expansion is observed experimentally with increased MMA upon alginate adsorption (Table S1).

The differences in headgroup position between the protonated and deprotonated forms can explain the trends associated with the overall increase in ordering at the $\mathrm{C} 2$ carbon that are not seen in low $\mathrm{pH}$ systems. With the carboxylic acid headgroup more embedded into the monolayer, the rotational motion of that headgroup is significantly restricted, thus increasing the order parameter. Conversely, the carboxylate headgroups exposed to the aqueous phase experience a 
wider range of motion, and their order parameter decreases. In the case of alginate binding in the presence of $\mathrm{Ca}^{2+}$, alginate has no impact on the carboxylic acids that are more deeply situated in the monolayer, but increases order associated with the carboxylates via the formation of calcium ion bridges that increase monolayer rigidity and decrease headgroup motion. In the case of alginate interacting with the monolayer without calcium bridges, we see a similar increase in order associated with the carboxylates and a decrease in order associated with the carboxylic acids. The mechanism for this behavior, although similar to that in calcium, is more likely explained by the decrease in headgroup separation associated with alginate interaction; the exposure of palmitic acid headgroups to the aqueous phase decreases order of the protonated form while at the same time increasing order of the carboxylate.

\section{Investigation of magnesium bridging}

With complementary insights gained into the divalent cationic bridging mechanism from both theory and experiment, the same alginate co-adsorption experiments were performed with $\mathrm{MgCl}_{2}$, the most abundant divalent cation in seawater $(\sim 53 \mathrm{mM}){ }^{88,89} \mathrm{Mg}^{2+}$ has such a strong hydration shell that the fully hydrated $\mathrm{Mg}^{2+}$ only weakly interacts with the alginate and palmitic acid carboxylate moieties. ${ }^{45-48,101,108}$ Both $10 \mathrm{mM}$ and $53 \mathrm{mM} \mathrm{MgCl}_{2}$ solutions increase IRRAS reflectance-absorbance for the alginate-containing spectra at $\sim 3580 \mathrm{~cm}^{-1}$, and the magnitude of the signal increase is similar (Figs. 8a and 8c). Calculation of the relative change reveals that the higher $\mathrm{MgCl}_{2}$ concentration causes a marginal increase in alginate co-adsorbed to the $\mathrm{d}_{31}$-palmitic acid monolayer (Figs. $8 \mathrm{~b}$ and $8 \mathrm{~d}$ ). With increasing $\mathrm{MgCl}_{2}$ concentration, the relative change in integrated peak area increases from $8 \%$ to $10 \%$ and from $3 \%$ to $9 \%$ in the TC and UC phases, respectively. The reduction in $\mathrm{OH}$ region relative change with film compression (TC to UC phase) 
further suggests weak binding. $\mathrm{Mg}^{2+}$ is not as efficient in shielding the palmitic acid carboxylate moieties from negatively charged alginate carboxylate moieties, yielding monolayer expansion and increased surface coverage in the TC phase. Film compression to the UC phase reduces the extent of available space for monolayer expansion, and increased dispersion forces between the lipid tails counterbalance the repulsive electrostatic interactions. Despite $\mathrm{Mg}^{2+}$ being $\sim 5$ times more abundant than $\mathrm{Ca}^{2+}$ in seawater, alginate co-adsorption mediated by $\mathrm{Mg}^{2+}$ is $\sim 3$ times weaker in comparison to $\mathrm{Ca}^{2+}$ when comparing seawater relative concentrations of $10 \mathrm{mM} \mathrm{Ca}^{2+}$ and $53 \mathrm{mM} \mathrm{Mg}^{2+}$. At $10 \mathrm{mM}$ concentrations for both cations, $\mathrm{Ca}^{2+}$ outperforms $\mathrm{Mg}^{2+}$ by a factor of $\sim 3$ in the TC phase and by a factor of $\sim 10$ in the UC phase (Figs. 1 and 8 ).
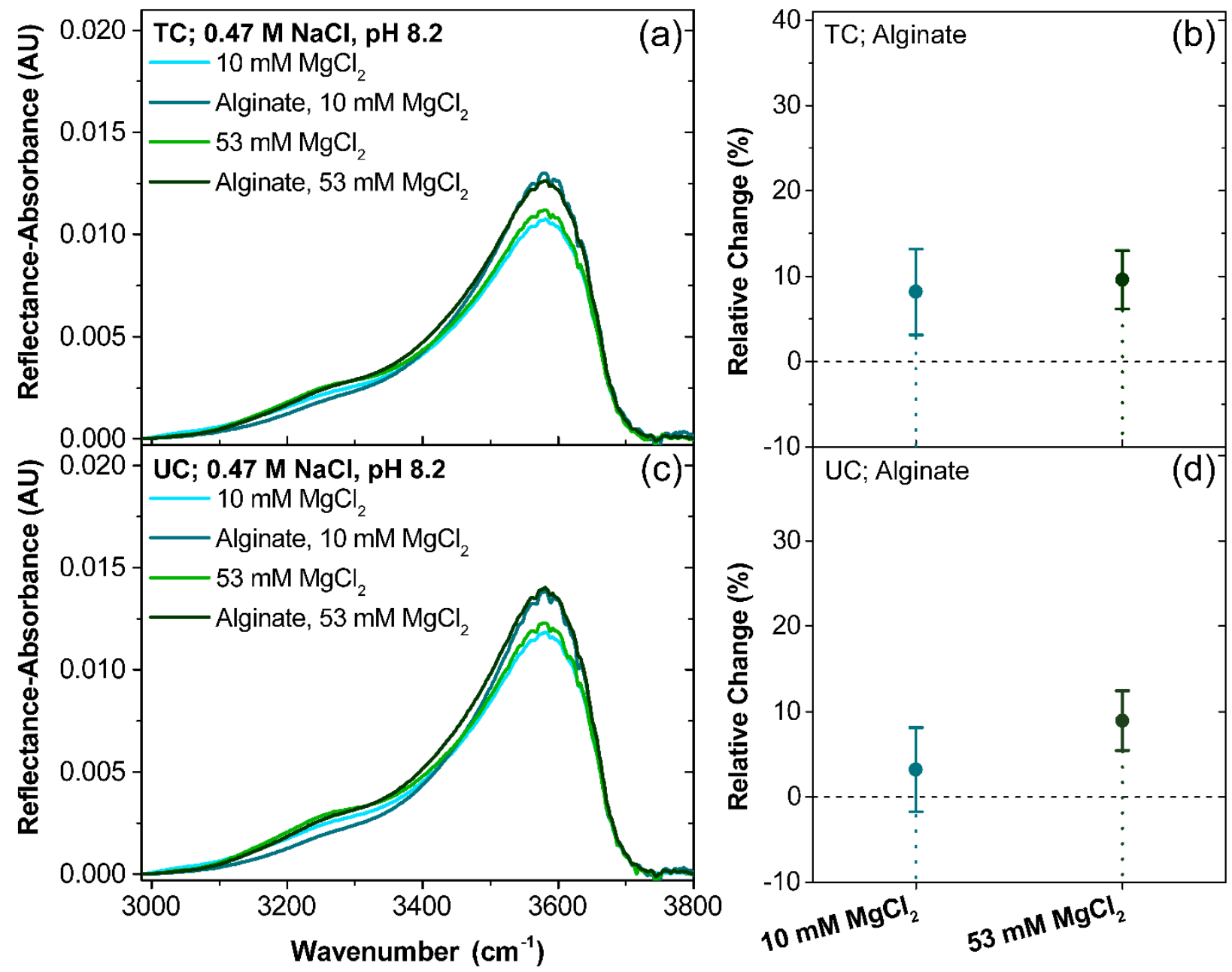
Fig. 8. IRRAS spectra of the $\mathrm{OH}$ stretching region and the corresponding relative changes in integrated peak area indicate that $\mathrm{Mg}^{2+}$ induces weak alginate co-adsorption to the $\mathrm{d}_{31}$-palmitic acid monolayer. Data points and error bars are color-coded to indicate differences in solution composition. Surface pressure was held constant in the (a) tilted condensed $(5 \mathrm{mN} / \mathrm{m})$ and (c) untilted condensed $(25 \mathrm{mN} / \mathrm{m})$ phases throughout spectral acquisition. The relative changes in integrated peak area between the solutions with and without alginate are quantified in the (b) tilted condensed and (d) untilted condensed phases. Positive relative change indicates alginate coadsorption to the monolayer, and $0 \%$ relative change indicates no co-adsorption.

The carboxylate region provides additional support for this weak $\mathrm{Mg}^{2+}$ bridging coadsorption mechanism (Fig. S16). For $\mathrm{d}_{31}$-palmitic acid spread onto the solution containing $10 \mathrm{mM}$ $\mathrm{MgCl}_{2}$, the $v_{\mathrm{S}} \mathrm{COO}^{-}$mode is blue-shifted by $1 \mathrm{~cm}^{-1}$ in the TC phase and $\sim 2.5 \mathrm{~cm}^{-1}$ in the UC phase, and the $v_{\mathrm{AS}} \mathrm{COO}^{-}$mode is red-shifted by $1 \mathrm{~cm}^{-1}$ in the TC phase and $\sim 3 \mathrm{~cm}^{-1}$ in the UC phase (Tables S8 and S9). These small spectral shifts suggest that the $\mathrm{d}_{31}$-palmitate carboxylate headgroup becomes dehydrated with the addition of alginate to the solution, ${ }^{95}$ perhaps via complexation of $\mathrm{Mg}^{2+}$ to the $\mathrm{d}_{31}$-palmitate carboxylate moiety. The integrated carboxylate peak areas do not change significantly between the salt water solution and alginate solution (Tables S12 and S13), suggesting no alginate co-adsorption.

Increasing the solution $\mathrm{MgCl}_{2}$ concentration to $53 \mathrm{mM}$ leads to some features of alginate co-adsorption to the monolayer (Fig. S16). The $\mathrm{d}_{31}$-palmitic acid $v_{\mathrm{AS}} \mathrm{COO}^{-}, v_{\mathrm{S}} \mathrm{COO}^{-}$, and $v \mathrm{C}$ $\mathrm{OH}$ modes blue shift upon alginate addition to the solution (Tables S14 and S15), similarly to the spectra corresponding to the solutions containing $10 \mathrm{mM} \mathrm{CaCl}_{2}$. The $v_{\mathrm{AS}} \mathrm{COO}^{-}$blue shifts $\sim 0.5 \mathrm{~cm}^{-1}$ in the TC phase and $\sim 3 \mathrm{~cm}^{-1}$ in the UC phase, the $v_{\mathrm{S}} \mathrm{COO}^{-}$blue shifts $\sim 4 \mathrm{~cm}^{-1}$ in the TC phase and $\sim 5 \mathrm{~cm}^{-1}$ in the UC phase, and the $v \mathrm{C}-\mathrm{OH}$ blue shifts $\sim 9 \mathrm{~cm}^{-1}$ in the TC phase and $\sim 12 \mathrm{~cm}^{-1}$ in the UC phase. The blue shifts are smaller than those observed with the $10 \mathrm{mM} \mathrm{CaCl}_{2}$ solution at $\mathrm{pH} 8.2$, either an indication of fewer $\mathrm{Mg}^{2+}$ bridging interactions or weaker bridging interactions. Secondly, the $v \mathrm{C}-\mathrm{OH}$ peak area decreases while the $v_{\mathrm{AS}} \mathrm{COO}^{-}$and $v_{\mathrm{S}} \mathrm{COO}^{-}$peak 
areas increase with alginate present in the solution, further supporting the hypothesis of alginate co-adsorption.

The $\mathrm{CD}_{2}$ scissoring modes of $\mathrm{d}_{31}$-palmitic acid spread onto the $\mathrm{MgCl}_{2}$ solutions corroborate the findings from the $\mathrm{OH}$ stretching and $\mathrm{COOH}$ stretching regions. At $10 \mathrm{mM} \mathrm{MgCl}_{2}$, the salt water and alginate spectra nearly overlap (Figs. S17a and S17c). There is a small increase in peak intensity of the TC spectrum corresponding to the alginate solution that could be attributed to alginate weakly co-adsorbed to the TC monolayer. Then the alginate is squeezed out upon film compression, causing the peak intensity difference to disappear in the UC phase. The solution containing $53 \mathrm{mM} \mathrm{MgCl}$ and alginate induces increased peak intensities in the $\mathrm{d}_{31}$-palmitic acid $\mathrm{CD}_{2}$ scissoring mode and the higher frequency regime relative to the spectra corresponding to the salt water solution (Figs. S17b and S17d). The signal enhancement is smaller in comparison to the system containing $10 \mathrm{mM} \mathrm{CaCl}_{2}$ and alginate at $\mathrm{pH} 8.2$, but the spectral trends match. Hence, the higher concentration of $\mathrm{MgCl}_{2}$ facilitates some alginate co-adsorption to the monolayer through $\mathrm{Mg}^{2+}$ bridging interactions.

\section{Conclusions}

We directly observe alginate co-adsorption to an insoluble $\mathrm{d}_{31}$-palmitic acid monolayer via divalent cationic bridging interactions using surface-sensitive infrared reflection-absorption spectroscopy (IRRAS) and molecular dynamics simulations. $\mathrm{Ca}^{2+}$ facilitates the greatest extent of alginate co-adsorption, as shown by the appearance of alginate vibrational modes in the IRRAS spectra and by the $\sim 27 \%$ and $\sim 32 \%$ increase in surface coverage in the TC and UC phases, respectively. Alginate co-adsorption is dependent upon $\mathrm{d}_{31}$-palmitic acid protonation state, however; $\mathrm{d}_{31}$-palmitate promotes alginate co-adsorption in the presence of divalent cations, 
whereas protonation inhibits co-adsorption. $\mathrm{Na}^{+}$cations alone are insufficient in facilitating coadsorption. $\mathrm{Mg}^{2+}$ induces $\sim 3$ times weaker alginate co-adsorption at a seawater concentration of $53 \mathrm{mM}$ in comparison to $10 \mathrm{mM} \mathrm{Ca}^{2+}$, and $\mathrm{Mg}^{2+}$ induces minimal co-adsorption when matching the $\mathrm{Ca}^{2+}$ seawater concentration $(10 \mathrm{mM})$. The hydration free energy of $\mathrm{Mg}^{2+}$ is much higher than that of $\mathrm{Ca}^{2+}$, meaning that $\mathrm{Mg}^{2+}$ cannot shed its hydration shell as readily to facilitate bridging interactions between the $d_{31}$-palmitate and alginate carboxylate moieties. The presence of alginate perturbs the hydration structure and dehydrates the $\mathrm{d}_{31}$-palmitic acid carboxylic acid headgroups, but alginate co-adsorption does not change the $\mathrm{d}_{31}$-palmitic acid lattice packing structure. Alginate co-adsorption is largely confined to the subsurface region of the film. Consequently, surface pressure plays a minimal role in the extent of alginate co-adsorption.

Our detailed experimental and computational characterization of the divalent cationic bridging interactions driving alginate co-adsorption to a sea surface microlayer (SSML) proxy film provides important physical and chemical insights into the potential mechanisms responsible for polysaccharide enrichment in sea spray aerosol (SSA). $\mathrm{Ca}^{2+}$ drives this bridging motif between the alginate and palmitic acid carboxylate moieties and outcompetes $\mathrm{Mg}^{2+}$ despite higher $\mathrm{Mg}^{2+}$ concentrations in seawater. Quantification of organic surface coverage via the $\mathrm{OH}$ stretching region integrated peak areas also provides a potentially useful parameter for aerosol representation in climate models. We demonstrate that soluble polysaccharides can interact electrostatically with other surface-active organic matter through seawater ionic bridging interactions, leading to polysaccharide surface enrichment in the SSML, and therefore, in SSA. 


\section{Author contributions}

K.A.C.-F. designed the study, and H.C.A. and R.E.A. supervised the project and acquired funding. K.A.C.-F., M.E.F., and J.K. performed the experiments. A.C.D. performed the molecular dynamics simulations, and K.A.C.-F. performed the quantum chemistry calculations. K.A.C.-F. and A.C.D. analyzed the data and wrote the paper with input from all authors.

\section{Conflicts of interest}

The authors declare no conflicts of interest.

\section{Acknowledgements}

All authors acknowledge funding from the National Science Foundation Center for Aerosol Impacts on Chemistry of the Environment (NSF-CAICE) under Award No. CHE-1801971. Quantum chemistry calculations were performed at the Ohio Supercomputer Center under Project Number PAS1711. We thank Kevin Carter-Fenk for assistance with the vibrational frequency calculations. We also thank Nicholas Wauer for helpful discussions.

\section{References}

1 L. N. Hawkins and L. M. Russell, Adv. Meteorol., 2010, 2010, 1-14.

2 L. M. Russell, L. N. Hawkins, A. A. Frossard, P. K. Quinn and T. S. Bates, Proc. Natl. Acad. Sci. U.S.A., 2010, 107, 6652-6657.

3 J. Y. Aller, J. C. Radway, W. P. Kilthau, D. W. Bothe, T. W. Wilson, R. D. Vaillancourt, P. K. Quinn, D. J. Coffman, B. J. Murray and D. A. Knopf, Atmos. Environ., 2017, 154, 331-347.

4 S. Elliott, S. M. Burrows, C. Deal, X. Liu, M. Long, O. Ogunro, L. M. Russell and O. Wingenter, Environ. Res. Lett., 2014, 9, 064012.

5 Q. Gao, C. Leck, C. Rauschenberg and P. A. Matrai, Ocean Sci., 2012, 8, 401-418.

6 T. Jayarathne, C. M. Sultana, C. Lee, F. Malfatti, J. L. Cox, M. A. Pendergraft, K. A. Moore, F. Azam, A. V. Tivanski, C. D. Cappa, T. H. Bertram, V. H. Grassian, K. A. Prather and E. A. Stone, Environ. Sci. Technol., 2016, 50, 11511-11520.

7 D. C. O. Thornton, S. D. Brooks and J. Chen, Front. Mar. Sci., 2016, 3, 1-14.

8 E. S. Hasenecz, T. Jayarathne, M. A. Pendergraft, M. V. Santander, K. J. Mayer, J. Sauer, C. Lee, W. S. Gibson, S. M. Kruse, F. Malfatti, K. A. Prather and E. A. Stone, ACS Earth Space Chem., 2020, 4, 1638-1649.

9 E. Rastelli, C. Corinaldesi, A. Dell'Anno, M. Lo Martire, S. Greco, M. Cristina Facchini, M. Rinaldi, C. O’Dowd, D. Ceburnis and R. Danovaro, Sci. Rep., 2017, 7, 11475.

10S. M. Burrows, E. Gobrogge, L. Fu, K. Link, S. M. Elliott, H. Wang and R. Walker, Geophys. Res. Lett., 2016, 43, 8306-8313.

11 K. A. Link, C.-Y. Hsieh, A. Tuladhar, Z. Chase, Z. Wang, H. Wang and R. A. Walker, Chem. Phys., 2018, 512, 104-110.

12 S. R. Schill, S. M. Burrows, E. S. Hasenecz, E. A. Stone and T. H. Bertram, Atmosphere, 2018, 9, 476 . 
13 K. A. Link, G. N. Spurzem, A. Tuladhar, Z. Chase, Z. Wang, H. Wang and R. A. Walker, J. Phys. Chem. A, 2019, 123, 5621-5632.

14K. A. Link, G. N. Spurzem, A. Tuladhar, Z. Chase, Z. Wang, H. Wang and R. A. Walker, J. Phys. Chem. B, 2019, 123, 8931-8938.

15 S. M. Burrows, O. Ogunro, A. A. Frossard, L. M. Russell, P. J. Rasch and S. M. Elliott, Atmos. Chem. Phys., 2014, 14, 13601-13629.

16P. K. Quinn, D. B. Collins, V. H. Grassian, K. A. Prather and T. S. Bates, Chem. Rev., 2015, 115, 4383-4399.

17R. E. Cochran, O. Laskina, J. V. Trueblood, A. D. Estillore, H. S. Morris, T. Jayarathne, C. M. Sultana, C. Lee, P. Lin, J. Laskin, A. Laskin, J. A. Dowling, Z. Qin, C. D. Cappa, T. H. Bertram,

A. V. Tivanski, E. A. Stone, K. A. Prather and V. H. Grassian, Chem, 2017, 2, 655-667.

18 T. H. Bertram, R. E. Cochran, V. H. Grassian and E. A. Stone, Chem. Soc. Rev., 2018, 47, 23742400.

19C. Leck and E. K. Bigg, Tellus B, 2005, 57, 305-316.

20 M. V. Orellana, P. A. Matrai, C. Leck, C. D. Rauschenberg, A. M. Lee and E. Coz, Proc. Natl. Acad. Sci. U.S.A., 2011, 108, 13612-13617.

21 C. Leck, Q. Gao, F. Mashayekhy Rad and U. Nilsson, Atmos. Chem. Phys., 2013, 13, 1257312588.

22C. Leck and E. Svensson, Atmos. Chem. Phys., 2015, 15, 2545-2568.

23 B. G. Pummer, H. Bauer, J. Bernardi, S. Bleicher and H. Grothe, Atmos. Chem. Phys., 2012, 12, 2541-2550.

24 N. Hiranuma, O. Möhler, K. Yamashita, T. Tajiri, A. Saito, A. Kiselev, N. Hoffmann, C. Hoose,

E. Jantsch, T. Koop and M. Murakami, Nat. Geosci., 2015, 8, 273-277.

25 B. G. Pummer, C. Budke, S. Augustin-Bauditz, D. Niedermeier, L. Felgitsch, C. J. Kampf, R.

G. Huber, K. R. Liedl, T. Loerting, T. Moschen, M. Schauperl, M. Tollinger, C. E. Morris, H.

Wex, H. Grothe, U. Pöschl, T. Koop and J. Fröhlich-Nowoisky, Atmos. Chem. Phys., 2015, 15, 4077-4091.

26T. W. Wilson, L. A. Ladino, P. A. Alpert, M. N. Breckels, I. M. Brooks, J. Browse, S. M.

Burrows, K. S. Carslaw, J. A. Huffman, C. Judd, W. P. Kilthau, R. H. Mason, G. McFiggans,

L. A. Miller, J. J. Nájera, E. Polishchuk, S. Rae, C. L. Schiller, M. Si, J. V. Temprado, T. F.

Whale, J. P. S. Wong, O. Wurl, J. D. Yakobi-Hancock, J. P. D. Abbatt, J. Y. Aller, A. K.

Bertram, D. A. Knopf and B. J. Murray, Nature, 2015, 525, 234-238.

27 K. Dreischmeier, C. Budke, L. Wiehemeier, T. Kottke and T. Koop, Sci. Rep., 2017, 7, 41890.

28 N. Hiranuma, K. Adachi, D. M. Bell, F. Belosi, H. Beydoun, B. Bhaduri, H. Bingemer, C.

Budke, H.-C. Clemen, F. Conen, K. M. Cory, J. Curtius, P. J. DeMott, O. Eppers, S. Grawe, S.

Hartmann, N. Hoffmann, K. Höhler, E. Jantsch, A. Kiselev, T. Koop, G. Kulkarni, A. Mayer, M. Murakami, B. J. Murray, A. Nicosia, M. D. Petters, M. Piazza, M. Polen, N. Reicher, Y. Rudich, A. Saito, G. Santachiara, T. Schiebel, G. P. Schill, J. Schneider, L. Segev, E. Stopelli, R. C. Sullivan, K. Suski, M. Szakáll, T. Tajiri, H. Taylor, Y. Tobo, R. Ullrich, D. Weber, H. Wex, T. F. Whale, C. L. Whiteside, K. Yamashita, A. Zelenyuk and O. Möhler, Atmos. Chem. Phys., 2019, 19, 4823-4849.

29 M. J. Wolf, A. Coe, L. A. Dove, M. A. Zawadowicz, K. Dooley, S. J. Biller, Y. Zhang, S. W. Chisholm and D. J. Cziczo, Environ. Sci. Technol., 2019, 53, 1139-1149.

30S. Zeppenfeld, M. van Pinxteren, M. Hartmann, A. Bracher, F. Stratmann and H. Herrmann, Environ. Sci. Technol., 2019, 53, 8747-8756. 
31E. S. Hasenecz, C. P. Kaluarachchi, H. D. Lee, A. V. Tivanski and E. A. Stone, ACS Earth Space Chem., 2019, 3, 2539-2548.

32P. a. J. Gorin and J. F. T. Spencer, Can. J. Chem., 1966, 44, 993-998.

33 A. Linker and R. S. Jones, J. Biol. Chem., 1966, 241, 3845-3851.

34 A. Haug, B. Larsen, O. Fykse, A. Block-Bolten, J. M. Toguri and H. Flood, Acta Chem. Scand., 1962, 16, 1908-1918.

35 A. Haug, B. Larsen, O. Smidsrød, O. Smidsrød, G. Eriksson, R. Blinc, S. Paušak, L. Ehrenberg and J. Dumanović, Acta Chem. Scand., 1967, 21, 691-704.

36 A. Haug, S. Myklestad, B. Larsen, O. Smidsrød, G. Eriksson, R. Blinc, S. Paušak, L. Ehrenberg and J. Dumanović, Acta Chem. Scand., 1967, 21, 768-778.

37 H. Grasdalen, B. Larsen and O. Smidsrød, Carbohyd. Res., 1979, 68, 23-31.

38F. A. Johnson, D. Q. M. Craig and A. D. Mercer, J. Pharm. Pharmacol., 1997, 49, 639-643.

39 K. Y. Lee and D. J. Mooney, Prog. Polym. Sci., 2012, 37, 106-126.

40E. R. Morris, D. A. Rees, D. Thom and J. Boyd, Carbohyd. Res., 1978, 66, 145-154.

41 Y. Fang, S. Al-Assaf, G. O. Phillips, K. Nishinari, T. Funami, P. A. Williams and L. Li, J. Phys. Chem. B, 2007, 111, 2456-2462.

42 H. Hecht and S. Srebnik, Biomacromolecules, 2016, 17, 2160-2167.

43 R. Kohn, Pure Appl. Chem., 1975, 42, 371-397.

44 A. Malovíková, M. Rinaudo and M. Milas, Biopolymers, 1994, 34, 1059-1064.

45 I. Donati, A. Cesàro and S. Paoletti, Biomacromolecules, 2006, 7, 281-287.

46I. Donati, F. Asaro and S. Paoletti, J. Phys. Chem. B, 2009, 113, 12877-12886.

47F. Topuz, A. Henke, W. Richtering and J. Groll, Soft Matter, 2012, 8, 4877.

48 U. T. D. Huynh, A. Lerbret, F. Neiers, O. Chambin and A. Assifaoui, J. Phys. Chem. B, 2016, 120, 1021-1032.

49 W.-C. Chin, M. V. Orellana and P. Verdugo, Nature, 1998, 391, 568-572.

50P. Verdugo, A. L. Alldredge, F. Azam, D. L. Kirchman, U. Passow and P. H. Santschi, Mar. Chem., 2004, 92, 67-85.

51 P. Verdugo, M. V. Orellana, W.-C. Chin, T. W. Petersen, G. van den Eng, R. Benner and J.

I. Hedges, Faraday Discuss., 2008, 139, 393-398.

52P. Verdugo, Annu. Rev. Mar. Sci., 2012, 4, 375-400.

53 X. Li, C. Leck, L. Sun, T. Hede, Y. Tu and H. Ågren, J. Phys. Chem. Lett., 2013, 4, 2637-2642.

54L. Sun, X. Li, T. Hede, Y. Tu, C. Leck and H. Ågren, Phys. Chem. Chem. Phys., 2014, 16, 25935-25941.

55 R. E. Cochran, O. Laskina, T. Jayarathne, A. Laskin, J. Laskin, P. Lin, C. Sultana, C. Lee, K.

A. Moore, C. D. Cappa, T. H. Bertram, K. A. Prather, V. H. Grassian and E. A. Stone, Environ.

Sci. Technol., 2016, 50, 2477-2486.

56F. M. Rad, C. Leck, L. L. Ilag and U. Nilsson, Rapid Commun. Mass Sp., 2018, 32, 942-950.

57 H. Tervahattu, J. Juhanoja and K. Kupiainen, J. Geophys. Res., 2002, 107, ACH 18-1.

58 M. Mochida, Y. Kitamori, K. Kawamura, Y. Nojiri and K. Suzuki, J. Geophys. Res., 2002, 107, 4325.

59E. M. Adams and H. C. Allen, Atmosphere, 2013, 4, 315-336.

60E. M. Adams, B. A. Wellen, R. Thiraux, S. K. Reddy, A. S. Vidalis, F. Paesani and H. C. Allen, Phys. Chem. Chem. Phys., 2017, 19, 10481-10490.

61 B. A. W. Rudd, A. S. Vidalis and H. C. Allen, Phys. Chem. Chem. Phys., 2018, 20, 1632016332. 
62 M. Shrestha, M. Luo, Y. Li, B. Xiang, W. Xiong and V. H. Grassian, Chem. Sci., 2018, 9, 57165723.

63P. Degen, M. Paulus, E. Zwar, V. Jakobi, S. Dogan, M. Tolan and H. Rehage, Surf. Interface Anal., 2019, 51, 1051-1058.

64F. J. Pavinatto, A. Pavinatto, L. Caseli, dos Santos David S., T. M. Nobre, M. E. D. Zaniquelli and O. N. Oliveira, Biomacromolecules, 2007, 8, 1633-1640.

65 P. Wydro, B. Krajewska and K. Hạc-Wydro, Biomacromolecules, 2007, 8, 2611-2617.

66B. Krajewska, P. Wydro and A. Jańczyk, Biomacromolecules, 2011, 12, 4144-4152.

67 B. Krajewska, P. Wydro and A. Kyzioł, Colloid Surface A, 2013, 434, 349-358.

68 A. Pavinatto, A. L. Souza, J. A. M. Delezuk, F. J. Pavinatto, S. P. Campana-Filho and O. N. Oliveira, Colloid Surface B, 2014, 114, 53-59.

69 A. Pavinatto, J. A. M. Delezuk, A. L. Souza, F. J. Pavinatto, D. Volpati, P. B. Miranda, S. P. Campana-Filho and O. N. Oliveira Jr., Colloid Surface B, 2016, 145, 201-207.

70H. Parra-Barraza, M. G. Burboa, M. Sánchez-Vázquez, J. Juárez, F. M. Goycoolea and M. A. Valdez, Biomacromolecules, 2005, 6, 2416-2426.

71 K. de Meijere, G. Brezesinski, O. Zschörnig, K. Arnold and H. Möhwald, Physica B, 1998, 248, 269-273.

72D. Huster and K. Arnold, Biophys. J., 1998, 75, 909-916.

73D. Huster, G. Paasche, U. Dietrich, O. Zschörnig, T. Gutberlet, K. Gawrisch and K. Arnold, Biophys. J., 1999, 77, 879-887.

74 W. Hua, D. Verreault, E. M. Adams, Z. Huang and H. C. Allen, J. Phys. Chem. C, 2013, 117, 19577-19585.

75 W. Humphrey, A. Dalke and K. Schulten, J. Mol. Graphics, 1996, 14, 33-38.

76L. Martínez, R. Andrade, E. G. Birgin and J. M. Martínez, J. Comput. Chem., 2009, 30, 21572164.

77 S. Jo, T. Kim, V. G. Iyer and W. Im, J. Comput. Chem., 2008, 29, 1859-1865.

78 S. Jo, K. C. Song, H. Desaire, A. D. MacKerell and W. Im, J. Comput. Chem., 2011, 32, 31353141.

79S.-J. Park, J. Lee, D. S. Patel, H. Ma, H. S. Lee, S. Jo and W. Im, Bioinformatics, 2017, 33, 3051-3057.

80 S.-J. Park, J. Lee, Y. Qi, N. R. Kern, H. S. Lee, S. Jo, I. Joung, K. Joo, J. Lee and W. Im, Glycobiology, 2019, 29, 320-331.

81 W. L. Jorgensen, J. Chandrasekhar, J. D. Madura, R. W. Impey and M. L. Klein, J. Chem. Phys., 1983, 79, 926-935.

82 J. Huang and A. D. MacKerell, J. Comput. Chem., 2013, 34, 2135-2145.

83 R. L. Davidchack, R. Handel and M. V. Tretyakov, J. Chem. Phys., 2009, 130, 234101.

84 T. Darden, D. York and L. Pedersen, J. Chem. Phys., 1993, 98, 10089-10092.

85 F. Perez and B. E. Granger, Comput. Sci. Eng., 2007, 9, 21-29.

86D. R. Roe and T. E. Cheatham, J. Chem. Theory Comput., 2013, 9, 3084-3095.

87H. J. C. Berendsen, D. van der Spoel and R. van Drunen, Comput. Phys. Commun., 1995, 91, 43-56.

88F. J. Millero, R. Feistel, D. G. Wright and T. J. McDougall, Deep-Sea Res. Pt. I, 2008, 55, 5072.

89F. J. Millero, Chemical oceanography, Taylor \& Francis, Boca Raton, 4th ed., 2013.

90P. B. Miranda, Q. Du and Y. R. Shen, Chem. Phys. Lett., 1998, 286, 1-8.

91 J. R. Kanicky and D. O. Shah, J. Colloid Interf. Sci., 2002, 256, 201-207. 
92D. S. McLean, D. Vercoe, K. R. Stack and D. Richardson, Appita J., 2005, 58, 362.

93 H. Bu, A.-L. Kjøniksen, A. Elgsaeter and B. Nyström, Colloid Surface A, 2006, 278, 166-174.

94G. M. Marion, F. J. Millero, M. F. Camões, P. Spitzer, R. Feistel and C.-T. A. Chen, Mar. Chem., 2011, 126, 89-96.

95 J. K. Denton, P. J. Kelleher, M. A. Johnson, M. D. Baer, S. M. Kathmann, C. J. Mundy, B. A. W. Rudd, H. C. Allen, T. H. Choi and K. D. Jordan, Proc. Natl. Acad. Sci. U.S.A., 2019, 116, 14874-14880.

96 M. Luo, N. A. Wauer, K. J. Angle, A. C. Dommer, M. Song, C. M. Nowak, R. E. Amaro and V. H. Grassian, Chem. Sci., 2020, 11, 10647-10656.

97 T. M. Aida, T. Yamagata, M. Watanabe and R. L. Smith, Carbohyd. Polym., 2010, 80, 296302.

98 J. Lu, H. Yang, J. Hao, C. Wu, L. Liu, N. Xu, R. J. Linhardt and Z. Zhang, Carbohyd. Polym., 2015, 122, 180-188.

99 K. A. Carter-Fenk and H. C. Allen, Atmosphere, 2018, 9, 503.

100 H.-J. Butt, K. Graf and M. Kappl, Physics and chemistry of interfaces, Wiley-VCH Verlag GmbH \& Co. KGaA, Weinheim, Germany, Third, Revised and Enlarged Edition., 2013.

101 C. Y. Tang, Z. Huang and H. C. Allen, J. Phys. Chem. B, 2011, 115, 34-40.

102 P. Balzerowski, K. Meister, J. Versluis and H. J. Bakker, Phys. Chem. Chem. Phys., 2016, 18, 2481-2487.

103 N. Tanaka, H. Kitano and N. Ise, Macromolecules, 1991, 24, 3017-3019.

104 D. E. Gragson and G. L. Richmond, J. Phys. Chem. B, 1998, 102, 3847-3861.

105 H. C. Allen, N. N. Casillas-Ituarte, M. R. Sierra-Hernández, X. Chen and C. Y. Tang, Phys.

Chem. Chem. Phys., 2009, 11, 5538-5549.

106 E. Le Calvez, D. Blaudez, T. Buffeteau and B. Desbat, Langmuir, 2001, 17, 670-674.

107 S. Kundu and D. Langevin, Colloid Surface A, 2008, 325, 81-85.

108 C. Y. Tang, Z. Huang and H. C. Allen, J. Phys. Chem. B, 2010, 114, 17068-17076.

109 J. F. Neal, W. Zhao, A. J. Grooms, A. H. Flood and H. C. Allen, J. Phys. Chem. C, 2018, 122, 26362-26371.

110 R. Mendelsohn, J. W. Brauner and A. Gericke, Annu. Rev. Phys. Chem., 1995, 46, 305334.

111 W. Lin, A. J. Clark and F. Paesani, Langmuir, 2015, 31, 2147-2156.

112 G. T. Grant, E. R. Morris, D. A. Rees, P. J. C. Smith and D. Thom, FEBS Lett., 1973, 32, 195-198.

113 B. T. Stokke, O. Smidsroed, P. Bruheim and G. Skjaak-Braek, Macromolecules, 1991, 24, 4637-4645.

114 B. T. Stokke, K. I. Draget, O. Smidsrød, Y. Yuguchi, H. Urakawa and K. Kajiwara, Macromolecules, 2000, 33, 1853-1863.

115 L. Li, Y. Fang, R. Vreeker, I. Appelqvist and E. Mendes, Biomacromolecules, 2007, 8, 464-468. 


\section{Electronic Supplementary Information for}

Calcium bridging drives polysaccharide co-adsorption to a proxy sea surface microlayer Kimberly A. Carter-Fenk, ${ }^{a}$ Abigail C. Dommer, ${ }^{b}$ Michelle E. Fiamingo, ${ }^{a}$ Jeongin J. Kim, ${ }^{a}$ Rommie E. Amaro, ${ }^{b}$ and Heather C. Allen ${ }^{a *}$

a. Department of Chemistry and Biochemistry, The Ohio State University, Columbus, OH 43210, USA

b. Department of Chemistry and Biochemistry, University of California, San Diego, La Jolla, CA 92093, USA

\section{Corresponding Author}

* Heather C. Allen (allen@chemistry.ohio-state.edu)

Table of Contents

1. Molecular dynamics system set-up

2. Mean molecular area data

3. D-guluronate and d31-palmitic acid vibrational frequency calculations

4. Carboxylate region spectral fitting

5. d33-Cetyl alcohol IRRAS spectral analysis

6. $\mathrm{CD}_{2}$ scissoring mode analysis

7. Radial distribution and number density profiles

8. Local order parameters

9. IRRAS spectra of alginate co-adsorption via magnesium bridging

10. References 


\section{Molecular dynamics system set-up}

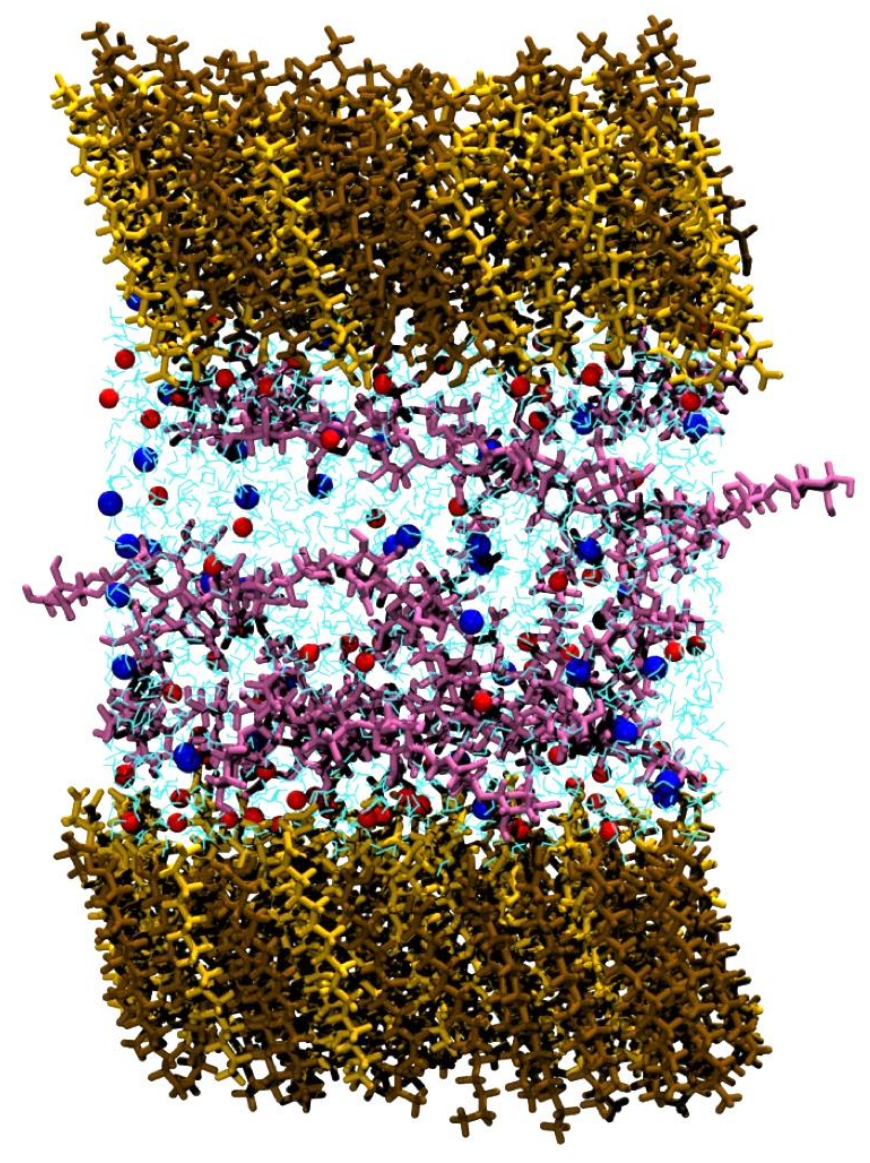

Fig. S1. Example of a molecular dynamics monolayer system set up to include alginate. Pictured: palmitic acid (brown, licorice representation), palmitate (yellow, licorice), water (cyan, lines) alginate (mauve, licorice), calcium (red, Van der Waals) and sodium (blue, Van der Waals). Above and below the monolayers is a vacuum region where no molecules were placed to approximate atmospheric air pressure.

\section{Mean molecular area data}

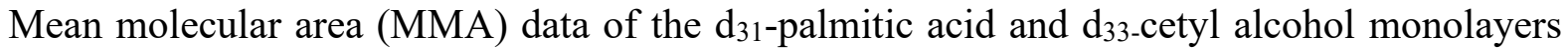
measured at constant surface pressure are tabulated below. Alginate consistently expands the monolayer relative to the salt water subphase, and the magnitude of monolayer expansion is greater at $5 \mathrm{mN} / \mathrm{m}$ than at $25 \mathrm{mN} / \mathrm{m}$. Enhanced dispersion interactions between the lipid alkyl chains and increased exchange interactions likely push alginate out of the plane of the compressed monolayer. 
Table S1. Average mean molecular area values $\left(\AA^{2} /\right.$ molecule $)$ and one standard deviation from the mean $\left(\sigma, \AA^{2} /\right.$ molecule $)$ of $\mathrm{d}_{31}$-palmitic acid $\left(\mathrm{d}_{31}\right.$-PA) and $\mathrm{d}_{33}$-cetyl alcohol $\left(\mathrm{d}_{33}-\mathrm{CA}\right)$ monolayers measured at constant surface pressures $5 \mathrm{mN} / \mathrm{m}$ and $25 \mathrm{mN} / \mathrm{m}$.

\begin{tabular}{|c|c|c|c|c|}
\hline \multirow{2}{*}{ Monolayer \& Subphase } & \multicolumn{2}{|c|}{$5 \mathrm{mN} / \mathrm{m}$} & \multicolumn{2}{|c|}{$25 \mathrm{mN} / \mathrm{m}$} \\
\hline & MMA & $\boldsymbol{\sigma}$ & MMA & $\boldsymbol{\sigma}$ \\
\hline (d $\mathrm{d}_{31}$-PA, $0.47 \mathrm{M} \mathrm{NaCl}, \mathrm{pH} 8.2$ & 22.66 & 0.29 & 20.57 & 0.33 \\
\hline $\mathrm{d}_{31}-\mathrm{PA}, 50 \mathrm{ppm}$ Alginate, $0.47 \mathrm{M} \mathrm{NaCl}, \mathrm{pH} 8.2$ & 25.48 & 0.44 & 21.50 & 0.44 \\
\hline $\mathrm{d}_{31}-\mathrm{PA}, 0.47 \mathrm{M} \mathrm{NaCl}, 10 \mathrm{mM} \mathrm{CaCl} 2, \mathrm{pH} 8.2$ & 22.36 & 0.16 & 20.92 & 0.11 \\
\hline $\mathrm{d}_{31}-\mathrm{PA}, 50 \mathrm{ppm}$ Alginate, $0.47 \mathrm{M} \mathrm{NaCl}, 10 \mathrm{mM} \mathrm{CaCl} 2, \mathrm{pH} 8.2$ & 23.27 & 0.65 & 21.56 & 0.32 \\
\hline $\mathrm{d}_{31}-\mathrm{PA}, 0.47 \mathrm{M} \mathrm{NaCl}, 10 \mathrm{mM} \mathrm{CaCl}_{2}, \mathrm{pH} 5.8$ & 25.21 & 0.24 & 22.67 & 0.20 \\
\hline $\mathrm{d}_{31}$-PA, 50 ppm Alginate, $0.47 \mathrm{M} \mathrm{NaCl}, 10 \mathrm{mM} \mathrm{CaCl}$, pH 5.8 & 27.29 & 0.48 & 22.99 & 0.92 \\
\hline $\mathrm{d}_{33}-\mathrm{CA}, 0.47 \mathrm{M} \mathrm{NaCl}, 10 \mathrm{mM} \mathrm{CaCl}_{2}, \mathrm{pH} 8.2$ & 20.62 & 0.15 & 17.85 & 0.09 \\
\hline $\mathrm{d}_{33}-\mathrm{CA}, 50 \mathrm{ppm}$ Alginate, $0.47 \mathrm{M} \mathrm{NaCl}, 10 \mathrm{mM} \mathrm{CaCl}_{2}, \mathrm{pH} 8.2$ & 21.91 & 0.08 & 18.72 & 0.05 \\
\hline $\mathrm{d}_{31}-\mathrm{PA}, 0.47 \mathrm{M} \mathrm{NaCl}, 10 \mathrm{mM} \mathrm{MgCl} 2, \mathrm{pH} 8.2$ & 24.27 & 0.04 & 21.40 & 0.14 \\
\hline $\mathrm{d}_{31}$-PA, $50 \mathrm{ppm}$ Alginate, $0.47 \mathrm{M} \mathrm{NaCl}, 10 \mathrm{mM} \mathrm{MgCl} 2, \mathrm{pH} 8.2$ & 26.51 & 0.13 & 22.08 & 0.17 \\
\hline $\mathrm{d}_{31}-\mathrm{PA}, 0.47 \mathrm{M} \mathrm{NaCl}, 53 \mathrm{mM} \mathrm{MgCl} 2, \mathrm{pH} 8.2$ & 24.17 & 0.10 & 21.80 & 0.09 \\
\hline $\mathrm{d}_{31}-\mathrm{PA}, 50$ ppm Alginate, $0.47 \mathrm{M} \mathrm{NaCl}, 53 \mathrm{mM} \mathrm{MgCl} 2, \mathrm{pH} 8.2$ & 27.06 & 0.43 & 22.86 & 0.27 \\
\hline
\end{tabular}

Table S2. The ratio of $\mathrm{d}_{31}$-palmitic acid $\left(\mathrm{d}_{31}-\mathrm{PA}\right)$ and $\mathrm{d}_{33}$-cetyl alcohol $\left(\mathrm{d}_{33}-\mathrm{CA}\right)$ MMA values $(\mathrm{Alg} / \mathrm{SW})$ and propagated error corresponding to the $50 \mathrm{ppm}$ alginate subphase MMA divided by the seawater subphase MMA.

\begin{tabular}{|c|c|c|c|c|}
\hline \multirow{2}{*}{ Monolayer \& Subphase } & \multicolumn{2}{|c|}{$5 \mathbf{~ m N} / \mathbf{m}$} & \multicolumn{2}{c|}{$\mathbf{2 5} \mathbf{~ m N} / \mathbf{m}$} \\
\cline { 2 - 5 } & Alg/SW & Error & Alg/SW & Error \\
\hline \hline $\mathrm{d}_{31}$-PA, 0.47 M NaCl, pH 8.2 & 1.124 & 0.022 & 1.045 & 0.026 \\
\hline $\mathrm{d}_{31}-\mathrm{PA}, 0.47 \mathrm{M} \mathrm{NaCl}, 10 \mathrm{mM} \mathrm{CaCl}_{2}, \mathrm{pH} 8.2$ & 1.041 & 0.029 & 1.030 & 0.016 \\
\hline $\mathrm{d}_{31}-\mathrm{PA}, 0.47 \mathrm{M} \mathrm{NaCl}, 10 \mathrm{mM} \mathrm{CaCl}_{2}, \mathrm{pH} 5.8$ & 1.083 & 0.020 & 1.014 & 0.041 \\
\hline $\mathrm{d}_{33}-\mathrm{CA}, 0.47 \mathrm{M} \mathrm{NaCl}, 10 \mathrm{mM} \mathrm{CaCl}_{2}, \mathrm{pH} 8.2$ & 1.062 & 0.008 & 1.049 & 0.005 \\
\hline $\mathrm{d}_{31}-\mathrm{PA}, 0.47 \mathrm{M} \mathrm{NaCl}, 10 \mathrm{mM} \mathrm{MgCl}_{2}, \mathrm{pH} 8.2$ & 1.092 & 0.005 & 1.032 & 0.010 \\
\hline $\mathrm{d}_{31}-\mathrm{PA}, 0.47 \mathrm{M} \mathrm{NaCl}, 53 \mathrm{mM} \mathrm{MgCl}_{2}, \mathrm{pH} 8.2$ & 1.120 & 0.017 & 1.048 & 0.012 \\
\hline
\end{tabular}

\section{D-guluronate and d31-palmitic acid vibrational frequency calculations}

To distinguish between peaks corresponding to the $\mathrm{d}_{31}$-palmitic acid monolayer or the coadsorbed alginate, harmonic vibrational frequency calculations were performed using Q-Chem v. 5.3.1. ${ }^{1}$ D-guluronic acid, an alginate monomer primarily responsible for cation binding, was selected to model the alginate vibrational modes (Figure S1a).$^{2-4}$ Both protonated $\mathrm{d}_{31}$-palmitic acid 
(Figure $\mathrm{S} 1 \mathrm{~b}$ ) and deprotonated $\mathrm{d}_{31}$-palmitate (Figure $\mathrm{S} 1 \mathrm{c}$ ) were modeled, and the atomic mass of 2.01410 was used for the deuterium atoms. ${ }^{5}$ Geometry optimization and harmonic frequency analysis were performed at the EDF2/6-31+G* level of theory. ${ }^{6}$ Frequencies, intensities, and vibrational mode assignments within the frequency region of the carboxylic acid headgroup and the C-D bending modes $\left(1090-1850 \mathrm{~cm}^{-1}\right)$ are tabulated in Tables S3-S5.

(a)

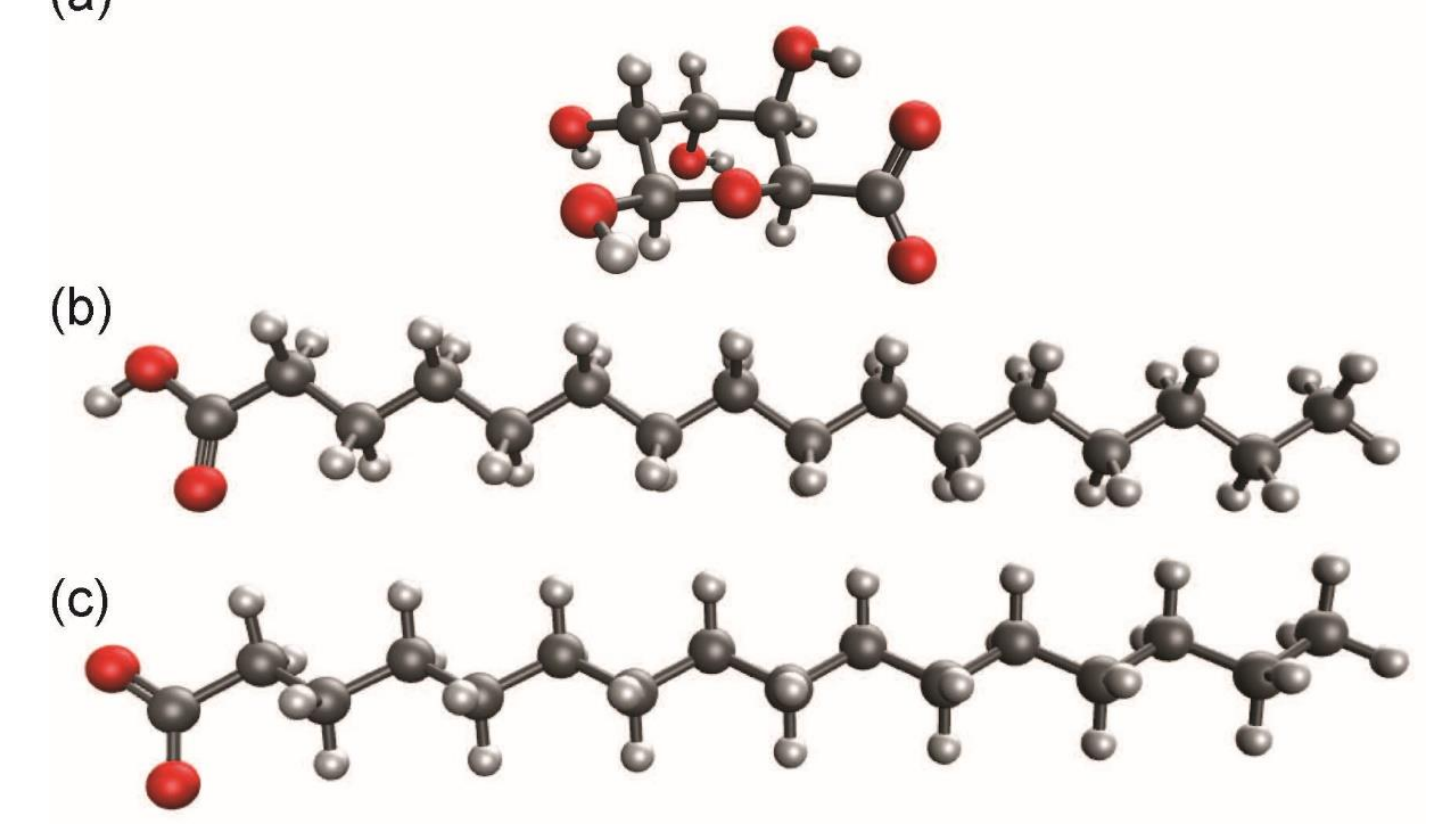

Fig. S2. Geometry optimized structures of (a) D-guluronate, (b) $\mathrm{d}_{31}$-palmitic acid, and (c) $\mathrm{d}_{31^{-}}$ palmitate. 
Table S3. Harmonic vibrational frequencies, intensities, and vibrational mode assignments of Dguluronate.

\begin{tabular}{|c|c|c|}
\hline $\begin{array}{c}\text { Wavenumber } \\
\mathbf{( c m}^{-1} \mathbf{)}\end{array}$ & $\begin{array}{c}\text { Intensity } \\
\mathbf{( k m} / \mathbf{m o l})\end{array}$ & Mode Assignments \\
\hline 1094.24 & 111.741 & C-O-H Bending, C-O-C Stretching \\
\hline 1100.50 & 145.998 & C-OH Stretching \\
\hline 1116.31 & 80.623 & C-O-C Stretching, C-O-H Bending \\
\hline 1148.48 & 211.874 & C-O-H Stretching, C-H Wagging \\
\hline 1154.90 & 2.637 & C-O-H Stretching and Bending \\
\hline 1206.32 & 34.863 & C-O-H Bending, C-H Wagging \\
\hline 1242.62 & 32.793 & C-H Wagging, C-O-H Bending \\
\hline 1264.93 & 32.675 & C-H Wagging, C-O-H Bending \\
\hline 1297.55 & 18.810 & C-H Wagging, C-O-H Bending \\
\hline 1317.06 & 32.035 & C-H Wagging, C-O-H Bending \\
\hline 1325.07 & 15.798 & C-H Wagging, C-O-H Bending \\
\hline 1340.30 & 18.708 & C-H Wagging, C-O-H Bending \\
\hline 1352.16 & 121.662 & C-H Wagging, C-O-H Bending, COO- Symmetric Stretching \\
\hline 1356.34 & 27.790 & C-H Wagging, C-O-H Bending, COO- Symmetric Stretching \\
\hline 1391.73 & 127.213 & COO- Symmetric Stretching, C-H Wagging \\
\hline 1400.35 & 16.914 & C-H Wagging, C-O-H Bending \\
\hline 1411.78 & 25.561 & C-O-H Bending, C-H Wagging \\
\hline 1439.87 & 44.051 & C-O-H Bending, C-H Wagging \\
\hline 1474.40 & 2.861 & C-O-H Bending, C-H Wagging \\
\hline 1547.29 & 384.253 & C-O-H Bending, COO- Asymmetric Stretching \\
\hline 1725.18 & 423.674 & COO- Asymmetric Stretching, C-O-H Bending \\
\hline
\end{tabular}


Table S4. Harmonic vibrational frequencies, intensities, and vibrational mode assignments of $\mathrm{d}_{31^{-}}$ palmitic acid.

\begin{tabular}{|c|c|c|}
\hline $\begin{array}{c}\text { Wavenumber } \\
\left(\mathrm{cm}^{-1}\right)\end{array}$ & $\begin{array}{l}\text { Intensity } \\
\text { (km/mol) }\end{array}$ & Mode Assignments \\
\hline 1092.09 & 0.403 & $\mathrm{CD}_{3}$ Bending, $\mathrm{CD}_{2}$ Bending \& Wagging \\
\hline 1093.01 & 4.856 & $\mathrm{CD}_{3}$ Bending \\
\hline 1093.67 & 7.022 & $\mathrm{CD}_{2}$ Bending \\
\hline 1108.35 & 13.932 & $\mathrm{CD}_{2}$ Bending \& Wagging, $\mathrm{CD}_{3}$ Bending \\
\hline 1116.04 & 2.674 & $\mathrm{CD}_{2}$ Bending \& Wagging \\
\hline 1117.22 & 0.663 & $\mathrm{CD}_{2}$ Bending \& Wagging \\
\hline 1119.12 & 0.914 & $\mathrm{CD}_{2}$ Bending \& Wagging \\
\hline 1121.34 & 0.634 & $\mathrm{CD}_{2}$ Bending \\
\hline 1123.82 & 1.570 & $\mathrm{CD}_{2}$ Bending \\
\hline 1125.90 & 0.640 & $\mathrm{CD}_{2}$ Bending \\
\hline 1127.50 & 11.375 & $\mathrm{CD}_{2}$ Bending \\
\hline 1128.73 & 8.575 & $\mathrm{CD}_{2}$ Bending, $\mathrm{CD}_{3}$ Bending \\
\hline 1132.35 & 1.303 & $\mathrm{CD}_{2}$ Bending \& Wagging, $\mathrm{CD}_{3}$ Bending \\
\hline 1141.51 & 14.964 & $\mathrm{CD}_{2}$ Bending, $\mathrm{C}-\mathrm{O}-\mathrm{H}$ Bending \& Stretching \\
\hline 1150.56 & 15.657 & $\mathrm{CD}_{2}$ Bending \& Wagging, $\mathrm{C}-\mathrm{O}-\mathrm{H}$ Bending \& Stretching \\
\hline 1159.16 & 46.521 & C-O-H Bending \& Stretching, $\mathrm{CD}_{2}$ Bending \& Wagging \\
\hline 1167.89 & 4.210 & $\mathrm{CD}_{2}$ Bending \& Wagging, $\mathrm{C}-\mathrm{O}-\mathrm{H}$ Bending \& Stretching \\
\hline 1177.22 & 4.233 & $\mathrm{CD}_{2}$ Bending, $\mathrm{C}-\mathrm{O}-\mathrm{H}$ Bending \& Stretching \\
\hline 1189.07 & 65.964 & C-O-H Bending \& Stretching, $\mathrm{CD}_{2}$ Wagging \\
\hline 1216.54 & 59.856 & C-O-H Bending \& Stretching, $\mathrm{CD}_{2}$ Wagging \\
\hline 1241.05 & 15.368 & $\mathrm{CD}_{2}$ Wagging, $\mathrm{C}-\mathrm{O}-\mathrm{H}$ Bending \\
\hline 1260.91 & 6.855 & $\mathrm{CD}_{2}$ Wagging, $\mathrm{C}-\mathrm{O}-\mathrm{H}$ Bending \\
\hline 1274.81 & 0.569 & $\mathrm{CD}_{2}$ Wagging, C-O-H Bending \\
\hline 1282.93 & 0.528 & $\mathrm{CD}_{2}$ Wagging, C-O-H Bending \\
\hline 1286.54 & 0.032 & $\mathrm{CD}_{2}$ Wagging, C-O-H Bending \\
\hline 1288.46 & 0.160 & $\mathrm{CD}_{2}$ Wagging, $\mathrm{C}-\mathrm{O}-\mathrm{H}$ Bending \\
\hline 1369.64 & 120.711 & C-O-H Bending \& Stretching \\
\hline 1827.90 & 299.335 & $\mathrm{C}=\mathrm{O}$ Stretching, $\mathrm{C}-\mathrm{O}-\mathrm{H}$ Bending \\
\hline
\end{tabular}


Table S5. Harmonic vibrational frequencies, intensities, and vibrational mode assignments of $\mathrm{d}_{31^{-}}$ palmitate.

\begin{tabular}{|c|c|c|}
\hline $\begin{array}{c}\text { Wavenumber } \\
\left(\mathrm{cm}^{-1}\right)\end{array}$ & $\begin{array}{l}\text { Intensity } \\
(\mathrm{km} / \mathrm{mol}) \\
\end{array}$ & Mode Assignments \\
\hline 1091.89 & 7.209 & $\mathrm{CD}_{3}$ Bending, $\mathrm{CD}_{2}$ Bending \& Wagging \\
\hline 1092.92 & 4.719 & $\mathrm{CD}_{3}$ Bending \\
\hline 1093.94 & 5.964 & $\mathrm{CD}_{2}$ Bending \& Wagging, $\mathrm{CD}_{3}$ Bending \\
\hline 1108.52 & 0.333 & $\mathrm{CD}_{2}$ Bending \& Wagging, $\mathrm{CD}_{3}$ Bending \\
\hline 1114.79 & 0.338 & $\mathrm{CD}_{2}$ Bending \& Wagging \\
\hline 1116.53 & 0.014 & $\mathrm{CD}_{2}$ Bending \& Wagging \\
\hline 1118.41 & 0.561 & $\mathrm{CD}_{2}$ Bending \& Wagging, $\mathrm{CD}_{3}$ Bending \\
\hline 1120.73 & 0.006 & $\mathrm{CD}_{2}$ Bending \& Wagging, $\mathrm{CD}_{3}$ Bending \\
\hline 1123.15 & 1.640 & $\mathrm{CD}_{2}$ Bending, $\mathrm{CD}_{3}$ Bending \\
\hline 1125.37 & 0.002 & $\mathrm{CD}_{2}$ Bending, $\mathrm{CD}_{3}$ Bending \\
\hline 1127.13 & 10.458 & $\mathrm{CD}_{2}$ Bending \\
\hline 1127.55 & 0.296 & $\mathrm{CD}_{2}$ Bending, $\mathrm{CD}_{3}$ Bending \\
\hline 1131.37 & 0.628 & $\mathrm{CD}_{2}$ Bending \& Wagging, $\mathrm{CD}_{3}$ Bending \\
\hline 1140.96 & 0.701 & $\mathrm{CD}_{2}$ Bending \& Wagging, $\mathrm{CD}_{3}$ Bending \\
\hline 1149.66 & 0.109 & $\mathrm{CD}_{2}$ Bending \& Wagging \\
\hline 1162.08 & 2.876 & $\mathrm{CD}_{2}$ Bending \& Wagging, $\mathrm{CD}_{3}$ Bending \\
\hline 1167.45 & 0.477 & $\mathrm{CD}_{2}$ Bending \& Wagging, $\mathrm{CD}_{3}$ Bending \\
\hline 1177.28 & 0.702 & $\mathrm{CD}_{2}$ Bending, $\mathrm{CD}_{3}$ Bending \\
\hline 1198.48 & 0.953 & $\mathrm{CD}_{2}$ Bending \& Wagging, $\mathrm{CD}_{3}$ Bending \\
\hline 1228.77 & 0.582 & $\mathrm{CD}_{2}$ Bending \& Wagging, $\mathrm{CD}_{3}$ Bending \\
\hline 1250.96 & 1.753 & $\mathrm{CD}_{2}$ Wagging, $\mathrm{CD}_{3}$ Bending \\
\hline 1265.36 & 0.348 & $\mathrm{CD}_{2}$ Wagging, $\mathrm{CD}_{3}$ Bending \\
\hline 1275.19 & 0.701 & $\mathrm{CD}_{2}$ Wagging, $\mathrm{CD}_{3}$ Bending \\
\hline 1281.76 & 0.054 & $\mathrm{CD}_{2}$ Wagging \\
\hline 1285.41 & 0.085 & $\mathrm{CD}_{2}$ Wagging \\
\hline 1371.58 & 328.038 & $\mathrm{COO}^{-}$Symmetric Stretching \\
\hline 1678.00 & 637.505 & $\mathrm{COO}^{-}$Asymmetric Stretching \\
\hline
\end{tabular}

\section{Carboxylate region spectral fitting}

Peaks within the $\mathrm{COOH}$ stretching region $\left(1150-1850 \mathrm{~cm}^{-1}\right)$ were fitted to Gaussian functions using OriginPro 9.0. The software uses the Levenberg-Marquardt algorithm to perform the nonlinear curve fitting routine. Eight points were placed along the baseline, and a $4^{\text {th }}$-order polynomial function was fitted to those points and used to define the spectral baseline. Peak fitting parameters were not fixed. 


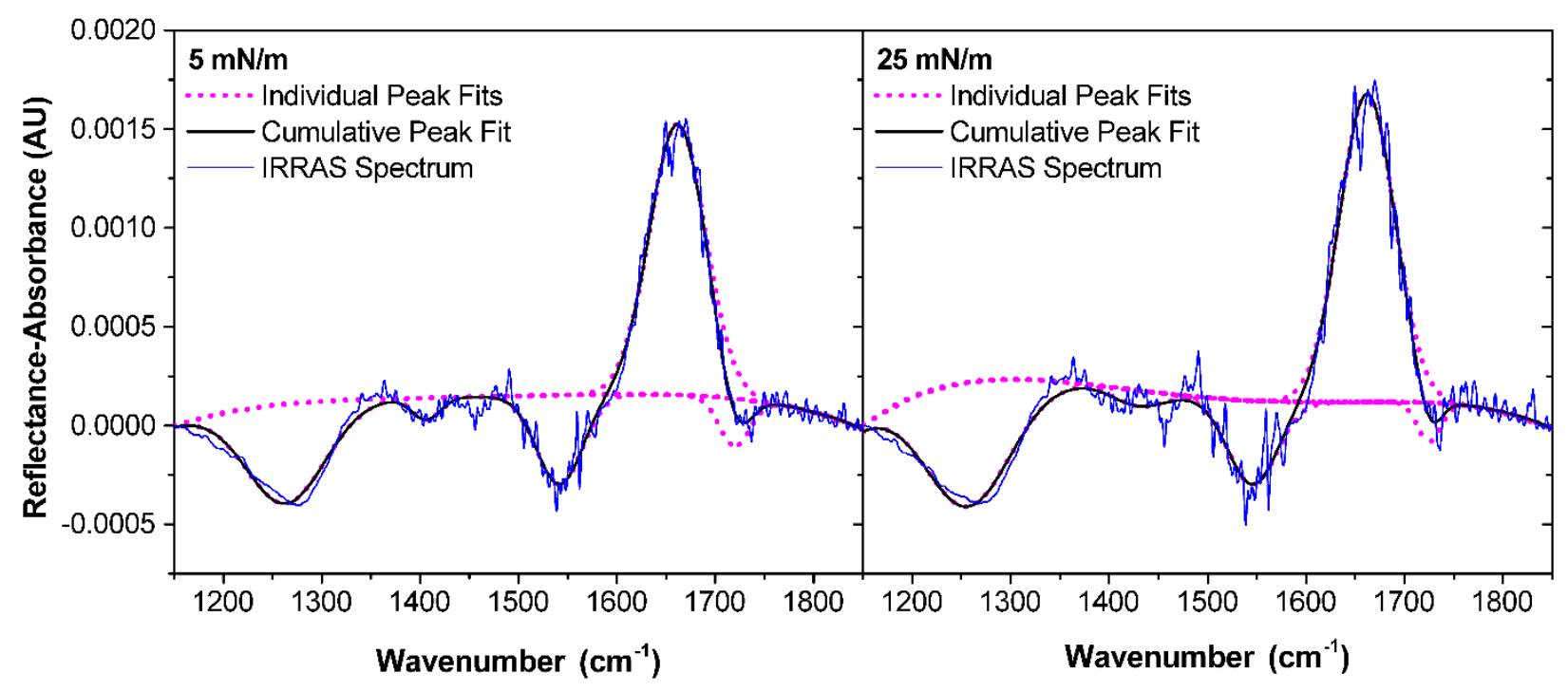

Fig. S3. IRRAS spectra and corresponding peak fits of a $\mathrm{d}_{31}$-palmitic acid monolayer at $5 \mathrm{mN} / \mathrm{m}$ (left) and $25 \mathrm{mN} / \mathrm{m}$ (right) spread onto an aqueous subphase of $0.47 \mathrm{M} \mathrm{NaCl}$ at $\mathrm{pH} 8.2$.

Table S6. Center wavelengths $\left(\lambda, \mathrm{cm}^{-1}\right)$, reflectance-absorbance intensities (RA Int.), peak areas, and full width at half maximum (FWHM, $\mathrm{cm}^{-1}$ ) values of Gaussian fits to IRRAS spectra in the $\mathrm{COOH}$ vibrational mode region of a $\mathrm{d}_{31}$-palmitic acid monolayer $(5 \mathrm{mN} / \mathrm{m}$ and $25 \mathrm{mN} / \mathrm{m}) \mathrm{spread}$ onto an aqueous subphase of $0.47 \mathrm{M} \mathrm{NaCl}$ at $\mathrm{pH} 8.2$.

\begin{tabular}{|c|c|c|c|c|c|c|c|c|}
\hline \multirow{2}{*}{$\begin{array}{c}\text { Vibrational } \\
\text { Mode }\end{array}$} & \multicolumn{5}{|c|}{$5 \mathbf{~ m N} / \mathbf{m}$} & \multicolumn{4}{c|}{$\mathbf{2 5} \mathbf{~ m N} / \mathbf{m}$} \\
\cline { 2 - 9 } & Center $\lambda$ & RA Int. & Area & FWHM & Center $\lambda$ & RA Int. & Area & FWHM \\
\hline$v \mathrm{C}-\mathrm{OH}$ & 1263.5 & $-5.02 \mathrm{E}-04$ & 0.0501 & 93.7 & 1256.7 & $-6.31 \mathrm{E}-04$ & 0.06895 & 102.7 \\
\hline$v_{\mathrm{S}} \mathrm{COO}^{-}$ & 1406.3 & $-1.10 \mathrm{E}-04$ & 0.00399 & 34.0 & 1429.7 & $-7.92 \mathrm{E}-05$ & 0.00509 & 60.4 \\
\hline$v_{\mathrm{AS}} \mathrm{COO}^{-}$ & 1541.6 & $-4.49 \mathrm{E}-04$ & 0.0261 & 54.5 & 1545.6 & $-4.23 \mathrm{E}-04$ & 0.0263 & 58.4 \\
\hline$\delta \mathrm{H}-\mathrm{O}-\mathrm{H}$ & 1661.5 & 0.00137 & 0.0975 & 66.9 & 1662.0 & 0.00156 & 0.109 & 66.0 \\
\hline$v \mathrm{C}=\mathrm{O}$ & 1719.6 & $-2.40 \mathrm{E}-04$ & 0.00942 & 36.8 & 1725.1 & $-1.96 \mathrm{E}-04$ & 0.00586 & 28.1 \\
\hline
\end{tabular}




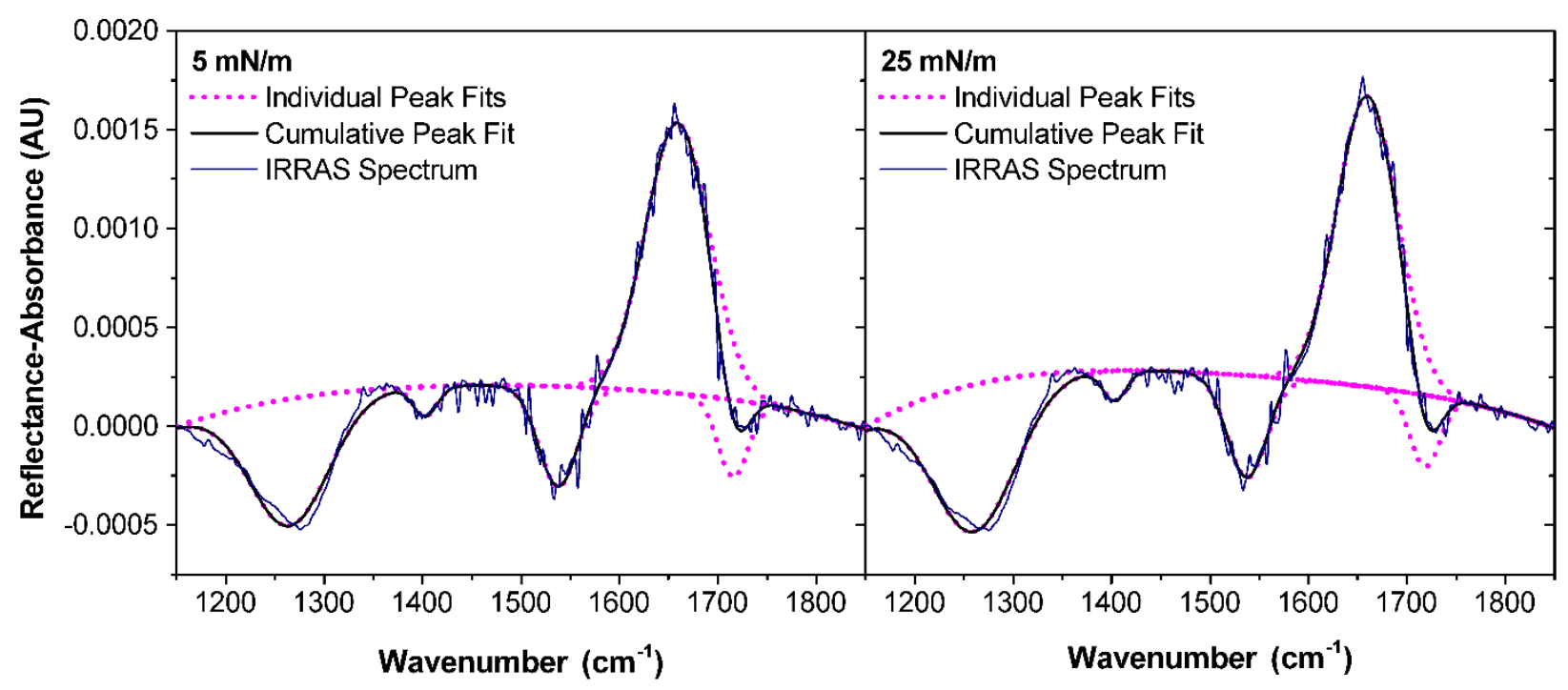

Fig. S4. IRRAS spectra and corresponding peak fits of a $\mathrm{d}_{31}$-palmitic acid monolayer at $5 \mathrm{mN} / \mathrm{m}$ (left) and $25 \mathrm{mN} / \mathrm{m}$ (right) spread onto an aqueous subphase of $0.47 \mathrm{M} \mathrm{NaCl}$ and $50 \mathrm{ppm}$ alginate at $\mathrm{pH} 8.2$.

Table S7. Center wavelengths $\left(\lambda, \mathrm{cm}^{-1}\right)$, reflectance-absorbance intensities (RA Int.), peak areas, and full width at half maximum (FWHM, $\mathrm{cm}^{-1}$ ) values of Gaussian fits to IRRAS spectra in the $\mathrm{COOH}$ vibrational mode region of a $\mathrm{d}_{31}$-palmitic acid monolayer $(5 \mathrm{mN} / \mathrm{m}$ and $25 \mathrm{mN} / \mathrm{m})$ spread onto an aqueous subphase of $0.47 \mathrm{M} \mathrm{NaCl}$ and $50 \mathrm{ppm}$ alginate at $\mathrm{pH}$ 8.2.

\begin{tabular}{|c|c|c|c|c|c|c|c|c|}
\hline \multirow{2}{*}{$\begin{array}{c}\text { Vibrational } \\
\text { Mode }\end{array}$} & \multicolumn{4}{|c|}{$\mathbf{5 ~ m N / m}$} & \multicolumn{5}{c|}{$\mathbf{2 5} \mathbf{~ m N} / \mathbf{m}$} \\
\cline { 2 - 9 } & Center $\lambda$ & RA Int. & Area & FWHM & Center $\lambda$ & RA Int. & Area & FWHM \\
\hline \hline$v \mathrm{C}-\mathrm{OH}$ & 1264.7 & $-6.42 \mathrm{E}-04$ & 0.0643 & 94.1 & 1260.5 & $-7.46 \mathrm{E}-04$ & 0.0789 & 99.3 \\
\hline$v_{\mathrm{S}} \mathrm{COO}^{-}$ & 1402.6 & $-1.50 \mathrm{E}-04$ & 0.00458 & 28.7 & 1402.9 & $-1.53 \mathrm{E}-04$ & 0.00461 & 28.3 \\
\hline$v_{\mathrm{AS}} \mathrm{COO}^{-}$ & 1537.8 & $-5.07 \mathrm{E}-04$ & 0.0253 & 46.9 & 1537.3 & $-5.16 \mathrm{E}-04$ & 0.0260 & 47.3 \\
\hline$\delta \mathrm{H}-\mathrm{O}-\mathrm{H}$ & 1658.9 & 0.00137 & 0.111 & 76.2 & 1659.6 & 0.00147 & 0.114 & 72.6 \\
\hline$v \mathrm{C}=\mathrm{O}$ & 1715.4 & $-3.88 \mathrm{E}-04$ & 0.0149 & 35.9 & 1718.3 & $-3.62 \mathrm{E}-04$ & 0.0139 & 36.0 \\
\hline
\end{tabular}




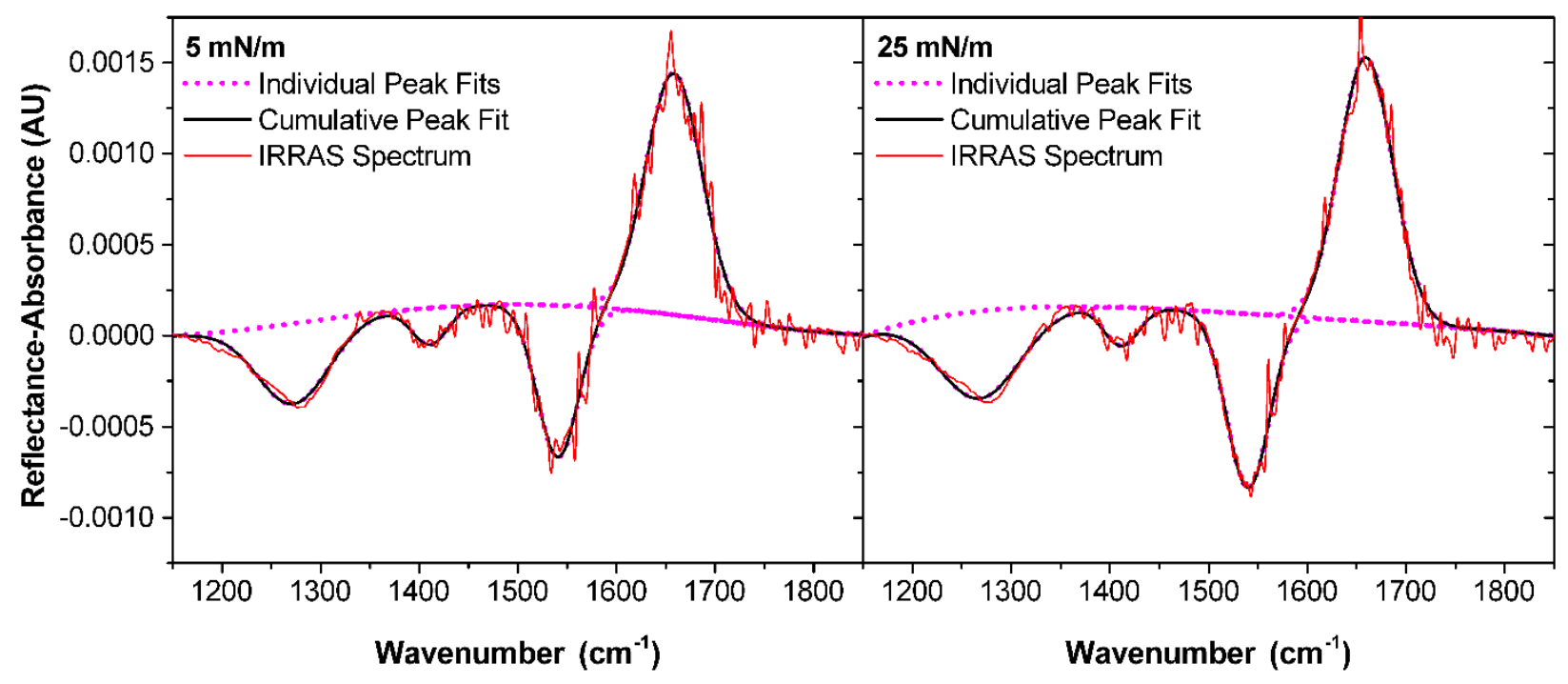

Fig. S5. IRRAS spectra and corresponding peak fits of a $\mathrm{d}_{31}$-palmitic acid monolayer at $5 \mathrm{mN} / \mathrm{m}$ (left) and $25 \mathrm{mN} / \mathrm{m}$ (right) spread onto an aqueous subphase of $0.47 \mathrm{M} \mathrm{NaCl}$ and $10 \mathrm{mM} \mathrm{CaCl}_{2}$ at $\mathrm{pH} 8.2$.

Table S8. Center wavelengths $\left(\lambda, \mathrm{cm}^{-1}\right)$, reflectance-absorbance intensities (RA Int.), peak areas, and full width at half maximum (FWHM, $\mathrm{cm}^{-1}$ ) values of Gaussian fits to IRRAS spectra in the $\mathrm{COOH}$ vibrational mode region of a $\mathrm{d}_{31}$-palmitic acid monolayer $(5 \mathrm{mN} / \mathrm{m}$ and $25 \mathrm{mN} / \mathrm{m}) \mathrm{spread}$ onto an aqueous subphase of $0.47 \mathrm{M} \mathrm{NaCl}$ and $10 \mathrm{mM} \mathrm{CaCl}_{2}$ at $\mathrm{pH} 8.2$.

\begin{tabular}{|c|c|c|c|c|c|c|c|c|}
\hline \multirow{2}{*}{$\begin{array}{c}\text { Vibrational } \\
\text { Mode }\end{array}$} & \multicolumn{5}{|c|}{$\mathbf{5 ~ m N / m}$} & \multicolumn{4}{c|}{$\mathbf{2 5} \mathbf{~ m N} / \mathbf{m}$} \\
\cline { 2 - 9 } & Center $\boldsymbol{\lambda}$ & RA Int. & Area & FWHM & Center $\boldsymbol{\lambda}$ & RA Int. & Area & FWHM \\
\hline \hline$v \mathrm{C}-\mathrm{OH}$ & 1272.6 & $-4.42 \mathrm{E}-04$ & 0.0401 & 85.0 & 1268.2 & $-4.81 \mathrm{E}-04$ & 0.0497 & 97.1 \\
\hline$v_{\mathrm{S}} \mathrm{COO}^{-}$ & 1410.8 & $-2.03 \mathrm{E}-04$ & 0.00908 & 41.9 & 1411.5 & $-2.12 \mathrm{E}-04$ & 0.00933 & 41.3 \\
\hline$v_{\mathrm{AS}} \mathrm{COO}^{-}$ & 1540.6 & $-8.35 \mathrm{E}-04$ & 0.0439 & 49.4 & 1539.9 & $-9.57 \mathrm{E}-04$ & 0.0515 & 50.6 \\
\hline$\delta \mathrm{H}-\mathrm{O}-\mathrm{H}$ & 1658.0 & 0.00133 & 0.0946 & 67.0 & 1659.5 & 0.00145 & 0.0994 & 64.4 \\
\hline
\end{tabular}




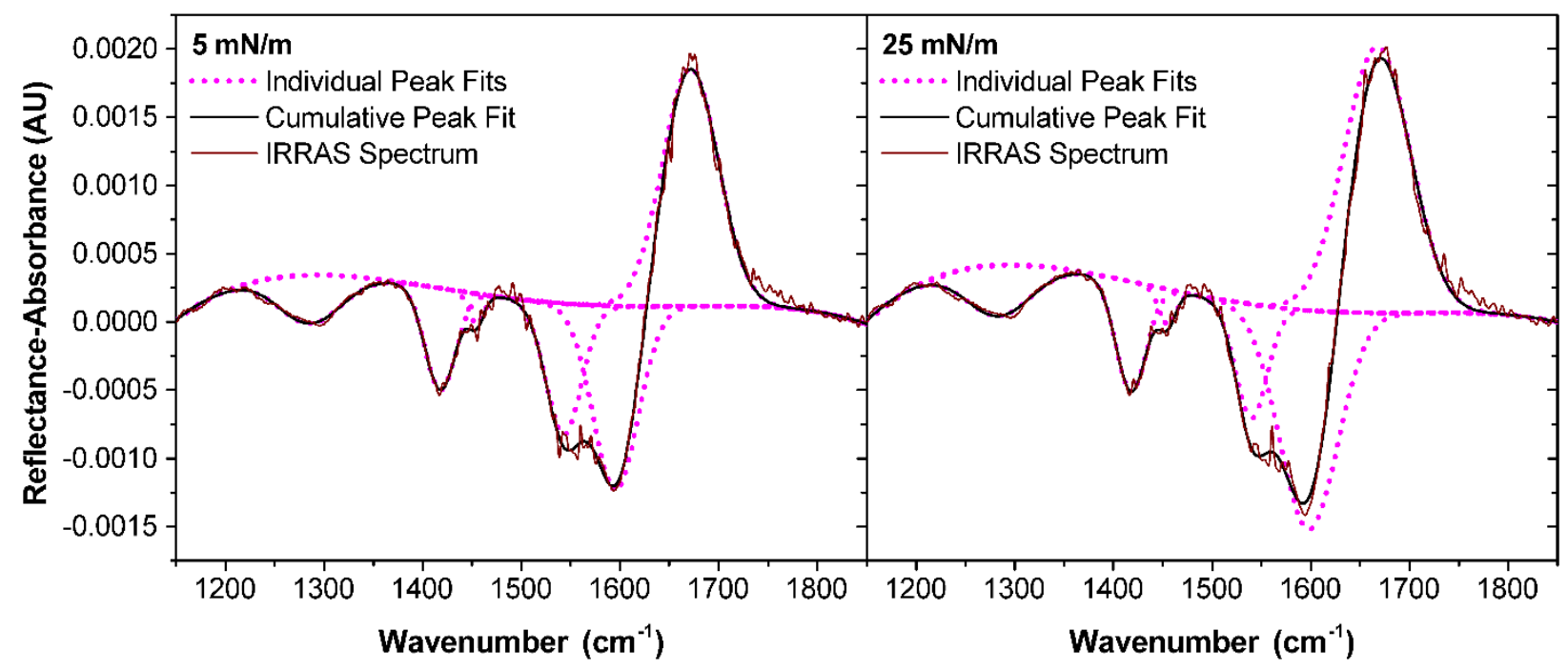

Fig. S6. IRRAS spectra and corresponding peak fits of a $\mathrm{d}_{31}$-palmitic acid monolayer at $5 \mathrm{mN} / \mathrm{m}$ (left) and $25 \mathrm{mN} / \mathrm{m}$ (right) spread onto an aqueous subphase of $0.47 \mathrm{M} \mathrm{NaCl}, 10 \mathrm{mM} \mathrm{CaCl}_{2}$, and $50 \mathrm{ppm}$ alginate at $\mathrm{pH} 8.2$.

Table S9. Center wavelengths $\left(\lambda, \mathrm{cm}^{-1}\right)$, reflectance-absorbance intensities (RA Int.), peak areas, and full width at half maximum (FWHM, $\mathrm{cm}^{-1}$ ) values of Gaussian fits to IRRAS spectra in the $\mathrm{COOH}$ vibrational mode region of a d 31 -palmitic acid monolayer $(5 \mathrm{mN} / \mathrm{m}$ and $25 \mathrm{mN} / \mathrm{m}) \mathrm{spread}$ onto an aqueous subphase of $0.47 \mathrm{M} \mathrm{NaCl}, 10 \mathrm{mM} \mathrm{CaCl}_{2}$, and $50 \mathrm{ppm}$ alginate at $\mathrm{pH} 8.2$.

\begin{tabular}{|c|c|c|c|c|c|c|c|c|}
\hline \multirow{2}{*}{$\begin{array}{l}\text { Vibrational } \\
\text { Mode }\end{array}$} & \multicolumn{4}{|c|}{$5 \mathrm{mN} / \mathrm{m}$} & \multicolumn{4}{|c|}{$25 \mathrm{mN} / \mathrm{m}$} \\
\hline & Center $\lambda$ & RA Int. & Area & FWHM & Center $\lambda$ & RA Int. & Area & FWHM \\
\hline$v \mathrm{C}-\mathrm{OH}$ & 1285.7 & $-3.58 \mathrm{E}-04$ & 0.0291 & 76.3 & 1283.5 & $-3.77 \mathrm{E}-04$ & 0.0318 & 79.2 \\
\hline $\begin{array}{c}v_{\mathrm{S}} \mathrm{COO}^{-} \\
\left(\mathrm{d}_{31} \text {-Palmitate }\right)\end{array}$ & 1417.8 & $-7.45 \mathrm{E}-04$ & 0.0293 & 36.9 & 1417.8 & $-8.07 \mathrm{E}-04$ & 0.0314 & 36.5 \\
\hline $\begin{array}{c}v_{\mathrm{S}} \mathrm{COO}^{-} \\
\text {(Alginate) }\end{array}$ & 1454.3 & $-2.16 \mathrm{E}-4$ & 0.00415 & 18.0 & 1454.7 & $-2.54 \mathrm{E}-4$ & 0.00558 & 20.7 \\
\hline $\begin{array}{c}v_{\text {AS }} \mathrm{COO}^{-} \\
\left(\mathrm{d}_{31} \text {-Palmitate }\right)\end{array}$ & 1543.0 & $9.58 \mathrm{E}-04$ & 0.0432 & 42.3 & 1539.8 & $-8.34 \mathrm{E}-04$ & 0.0336 & 37.9 \\
\hline $\begin{array}{l}v_{\mathrm{AS}} \mathrm{COO}^{-} \\
\text {(Alginate) }\end{array}$ & 1595.4 & 0.00135 & 0.0768 & 53.6 & 1597.9 & -0.00160 & 0.118 & 69.0 \\
\hline$\delta \mathrm{H}-\mathrm{O}-\mathrm{H}$ & 1671.3 & 0.00174 & 0.124 & 66.6 & 1667.3 & 0.00195 & 0.164 & 79.0 \\
\hline
\end{tabular}




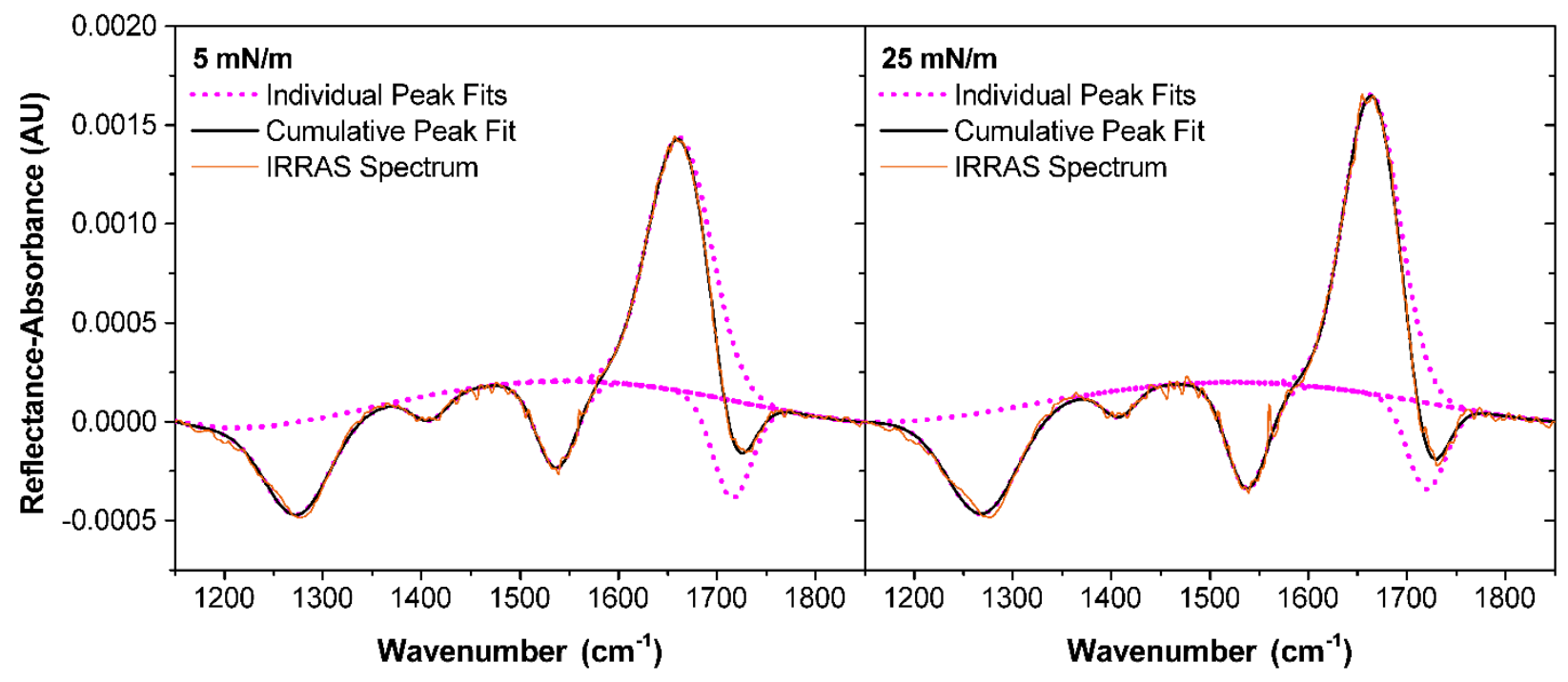

Fig. S7. IRRAS spectra and corresponding peak fits of a $\mathrm{d}_{31}$-palmitic acid monolayer at $5 \mathrm{mN} / \mathrm{m}$ (left) and $25 \mathrm{mN} / \mathrm{m}$ (right) spread onto an aqueous subphase of $0.47 \mathrm{M} \mathrm{NaCl}$ and $10 \mathrm{mM} \mathrm{CaCl}_{2}$ at $\mathrm{pH} 5.8$.

Table S10. Center wavelengths $\left(\lambda, \mathrm{cm}^{-1}\right)$, reflectance-absorbance intensities (RA Int.), peak areas, and full width at half maximum (FWHM, $\mathrm{cm}^{-1}$ ) values of Gaussian fits to IRRAS spectra in the $\mathrm{COOH}$ vibrational mode region of a $\mathrm{d}_{31}$-palmitic acid monolayer $(5 \mathrm{mN} / \mathrm{m}$ and $25 \mathrm{mN} / \mathrm{m}) \mathrm{spread}$ onto an aqueous subphase of $0.47 \mathrm{M} \mathrm{NaCl}$ and $10 \mathrm{mM} \mathrm{CaCl}_{2}$ at $\mathrm{pH} 5.8$.

\begin{tabular}{|c|c|c|c|c|c|c|c|c|}
\hline \multirow{2}{*}{$\begin{array}{c}\text { Vibrational } \\
\text { Mode }\end{array}$} & \multicolumn{4}{|c|}{$\mathbf{5 ~ m N / m}$} & \multicolumn{4}{c|}{$\mathbf{2 5} \mathbf{~ m N} / \mathbf{m}$} \\
\cline { 2 - 9 } & Center $\boldsymbol{\lambda}$ & RA Int. & Area & FWHM & Center $\boldsymbol{\lambda}$ & RA Int. & Area & FWHM \\
\hline \hline$v \mathrm{C}-\mathrm{OH}$ & 1274.0 & $-4.67 \mathrm{E}-04$ & 0.0377 & 75.8 & 1269.6 & $-5.11 \mathrm{E}-04$ & 0.0448 & 82.4 \\
\hline$v_{\mathrm{S}} \mathrm{COO}^{-}$ & 1408.2 & $-1.27 \mathrm{E}-04$ & 0.00570 & 42.0 & 1407.9 & $-1.36 \mathrm{E}-04$ & 0.00563 & 38.9 \\
\hline$v_{\mathrm{AS}} \mathrm{COO}^{-}$ & 1536.9 & $-4.40 \mathrm{E}-04$ & 0.0225 & 48.0 & 1538.0 & $-5.36 \mathrm{E}-04$ & 0.0281 & 49.2 \\
\hline$\delta \mathrm{H}-\mathrm{O}-\mathrm{H}$ & 1661.6 & 0.00128 & 0.102 & 74.9 & 1664.1 & 0.00151 & 0.107 & 66.8 \\
\hline$v \mathrm{C}=\mathrm{O}$ & 1715.2 & $-4.91 \mathrm{E}-04$ & 0.0239 & 45.8 & 1719.7 & $-4.36 \mathrm{E}-04$ & 0.0209 & 45.0 \\
\hline
\end{tabular}




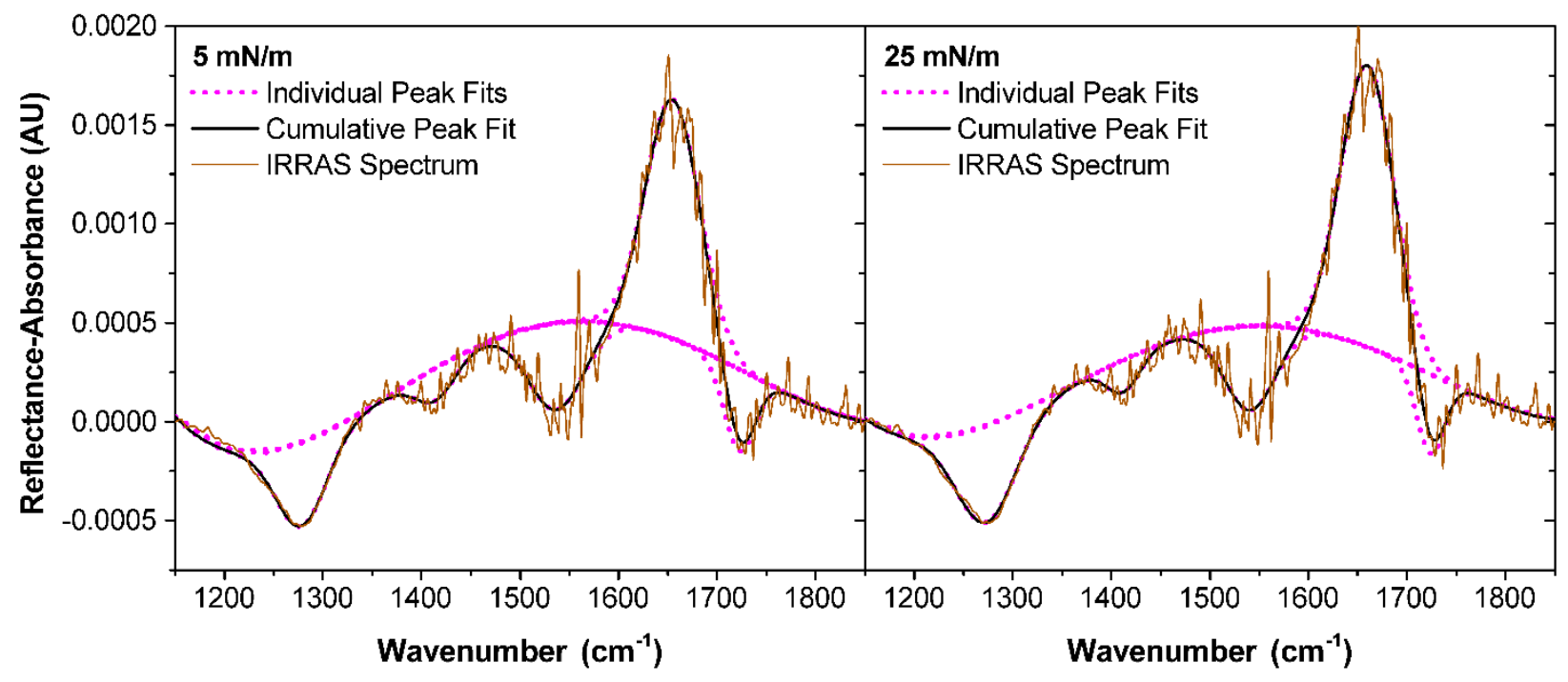

Fig. S8. IRRAS spectra and corresponding peak fits of a $\mathrm{d}_{31}$-palmitic acid monolayer at $5 \mathrm{mN} / \mathrm{m}$ (left) and $25 \mathrm{mN} / \mathrm{m}$ (right) spread onto an aqueous subphase of $0.47 \mathrm{M} \mathrm{NaCl}, 10 \mathrm{mM} \mathrm{CaCl}_{2}$, and $50 \mathrm{ppm}$ alginate at $\mathrm{pH} 5.8$.

Table S11. Center wavelengths $\left(\lambda, \mathrm{cm}^{-1}\right)$, reflectance-absorbance intensities (RA Int.), peak areas, and full width at half maximum (FWHM, $\mathrm{cm}^{-1}$ ) values of Gaussian fits to IRRAS spectra in the $\mathrm{COOH}$ vibrational mode region of a $\mathrm{d}_{31}$-palmitic acid monolayer $(5 \mathrm{mN} / \mathrm{m}$ and $25 \mathrm{mN} / \mathrm{m}) \mathrm{spread}$ onto an aqueous subphase of $0.47 \mathrm{M} \mathrm{NaCl}, 10 \mathrm{mM} \mathrm{CaCl}_{2}$, and $50 \mathrm{ppm}$ alginate at $\mathrm{pH} 5.8$.

\begin{tabular}{|c|c|c|c|c|c|c|c|c|}
\hline \multirow{2}{*}{$\begin{array}{c}\text { Vibrational } \\
\text { Mode }\end{array}$} & \multicolumn{4}{|c|}{$\mathbf{5 ~ m N / m}$} & \multicolumn{4}{c|}{$\mathbf{2 5} \mathbf{~ m N} / \mathbf{m}$} \\
\cline { 2 - 9 } & Center $\boldsymbol{\lambda}$ & RA Int. & Area & FWHM & Center $\boldsymbol{\lambda}$ & RA Int. & Area & FWHM \\
\hline \hline$v \mathrm{C}-\mathrm{OH}$ & 1278.6 & $-4.18 \mathrm{E}-04$ & 0.0264 & 59.2 & 1273.6 & $-4.86 \mathrm{E}-04$ & 0.0363 & 70.1 \\
\hline$v_{\mathrm{S}} \mathrm{COO}^{-}$ & 1414.3 & $-1.67 \mathrm{E}-04$ & 0.00834 & 46.8 & 1412.1 & $-1.65 \mathrm{E}-04$ & 0.00689 & 39.2 \\
\hline$v_{\mathrm{AS}} \mathrm{COO}^{-}$ & 1536.8 & $-4.42 \mathrm{E}-04$ & 0.0314 & 66.8 & 1540.6 & $-4.29 \mathrm{E}-04$ & 0.0280 & 61.3 \\
\hline$\delta \mathrm{H}-\mathrm{O}-\mathrm{H}$ & 1654.9 & 0.00121 & 0.0829 & 64.6 & 1659.8 & 0.00142 & 0.0969 & 64.0 \\
\hline$v \mathrm{C}=\mathrm{O}$ & 1722.6 & $-4.12 \mathrm{E}-04$ & 0.0162 & 37.0 & 1724.1 & $-4.00 \mathrm{E}-04$ & 0.0142 & 33.4 \\
\hline
\end{tabular}




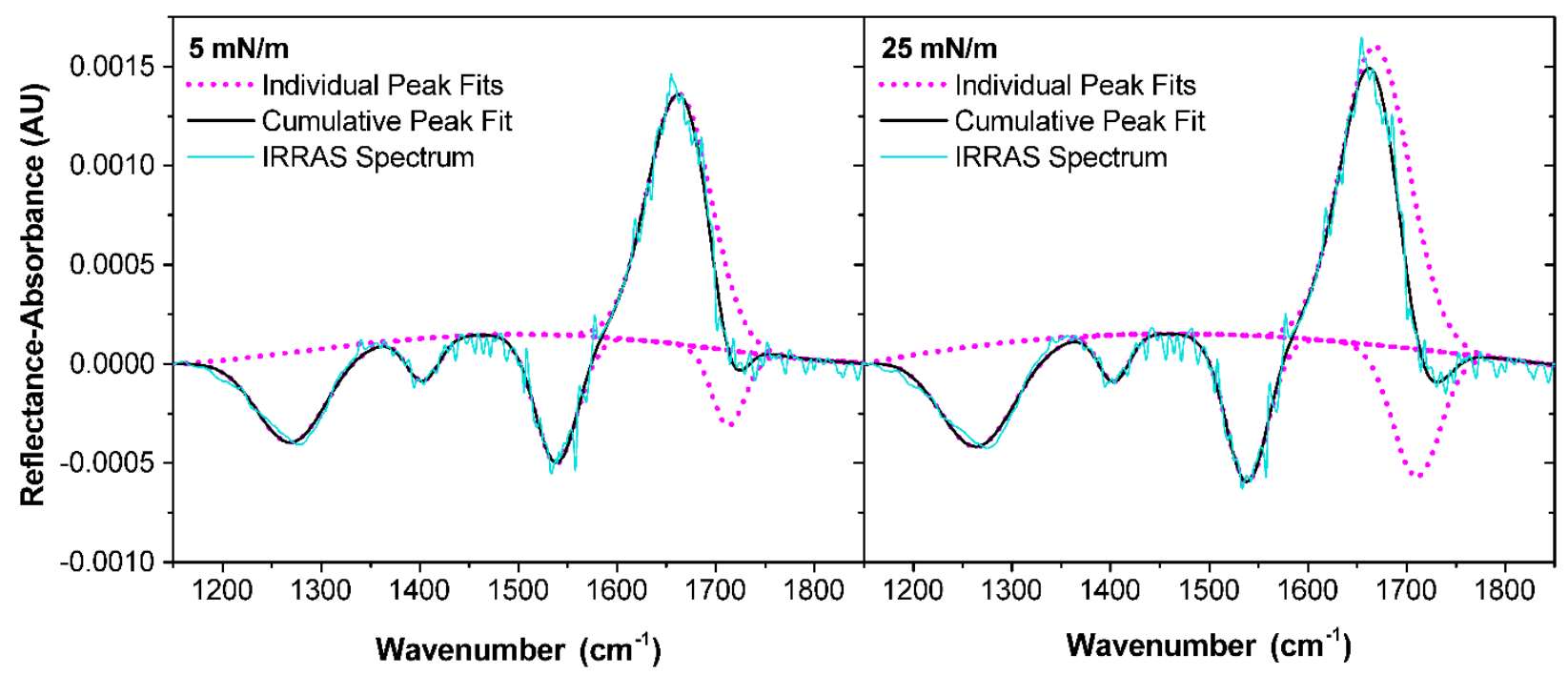

Fig. S9. IRRAS spectra and corresponding peak fits of a $\mathrm{d}_{31}$-palmitic acid monolayer at $5 \mathrm{mN} / \mathrm{m}$ (left) and $25 \mathrm{mN} / \mathrm{m}$ (right) spread onto an aqueous subphase of $0.47 \mathrm{M} \mathrm{NaCl}$ and $10 \mathrm{mM} \mathrm{MgCl} 2$ at $\mathrm{pH} 8.2$.

Table S12. Center wavelengths $\left(\lambda, \mathrm{cm}^{-1}\right)$, reflectance-absorbance intensities (RA Int.), peak areas, and full width at half maximum (FWHM, $\mathrm{cm}^{-1}$ ) values of Gaussian fits to IRRAS spectra in the $\mathrm{COOH}$ vibrational mode region of a $\mathrm{d}_{31}$-palmitic acid monolayer $(5 \mathrm{mN} / \mathrm{m}$ and $25 \mathrm{mN} / \mathrm{m}) \mathrm{spread}$ onto an aqueous subphase of $0.47 \mathrm{M} \mathrm{NaCl}$ and $10 \mathrm{mM} \mathrm{MgCl}_{2}$ at $\mathrm{pH}$ 8.2.

\begin{tabular}{|c|c|c|c|c|c|c|c|c|}
\hline \multirow{2}{*}{$\begin{array}{c}\text { Vibrational } \\
\text { Mode }\end{array}$} & \multicolumn{5}{|c|}{$\mathbf{5 ~ m N / m}$} & \multicolumn{4}{c|}{$\mathbf{2 5} \mathbf{~ m N} / \mathbf{m}$} \\
\cline { 2 - 9 } & Center $\lambda$ & RA Int. & Area & FWHM & Center $\lambda$ & RA Int. & Area & FWHM \\
\hline \hline$v \mathrm{C}-\mathrm{OH}$ & 1270.3 & $-4.53 \mathrm{E}-04$ & 0.0398 & 82.6 & 1265.3 & $-5.08 \mathrm{E}-04$ & 0.0484 & 89.4 \\
\hline$v_{\mathrm{S}} \mathrm{COO}^{-}$ & 1403.0 & $-2.15 \mathrm{E}-04$ & 0.00888 & 38.8 & 1403.3 & $-2.36 \mathrm{E}-04$ & 0.00911 & 36.3 \\
\hline$v_{\mathrm{AS}} \mathrm{COO}^{-}$ & 1538.4 & $-6.46 \mathrm{E}-04$ & 0.0347 & 50.5 & 1538.2 & $-7.39 \mathrm{E}-04$ & 0.0393 & 49.9 \\
\hline$\delta \mathrm{H}-\mathrm{O}-\mathrm{H}$ & 1662.6 & 0.00126 & 0.102 & 75.9 & 1668.1 & 0.00151 & 0.130 & 80.9 \\
\hline$v \mathrm{C}=\mathrm{O}$ & 1712.6 & $-3.79 \mathrm{E}-04$ & 0.0159 & 39.5 & 1710.1 & $-6.41 \mathrm{E}-04$ & 0.0388 & 56.8 \\
\hline
\end{tabular}




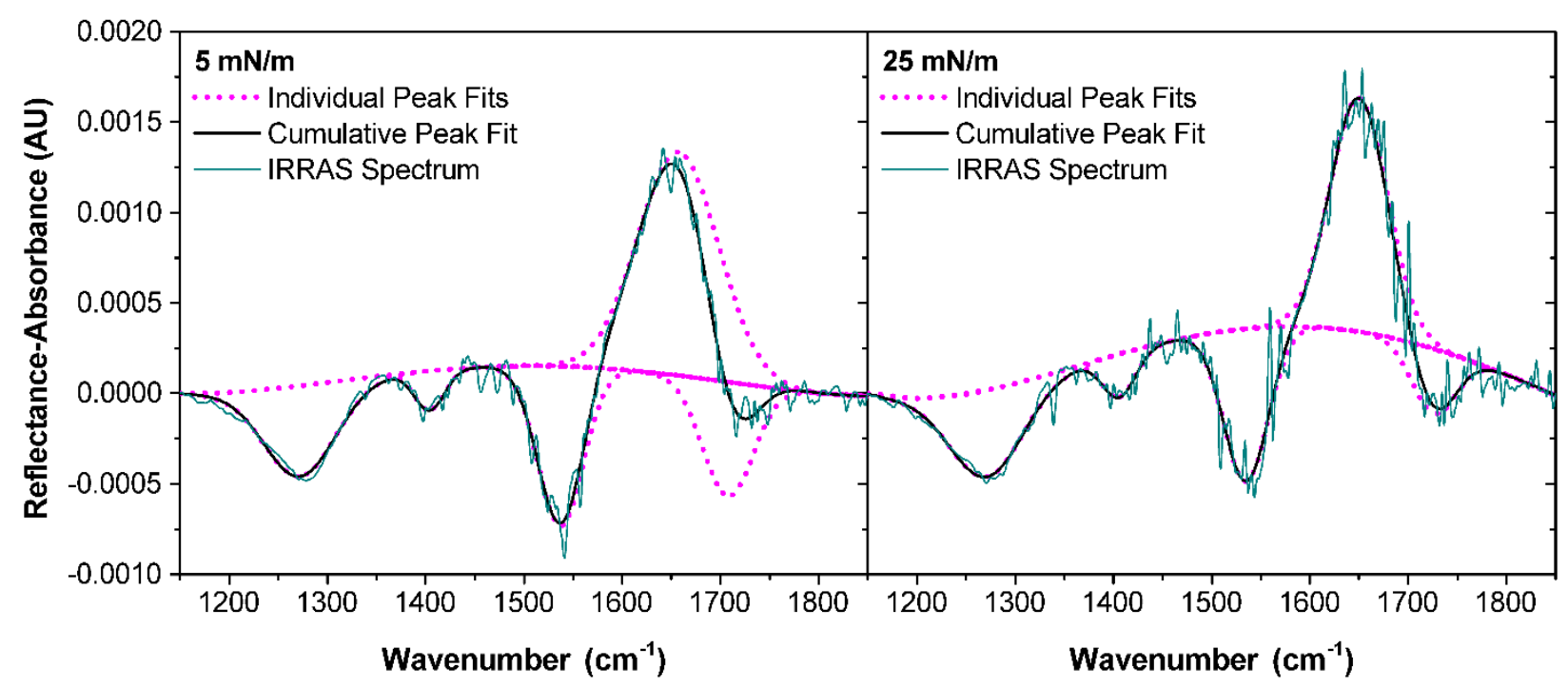

Fig. S10. IRRAS spectra and corresponding peak fits of a $\mathrm{d}_{31}$-palmitic acid monolayer at $5 \mathrm{mN} / \mathrm{m}$ (left) and $25 \mathrm{mN} / \mathrm{m}$ (right) spread onto an aqueous subphase of $0.47 \mathrm{M} \mathrm{NaCl}, 10 \mathrm{mM} \mathrm{MgCl}$, and $50 \mathrm{ppm}$ alginate at $\mathrm{pH} 8.2$.

Table S13. Center wavelengths $\left(\lambda, \mathrm{cm}^{-1}\right)$, reflectance-absorbance intensities (RA Int.), peak areas, and full width at half maximum (FWHM, $\mathrm{cm}^{-1}$ ) values of Gaussian fits to IRRAS spectra in the $\mathrm{COOH}$ vibrational mode region of a $\mathrm{d}_{31}$-palmitic acid monolayer $(5 \mathrm{mN} / \mathrm{m}$ and $25 \mathrm{mN} / \mathrm{m}) \mathrm{spread}$ onto an aqueous subphase of $0.47 \mathrm{M} \mathrm{NaCl}, 10 \mathrm{mM} \mathrm{MgCl}_{2}$, and $50 \mathrm{ppm}$ alginate at $\mathrm{pH} 8.2$.

\begin{tabular}{|c|c|c|c|c|c|c|c|c|}
\hline \multirow{2}{*}{$\begin{array}{c}\text { Vibrational } \\
\text { Mode }\end{array}$} & \multicolumn{4}{|c|}{$\mathbf{5 ~ m N / m}$} & \multicolumn{5}{c|}{$\mathbf{2 5}$ mN/m } \\
\cline { 2 - 9 } & Center $\lambda$ & RA Int. & Area & FWHM & Center $\lambda$ & RA Int. & Area & FWHM \\
\hline \hline$v \mathrm{C}-\mathrm{OH}$ & 1272.1 & $-4.99 \mathrm{E}-04$ & 0.0455 & 85.5 & 1271.4 & $-4.78 \mathrm{E}-04$ & 0.0439 & 86.2 \\
\hline$v_{\mathrm{S}} \mathrm{COO}^{-}$ & 1404.0 & $-2.19 \mathrm{E}-04$ & 0.00840 & 36.1 & 1405.7 & $-2.40 \mathrm{E}-04$ & 0.0101 & 39.6 \\
\hline$v_{\mathrm{AS}} \mathrm{COO}^{-}$ & 1537.3 & $-8.85 \mathrm{E}-04$ & 0.0512 & 54.4 & 1534.9 & $-8.45 \mathrm{E}-04$ & 0.0478 & 53.2 \\
\hline$\delta \mathrm{H}-\mathrm{O}-\mathrm{H}$ & 1657.2 & 0.00123 & 0.126 & 96.2 & 1649.7 & 0.00129 & 0.0944 & 68.7 \\
\hline$v \mathrm{C}=\mathrm{O}$ & 1707.7 & $-6.31 \mathrm{E}-04$ & 0.0405 & 60.3 & 1726.2 & $-3.58 \mathrm{E}-04$ & 0.0200 & 52.4 \\
\hline
\end{tabular}




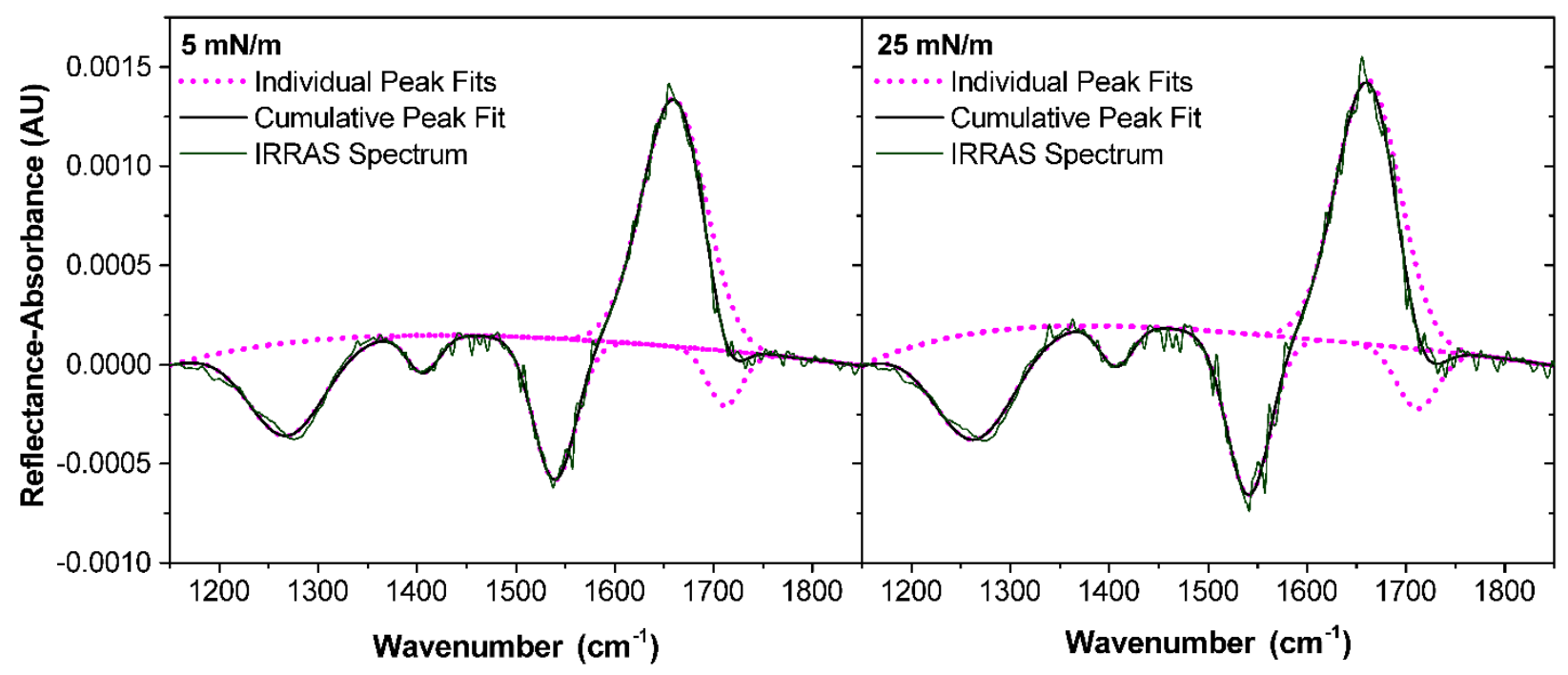

Fig. S11. IRRAS spectra and corresponding peak fits of a $d_{31}$-palmitic acid monolayer at $5 \mathrm{mN} / \mathrm{m}$ (left) and $25 \mathrm{mN} / \mathrm{m}$ (right) spread onto an aqueous subphase of $0.47 \mathrm{M} \mathrm{NaCl}$ and $53 \mathrm{mM} \mathrm{MgCl} 2$ at $\mathrm{pH} 8.2$.

Table S14. Center wavelengths $\left(\lambda, \mathrm{cm}^{-1}\right)$, reflectance-absorbance intensities (RA Int.), peak areas, and full width at half maximum (FWHM, $\mathrm{cm}^{-1}$ ) values of Gaussian fits to IRRAS spectra in the $\mathrm{COOH}$ vibrational mode region of a $\mathrm{d}_{31}$-palmitic acid monolayer $(5 \mathrm{mN} / \mathrm{m}$ and $25 \mathrm{mN} / \mathrm{m}) \mathrm{spread}$ onto an aqueous subphase of $0.47 \mathrm{M} \mathrm{NaCl}$ and $53 \mathrm{mM} \mathrm{MgCl}_{2}$ at $\mathrm{pH} 8.2$.

\begin{tabular}{|c|c|c|c|c|c|c|c|c|}
\hline \multirow{2}{*}{$\begin{array}{c}\text { Vibrational } \\
\text { Mode }\end{array}$} & \multicolumn{4}{|c|}{$\mathbf{5 ~ m N / m}$} & \multicolumn{5}{c|}{$\mathbf{2 5} \mathbf{~ m N} / \mathbf{m}$} \\
\cline { 2 - 9 } & Center $\boldsymbol{\lambda}$ & RA Int. & Area & FWHM & Center $\lambda$ & RA Int. & Area & FWHM \\
\hline \hline$v \mathrm{C}-\mathrm{OH}$ & 1268.6 & $-4.69 \mathrm{E}-04$ & 0.0447 & 89.6 & 1264.1 & $-5.37 \mathrm{E}-04$ & 0.0543 & 95.1 \\
\hline$v_{\mathrm{S}} \mathrm{COO}^{-}$ & 1406.0 & $-1.89 \mathrm{E}-04$ & 0.00768 & 38.1 & 1406.8 & $-2.05 \mathrm{E}-04$ & 0.00834 & 38.3 \\
\hline$v_{\mathrm{AS}} \mathrm{COO}^{-}$ & 1539.3 & $-7.13 \mathrm{E}-04$ & 0.0381 & 50.1 & 1540.6 & $-8.13 \mathrm{E}-04$ & 0.0445 & 51.4 \\
\hline$\delta \mathrm{H}-\mathrm{O}-\mathrm{H}$ & 1659.5 & 0.00125 & 0.100 & 75.6 & 1661.1 & 0.00133 & 0.107 & 75.4 \\
\hline$v \mathrm{C}=\mathrm{O}$ & 1711.0 & $-2.77 \mathrm{E}-04$ & 0.0119 & 40.4 & 1711.1 & $-3.01 \mathrm{E}-04$ & 0.0154 & 48.2 \\
\hline
\end{tabular}




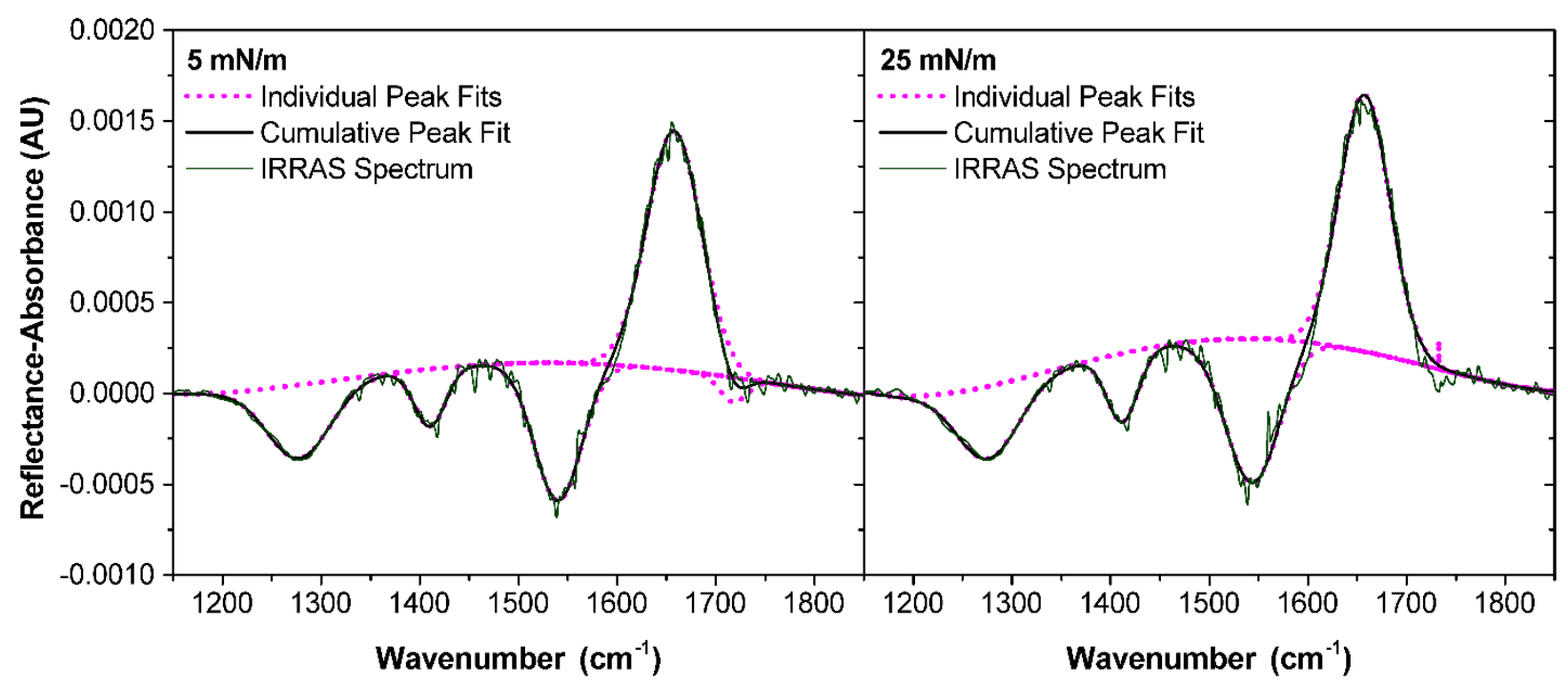

Fig. S12. IRRAS spectra and corresponding peak fits of a $\mathrm{d}_{31}$-palmitic acid monolayer at $5 \mathrm{mN} / \mathrm{m}$ (left) and $25 \mathrm{mN} / \mathrm{m}$ (right) spread onto an aqueous subphase of $0.47 \mathrm{M} \mathrm{NaCl}, 53 \mathrm{mM} \mathrm{MgCl}$, and $50 \mathrm{ppm}$ alginate at $\mathrm{pH} 8.2$.

Table S15. Center wavelengths $\left(\lambda, \mathrm{cm}^{-1}\right)$, reflectance-absorbance intensities (RA Int.), peak areas, and full width at half maximum (FWHM, $\mathrm{cm}^{-1}$ ) values of Gaussian fits to IRRAS spectra in the $\mathrm{COOH}$ vibrational mode region of a $\mathrm{d}_{31}$-palmitic acid monolayer $(5 \mathrm{mN} / \mathrm{m}$ and $25 \mathrm{mN} / \mathrm{m}) \mathrm{spread}$ onto an aqueous subphase of $0.47 \mathrm{M} \mathrm{NaCl}, 53 \mathrm{mM} \mathrm{MgCl}_{2}$, and $50 \mathrm{ppm}$ alginate at $\mathrm{pH} 8.2$.

\begin{tabular}{|c|c|c|c|c|c|c|c|c|}
\hline \multirow{2}{*}{$\begin{array}{c}\text { Vibrational } \\
\text { Mode }\end{array}$} & \multicolumn{4}{|c|}{$\mathbf{5 ~ m N / m}$} & \multicolumn{5}{c|}{$\mathbf{2 5} \mathbf{~ m N} / \mathbf{m}$} \\
\cline { 2 - 9 } & Center $\lambda$ & RA Int. & Area & FWHM & Center $\lambda$ & RA Int. & Area & FWHM \\
\hline \hline$v \mathrm{C}-\mathrm{OH}$ & 1277.5 & $-4.05 \mathrm{E}-04$ & 0.0322 & 74.7 & 1276.1 & $-3.97 \mathrm{E}-04$ & 0.0308 & 72.9 \\
\hline$v_{\mathrm{S}} \mathrm{COO}^{-}$ & 1410.3 & $-3.18 \mathrm{E}-04$ & 0.0126 & 37.1 & 1412.1 & $-3.80 \mathrm{E}-04$ & 0.0150 & 37.2 \\
\hline$v_{\mathrm{AS}} \mathrm{COO}^{-}$ & 1539.9 & $-7.59 \mathrm{E}-04$ & 0.0453 & 56.0 & 1543.5 & $-7.94 \mathrm{E}-04$ & 0.0540 & 63.8 \\
\hline$\delta \mathrm{H}-\mathrm{O}-\mathrm{H}$ & 1657.6 & 0.00132 & 0.0910 & 64.9 & 1657.4 & 0.00141 & 0.0916 & 60.9 \\
\hline$v \mathrm{C}=\mathrm{O}$ & 1717.7 & $-1.35 \mathrm{E}-04$ & 0.00451 & 31.3 & 1732.6 & $1.60 \mathrm{E}-04$ & $7.92 \mathrm{E}-07$ & 0.00464 \\
\hline
\end{tabular}

\section{5. d33-Cetyl alcohol IRRAS spectral analysis}

The carboxylic acid stretching region $\left(1150-1850 \mathrm{~cm}^{-1}\right)$ was analyzed for the $\mathrm{d}_{33}$-cetyl alcohol spectra to further examine the extent of alginate co-adsorption to the monolayer (Fig. S13). Cetyl alcohol only exhibits the $\mathrm{C}-\mathrm{OH}$ stretching mode, so any carboxylic acid peaks can be attributed to alginate co-adsorption. Neither the $v_{\mathrm{S}} \mathrm{COO}^{-}, v_{\mathrm{AS}} \mathrm{COO}^{-}$, nor the $v \mathrm{C}=\mathrm{O}$ stretches appear at either surface pressure, indicating no alginate co-adsorption. The $\delta \mathrm{H}-\mathrm{O}-\mathrm{H}$ mode red shifts in response 
to alginate within the aqueous subphase, possibly caused by alginate solvation within the probing region of IRRAS.

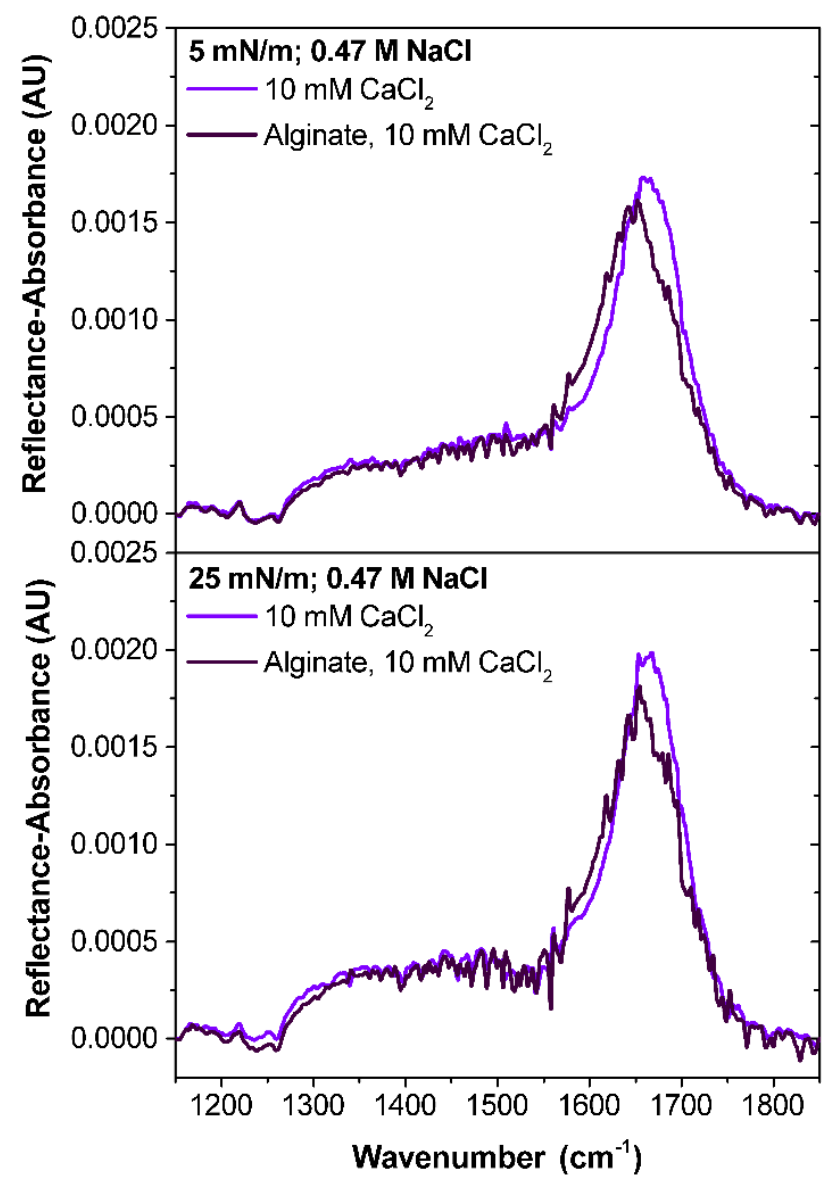

Fig. S13. IRRAS spectra of $\mathrm{d}_{33}$-cetyl alcohol collected and analyzed within the COOH stretching region at constant surface pressures of $5 \mathrm{mN} / \mathrm{m}$ (top) and $25 \mathrm{mN} / \mathrm{m}$ (bottom). The light purple curves correspond to the monolayer spread onto a $0.47 \mathrm{M} \mathrm{NaCl}$ and $10 \mathrm{mM} \mathrm{CaCl}_{2}$ subphase at $\mathrm{pH}$ 8.2. The dark purple curves correspond to the monolayer spread onto a $0.47 \mathrm{M} \mathrm{NaCl}, 10 \mathrm{mM}$ $\mathrm{CaCl}_{2}$, and $50 \mathrm{ppm}$ alginate subphase. All spectra represent averages of at least triplicate measurements.

\section{6. $\mathrm{CD}_{2}$ scissoring mode analysis}

The $\mathrm{CD}_{2}$ scissoring mode region $\left(1070-1110 \mathrm{~cm}^{-1}\right)$ was analyzed using OriginPro 9.0. A baseline was fitted to a line between the two endpoints of the region, and then the baseline was 
subtracted from the spectrum. Following baseline subtraction, the center frequency of the $\mathrm{CD}_{2}$ scissoring mode was determined with the Peak Analyzer tool in Origin.

Table S16. Center wavelengths $\left(\lambda, \mathrm{cm}^{-1}\right)$ of the IRRAS $\mathrm{CD}_{2}$ scissoring mode of $\mathrm{d}_{31}$-palmitic acid $\left(\mathrm{d}_{31}-\mathrm{PA}\right)$ and $\mathrm{d}_{33}$-cetyl alcohol $\left(\mathrm{d}_{33}-\mathrm{CA}\right)$ monolayers measured at constant surface pressures 5 $\mathrm{mN} / \mathrm{m}$ and $25 \mathrm{mN} / \mathrm{m}$.

\begin{tabular}{|c|c|c|}
\hline \multirow{2}{*}{ Monolayer \& Subphase } & \multicolumn{2}{|c|}{$\mathrm{CD}_{2}$ Scissoring Mode $\lambda$} \\
\hline & $5 \mathrm{mN} / \mathrm{m}$ & $25 \mathrm{mN} / \mathrm{m}$ \\
\hline $\mathrm{d}_{31}-\mathrm{PA}, 0.47 \mathrm{M} \mathrm{NaCl}, \mathrm{pH} 8.2$ & 1089.5 & 1089.0 \\
\hline $\mathrm{d}_{31}-\mathrm{PA}, 50 \mathrm{ppm}$ Alginate, $0.47 \mathrm{M} \mathrm{NaCl}, \mathrm{pH} 8.2$ & 1089.5 & 1089.0 \\
\hline $\mathrm{d}_{31}-\mathrm{PA}, 0.47 \mathrm{M} \mathrm{NaCl}, 10 \mathrm{mM} \mathrm{CaCl}, \mathrm{pH} 8.2$ & 1089.4 & 1089.4 \\
\hline $\mathrm{d}_{31}-\mathrm{PA}, 50 \mathrm{ppm}$ Alginate, $0.47 \mathrm{M} \mathrm{NaCl}, 10 \mathrm{mM} \mathrm{CaCl} 2, \mathrm{pH} 8.2$ & 1089.4 & 1089.5 \\
\hline $\mathrm{d}_{31}-\mathrm{PA}, 0.47 \mathrm{M} \mathrm{NaCl}, 10 \mathrm{mM} \mathrm{CaCl}_{2}, \mathrm{pH} 5.8$ & 1089.5 & 1089.5 \\
\hline $\mathrm{d}_{31}-\mathrm{PA}, 50 \mathrm{ppm}$ Alginate, $0.47 \mathrm{M} \mathrm{NaCl}, 10 \mathrm{mM} \mathrm{CaCl} 2, \mathrm{pH} 5.8$ & 1089.5 & 1089.5 \\
\hline $\mathrm{d}_{33}-\mathrm{CA}, 0.47 \mathrm{M} \mathrm{NaCl}, 10 \mathrm{mM} \mathrm{CaCl} 2, \mathrm{pH} 8.2$ & 1089.0 & 1089.0 \\
\hline $\mathrm{d}_{33}-\mathrm{CA}, 50 \mathrm{ppm}$ Alginate, $0.47 \mathrm{M} \mathrm{NaCl}, 10 \mathrm{mM} \mathrm{CaCl} 2, \mathrm{pH} 8.2$ & 1089.0 & 1089.0 \\
\hline $\mathrm{d}_{31}-\mathrm{PA}, 0.47 \mathrm{M} \mathrm{NaCl}, 10 \mathrm{mM} \mathrm{MgCl} 2, \mathrm{pH} 8.2$ & 1089.5 & 1089.0 \\
\hline $\mathrm{d}_{31}-\mathrm{PA}, 50 \mathrm{ppm}$ Alginate, $0.47 \mathrm{M} \mathrm{NaCl}, 10 \mathrm{mM} \mathrm{MgCl} 2, \mathrm{pH} 8.2$ & 1089.5 & 1089.0 \\
\hline $\mathrm{d}_{31}-\mathrm{PA}, 0.47 \mathrm{M} \mathrm{NaCl}, 53 \mathrm{mM} \mathrm{MgCl} 2, \mathrm{pH} 8.2$ & 1089.5 & 1089.0 \\
\hline $\mathrm{d}_{31}-\mathrm{PA}, 50 \mathrm{ppm}$ Alginate, $0.47 \mathrm{M} \mathrm{NaCl}, 53 \mathrm{mM} \mathrm{MgCl} 2, \mathrm{pH} 8.2$ & 1089.5 & 1089.5 \\
\hline
\end{tabular}


7. Radial distribution and number density profiles
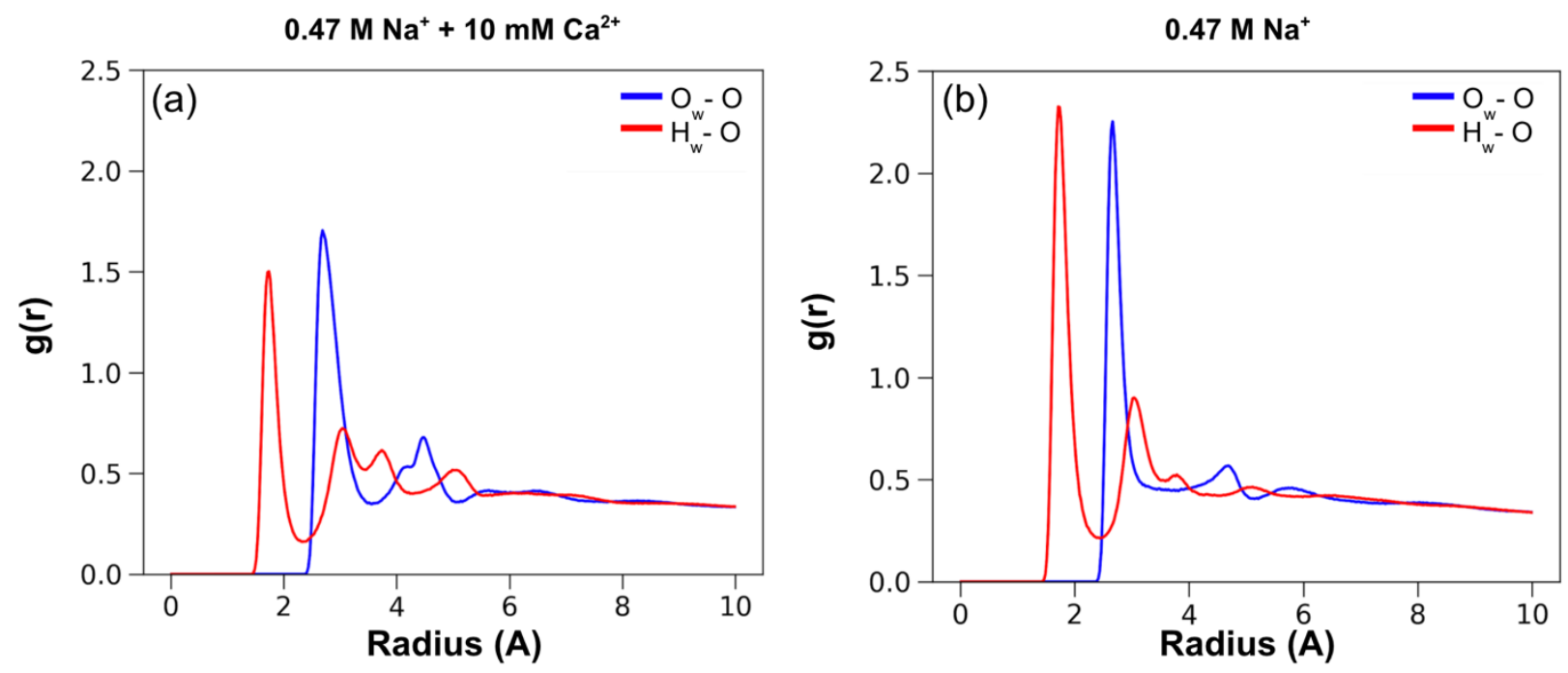

Fig. S14. $\mathrm{RDF}$ of water $\mathrm{O}_{\mathrm{w}}$ and $\mathrm{H}_{\mathrm{w}}$ with respect to palmitate headgroup -OH oxygen in the presence (a) and absence (b) of calcium. Both systems contain alginate in the aqueous phase. 


\section{Local order parameters}

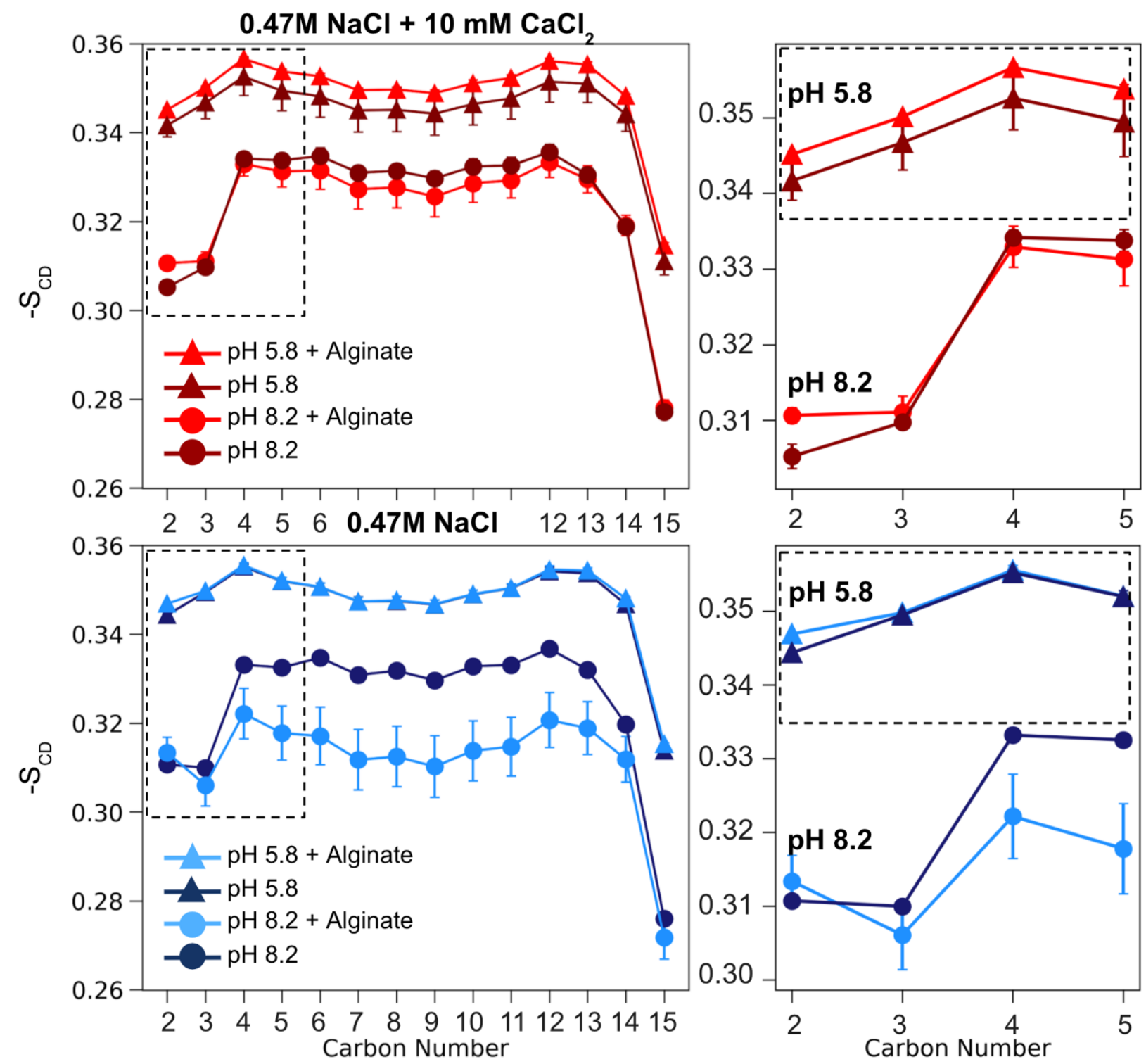

Fig. S15. Local order parameters for all systems, not separated based on protonation state, with close-ups of the carbon $\mathrm{C} 2-\mathrm{C} 4$ regions. 


\section{IRRAS spectra of alginate co-adsorption via magnesium bridging}

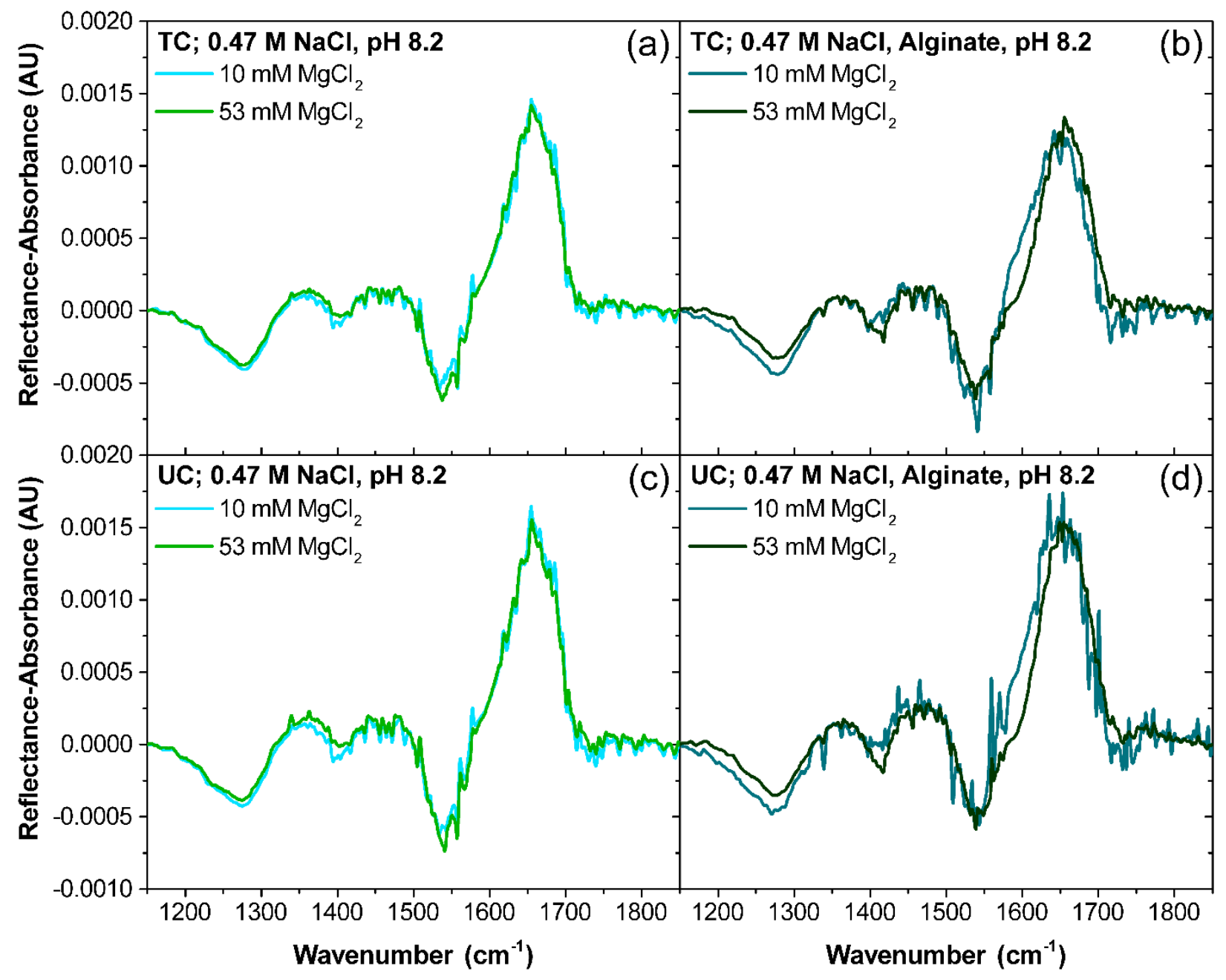

Fig. S16. IRRAS spectra of the $\mathrm{COOH}$ stretching region indicate weak alginate co-adsorption to the $\mathrm{d}_{31}$-palmitic acid monolayer via $\mathrm{Mg}^{2+}$ bridging interactions. Spectral lines are color-coded to indicate differences in solution composition. Surface pressure was held constant in the (a), (b) tilted condensed $(5 \mathrm{mN} / \mathrm{m})$ and (c), (d) untilted condensed $(25 \mathrm{mN} / \mathrm{m})$ phases throughout spectral acquisition. Spectra corresponding to the salt water solutions are shown in (a) and (c), and spectra corresponding to the salt water solutions containing $50 \mathrm{ppm}$ alginate are shown in (b) and (d). 


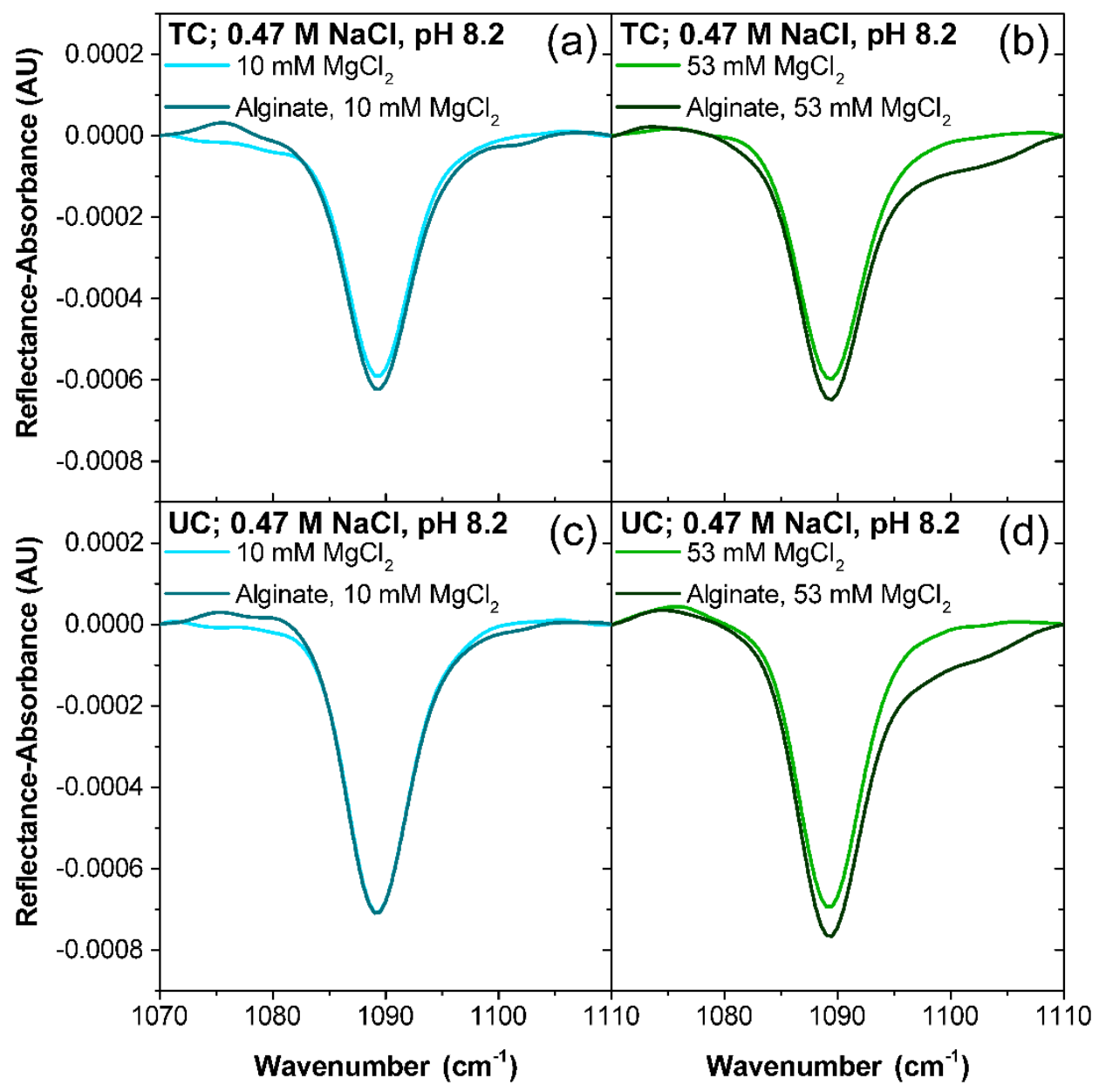

Fig. S17. IRRAS spectra of the $\mathrm{CD}_{2}$ scissoring mode region demonstrate weak alginate coadsorption to the $\mathrm{d}_{31}$-palmitic acid monolayer in the presence of $53 \mathrm{mM} \mathrm{MgCl} 2$ at $\mathrm{pH} 8.2$, and the spectra indicate no changes in the $\mathrm{d}_{31}$-palmitic acid lattice packing upon adsorption. Spectral lines are color-coded to indicate differences in solution composition. Surface pressure was held constant in the (a), (b) tilted condensed $(5 \mathrm{mN} / \mathrm{m})$ and (c), (d) untilted condensed $(25 \mathrm{mN} / \mathrm{m})$ phases throughout spectral acquisition.

\section{References}

1 Y. Shao, Z. Gan, E. Epifanovsky, A. T. B. Gilbert, M. Wormit, J. Kussmann, A. W. Lange, A. Behn, J. Deng, X. Feng, D. Ghosh, M. Goldey, P. R. Horn, L. D. Jacobson, I. Kaliman, R. Z. Khaliullin, T. Kuś, A. Landau, J. Liu, E. I. Proynov, Y. M. Rhee, R. M. Richard, M. A. Rohrdanz, R. P. Steele, E. J. Sundstrom, H. L. W. III, P. M. Zimmerman, D. Zuev, B. Albrecht, E. Alguire, B. Austin, G. J. O. Beran, Y. A. Bernard, E. Berquist, K. Brandhorst, K. B.

Bravaya, S. T. Brown, D. Casanova, C.-M. Chang, Y. Chen, S. H. Chien, K. D. Closser, D. L. Crittenden, M. Diedenhofen, R. A. D. Jr, H. Do, A. D. Dutoi, R. G. Edgar, S. Fatehi, L. FustiMolnar, A. Ghysels, A. Golubeva-Zadorozhnaya, J. Gomes, M. W. D. Hanson-Heine, P. H. P. Harbach, A. W. Hauser, E. G. Hohenstein, Z. C. Holden, T.-C. Jagau, H. Ji, B. Kaduk, K. Khistyaev, J. Kim, J. Kim, R. A. King, P. Klunzinger, D. Kosenkov, T. Kowalczyk, C. M. 
Krauter, K. U. Lao, A. D. Laurent, K. V. Lawler, S. V. Levchenko, C. Y. Lin, F. Liu, E. Livshits, R. C. Lochan, A. Luenser, P. Manohar, S. F. Manzer, S.-P. Mao, N. Mardirossian, A. V. Marenich, S. A. Maurer, N. J. Mayhall, E. Neuscamman, C. M. Oana, R. Olivares-Amaya, D. P. O’Neill, J. A. Parkhill, T. M. Perrine, R. Peverati, A. Prociuk, D. R. Rehn, E. Rosta, N. J. Russ, S. M. Sharada, S. Sharma, D. W. Small, A. Sodt, T. Stein, D. Stück, Y.-C. Su, A. J. W. Thom, T. Tsuchimochi, V. Vanovschi, L. Vogt, O. Vydrov, T. Wang, M. A. Watson, J. Wenzel, A. White, C. F. Williams, J. Yang, S. Yeganeh, S. R. Yost, Z.-Q. You, I. Y. Zhang, X. Zhang, Y. Zhao, B. R. Brooks, G. K. L. Chan, D. M. Chipman, C. J. Cramer, W. A. G. III, M. S. Gordon, W. J. Hehre, A. Klamt, H. F. S. III, M. W. Schmidt, C. D. Sherrill, D. G. Truhlar, A. Warshel, X. Xu, A. Aspuru-Guzik, R. Baer, A. T. Bell, N. A. Besley, J.-D. Chai, A. Dreuw, B. D. Dunietz, T. R. Furlani, S. R. Gwaltney, C.-P. Hsu, Y. Jung, J. Kong, D. S. Lambrecht, W. Liang, C. Ochsenfeld, V. A. Rassolov, L. V. Slipchenko, J. E. Subotnik, T. V. Voorhis, J. M. Herbert, A. I. Krylov, P. M. W. Gill and M. Head-Gordon, Mol. Phys., 2015, 113, 184-215. 2 A. Haug, S. Myklestad, B. Larsen, O. Smidsrød, G. Eriksson, R. Blinc, S. Paušak, L. Ehrenberg and J. Dumanović, Acta Chem. Scand., 1967, 21, 768-778.

3 E. R. Morris, D. A. Rees, D. Thom and J. Boyd, Carbohyd. Res., 1978, 66, 145-154.

4K. Y. Lee and D. J. Mooney, Prog. Polym. Sci., 2012, 37, 106-126.

5 J. R. Rumble, Ed., CRC Handbook of Chemistry and Physics.

6C. Y. Lin, M. W. George and P. M. W. Gill, Aust. J. Chem., 2004, 57, 365. 
